University of Tennessee Health Science Center UTHSC Digital Commons

\title{
Trabecular Calcium Phosphate Scaffolds for Bone Regeneration
}

Mark Ryan Appleford

University of Tennessee Health Science Center

Follow this and additional works at: https://dc.uthsc.edu/dissertations

Part of the Medical Biotechnology Commons

\section{Recommended Citation}

Appleford, Mark Ryan , "Trabecular Calcium Phosphate Scaffolds for Bone Regeneration" (2007). Theses and Dissertations (ETD). Paper 18. http://dx.doi.org/10.21007/etd.cghs.2007.0017.

This Dissertation is brought to you for free and open access by the College of Graduate Health Sciences at UTHSC Digital Commons. It has been accepted for inclusion in Theses and Dissertations (ETD) by an authorized administrator of UTHSC Digital Commons. For more information, please contact jwelch30@uthsc.edu. 


\title{
Trabecular Calcium Phosphate Scaffolds for Bone Regeneration
}

\begin{abstract}
Bone tissue engineering represents a strategy for the repair or regeneration of damaged bone in the body. The science underlying this clinical therapy bridges the traditional fields of cell biology, materials science and mechanical engineering with the aim to identify how cells behave on physiologically relevant materials with natural mechanical stimuli. The objectives of this research were to develop and characterize calcium phosphate ceramic scaffolds matched to the local architecture of natural trabecular bone and to apply tissue engineering strategies for the study of cell behavior in both in vitro and in vivo models. The specific role of environment on cell stress pathways was evaluated on three dimensional (3-D) calcium phosphate scaffolds resembling vertebral trabecular bone. A scaffold foam dipping technique was employed in the fabrication of fully sintered hydroxyapatite and tricalcium phosphate scaffolds. Study of the early cell behavior on two dimension (2-D) controls and scaffolds was performed using human embryonic palatal mesenchyme cells (HEPM), an osteoblast precursor cell line. Cell stress signaling was identified in response to the 3-D architecture using; members of the mitogen activated protein kinase cascade, cell survival signals and adhesion dependant proteins. The application of low intensity pulsed ultrasound (LIPUS) or fluid perfusion further stimulated cell-scaffold hybrids for short and long term in vitro study. Additionally, an animal model was characterized using the scaffolds for the repair of a segmental defect in the canine mandible.Study of the cell stress signaling mechanisms identified high activation of stress pathways on 3-D materials compared to controls with a corresponding increase in anti- apoptosis signaling. Similar trends were found with LIPUS stimulation demonstrating that changes in adhesion proteins during attachment may account for the alteration in stress pathways activated by bone precursors. The absence of cell death and the activation of an anti-apoptosis signal suggest that cells are able to manage these stress levels which may be required for proper function. Supporting this theory, long term in vitro perfusion studies demonstrated that the process of cell transition into a mature bone phenotype was improved with the fluid shear forces of perfusion. Finally, the scaffolds were applied for repair of a segmental defect in the canine mandible and demonstrated extensive bone in-growth and partially-organized, lamellar collagen fiber assembly characteristic of organized bone. The open architecture of the scaffold design also allowed for substantial blood vessel infiltration. This research demonstrated the importance of architecture on bone cell response for in vitro cell study and for clinical application. The scaffold design provides a bridge between laboratory based signaling mechanisms and the development of clinical therapies in regenerative orthopedics.
\end{abstract}

\section{Document Type}

Dissertation

Degree Name

Doctor of Philosophy (PhD)

Program

Biomedical Engineering

Research Advisor

Joo L. Ong, Ph.D.

\section{Keywords}

cell signaling, hydroxyapatite, tricalcium phosphate, tissue engineering, osseointegration, ultrasound, perfusion 


\section{Subject Categories}

Medical Biotechnology | Medicine and Health Sciences 


\title{
TRABECULAR CALCIUM PHOSPHATE SCAFFOLDS FOR BONE REGENERATION
}

\author{
A Dissertation \\ Presented for \\ The Graduate Studies Council \\ The University of Tennessee \\ Health Science Center
}

\author{
In Partial Fulfillment \\ Of the Requirements for the Degree \\ Doctor of Philosophy \\ In the Joint Graduate Program in Biomedical Engineering \\ From the University of Tennessee \\ And \\ The University of Memphis
}

By

Mark Ryan Appleford

May, 2007 
Chapter 3 (C) 2007 by Biomaterials.

All other material (C) 2007 by Mark Ryan Appleford 


\section{DEDICATION}

This dissertation is dedicated to my parents,

Thomas and Darlene Appleford, for their love and support. 


\section{ACKNOWLEDGEMENTS}

I would like to thank my advisor, Dr. Joo L. Ong for the opportunity to develop this research and for his guidance. I would also like to express my gratitude to my committee members, Dr. Judith Cole, Dr. Warren Haggard, Dr. Joel D. Bumgardner, Dr. Ken Nishimoto and Dr. Peter Yang for their excellent advice and experience. I am deeply indebted to the members of the Biomaterials and Tissue Engineering Laboratory; Mason Bettenga, Jiri Protivinsky and especially Dr. Sunho Oh without whom this research would not be possible and to Dr. David Carnes for graciously providing research space and guidance at the University of Texas Health Science Center. I would also like to thank the journal, Biomaterials, for granting permission to use my published work in this dissertation. These studies were supported in part from the National Institutes of Health.

To my family and friends, a gracious thank you is well deserved. To my parents, Tom and Darlene Appleford, I owe especial thanks for their encouragement, support and for reminding me to keep all things in 'perspective'. 


\begin{abstract}
Bone tissue engineering represents a strategy for the repair or regeneration of damaged bone in the body. The science underlying this clinical therapy bridges the traditional fields of cell biology, materials science and mechanical engineering with the aim to identify how cells behave on physiologically relevant materials with natural mechanical stimuli. The objectives of this research were to develop and characterize calcium phosphate ceramic scaffolds matched to the local architecture of natural trabecular bone and to apply tissue engineering strategies for the study of cell behavior in both in vitro and in vivo models.
\end{abstract}

The specific role of environment on cell stress pathways was evaluated on three dimensional (3-D) calcium phosphate scaffolds resembling vertebral trabecular bone. A scaffold foam dipping technique was employed in the fabrication of fully sintered hydroxyapatite and tricalcium phosphate scaffolds. Study of the early cell behavior on two dimension (2-D) controls and scaffolds was performed using human embryonic palatal mesenchyme cells (HEPM), an osteoblast precursor cell line. Cell stress signaling was identified in response to the 3-D architecture using; members of the mitogen activated protein kinase cascade, cell survival signals and adhesion dependant proteins. The application of low intensity pulsed ultrasound (LIPUS) or fluid perfusion further stimulated cell-scaffold hybrids for short and long term in vitro study. Additionally, an animal model was characterized using the scaffolds for the repair of a segmental defect in the canine mandible.

Study of the cell stress signaling mechanisms identified high activation of stress 
pathways on 3-D materials compared to controls with a corresponding increase in antiapoptosis signaling. Similar trends were found with LIPUS stimulation demonstrating that changes in adhesion proteins during attachment may account for the alteration in stress pathways activated by bone precursors. The absence of cell death and the activation of an anti-apoptosis signal suggest that cells are able to manage these stress levels which may be required for proper function. Supporting this theory, long term in vitro perfusion studies demonstrated that the process of cell transition into a mature bone phenotype was improved with the fluid shear forces of perfusion. Finally, the scaffolds were applied for repair of a segmental defect in the canine mandible and demonstrated extensive bone in-growth and partially-organized, lamellar collagen fiber assembly characteristic of organized bone. The open architecture of the scaffold design also allowed for substantial blood vessel infiltration.

This research demonstrated the importance of architecture on bone cell response for in vitro cell study and for clinical application. The scaffold design provides a bridge between laboratory based signaling mechanisms and the development of clinical therapies in regenerative orthopedics. 


\section{TABLE OF CONTENTS}

Chapter 1. Introduction 1

1.1 Bone background 1

1.2 Bone cells 2

1.3 Bone composition and classification 3

1.4 Scaffold design $\quad 5$

$\begin{array}{lll}1.5 & \text { Scaffold porosity } & 7\end{array}$

$\begin{array}{lll}1.6 & \text { Scaffolds as platforms for cell study } & 8\end{array}$

1.7 Bone stress signaling 9

$\begin{array}{lll}1.8 & \text { Mechanical stimuli } & 10\end{array}$

1.9 Ultrasound 11

1.10 Flow perfusion $\quad 11$

Chapter 2. Objectives and hypothesis testing 13

2.1 Overall goals 13

2.2 Specific hypotheses 14

2.2.1 Osteoblast precursor stress signaling in trabecular HA and TCP scaffolds compared to 2-D surfaces $\quad 14$

2.2.2 Adhesion and stress response of osteoblast precursors in trabecular HA and TCP scaffolds in response to ultrasound 15

2.2.3 Osteoblast precursor response to fluid perfusion in trabecular nano and micro surface HA scaffolds 15

2.2.4 Trabecular nano and micro surface HA scaffolds for in vivo bone repair

Chapter 3. Effects of trabecular calcium phosphate scaffolds on stress-signaling in osteoblast precursor cells

3.1 Abstract

3.2 Introduction

3.3 Materials and methods 19

$\begin{array}{lll}\text { 3.3.1 Sample preparation } & 19\end{array}$

3.3.2 Sample characterization 20

3.3.3 Cell culture and adhesion 21

3.3.4 Material phospho-specific antibody cell-based ELISA (PACE) 22

3.3.5 Statistical analysis 23

3.4 Results 23

3.4.1 Material characterization 23

3.4.2 Cell adhesion 25

3.4.3 Activation of ERK1/2 on CP's 28 
3.4.4 Activation of p38 on CP's 28

$\begin{array}{ll}\text { 3.4.5 Activation of JNK on CP's } & 28\end{array}$

3.4.6 Activation of AKT on CP's 32

3.5 Discussion $\quad 32$

$\begin{array}{lll}\text { 3.5.1 Scaffold architecture } & 34\end{array}$

3.5.2 PACE testing for cell-biomaterial constructs 35

3.5.3 Intracellular stress pathways in a physiological simulated
environment

3.5.4 Anti-apoptosis signaling $\quad 36$

$\begin{array}{lll}3.6 & \text { Conclusion } & 37\end{array}$

Chapter 4. Ultrasound effect on osteoblast precursor cells in trabecular calcium phosphate scaffolds 38

4.1 Abstract 38

$\begin{array}{lll}4.2 & \text { Introduction } & 39\end{array}$

4.3 Materials and methods $\quad 41$

4.3.1 Sample preparation $\quad 41$

4.3.2 Sample characterization 41

4.3.3 HEPM cell culture $\quad 42$

4.3.4 Stimulation with ultrasound 43

4.3.5 Phospho-specific antibody cell-based ELISA (PACE) 43

4.3.6 Adhesion protein immuno-detection 44

$\begin{array}{lll}4.3 .7 & \text { Statistical analysis } & 45\end{array}$

4.4 Results 45

4.4.1 Material characterization 45

4.4.2 Ultrasound stimulations of cellular protein markers in 2-D 47

4.4.3 Activation of cell protein markers with scaffold extract media, cellscaffolds and LIPUS $\quad 47$

4.4.4 Stimulation of adhesion proteins $\quad 50$

4.5 Discussion $\quad 52$

4.5.1 Scaffold design and calcium release 52

4.5.2 Ultrasound stimulation of HEPM cells in 2-D 54

4.5.3 Scaffold and ultrasound stimulation of HEPM cells 55

$\begin{array}{lll}4.6 & \text { Conclusion } & 56\end{array}$

Chapter 5. Flow perfusion of osteoblast precursor cells in trabecular nanocoated hydroxyapatite scaffolds

$\begin{array}{llr}5.1 & \text { Abstract } & 58\end{array}$

$\begin{array}{lll}5.2 & \text { Introduction } & 59\end{array}$

$\begin{array}{lll}5.3 & \text { Materials and methods } & 60\end{array}$

$\begin{array}{lll}\text { 5.3.1 Sample preparation } & 60\end{array}$

5.3.2 Sample characterization $\quad 61$

5.3.3 HEPM cell culture $\quad 62$ 
$\begin{array}{lll}\text { 5.3.4 Cell adhesion and MTT viability } & 62\end{array}$

$\begin{array}{lll}\text { 5.3.5 Perfusion system } & 63\end{array}$

5.3.6 Protein assay 64

$\begin{array}{lll}\text { 5.3.7 Osteocalcin and osteopontin assays } & 64\end{array}$

$\begin{array}{lll}5.3 .8 & \text { Statistical analysis } & 65\end{array}$

5.4 Results $\quad 65$

5.4.1 Material characterization $\quad 65$

$\begin{array}{lll}\text { 5.4.2 Cell attachment and viability } & 66\end{array}$

5.4.3 Cell total protein and differentiation markers 67

$\begin{array}{lll}5.5 & \text { Discussion } & 69\end{array}$

$\begin{array}{lll}\text { 5.5.1 Scaffold design and calcium release } & 71\end{array}$

$\begin{array}{ll}\text { 5.5.2 Early cell behavior on HA scaffolds } & 71\end{array}$

5.5.3 HEPM differentiation in response to perfusion 72

$\begin{array}{lll}5.6 & \text { Conclusion } & 74\end{array}$

Chapter 6. In vivo study on hydroxyapatite scaffolds with trabecular architecture for bone repair

6.1 Abstract 75

6.2 Introduction 76

6.3 Materials and methods $\quad 78$

$\begin{array}{lll}\text { 6.3.1 Scaffold preparation } & 78\end{array}$

$\begin{array}{lll}\text { 6.3.2 Scaffold characterization } & 80\end{array}$

$\begin{array}{lll}6.3 .3 & \text { Surgical procedure } & 81\end{array}$

$\begin{array}{lll}\text { 6.3.4 Statistical analysis } & 84\end{array}$

$\begin{array}{lll}6.4 & \text { Results } & 84\end{array}$

$\begin{array}{lll}\text { 6.4.1 Material characterization } & 85\end{array}$

$\begin{array}{ll}\text { 6.4.2 In vivo analysis } & 85\end{array}$

6.5 Discussion 94

6.6 Conclusion 96

$\begin{array}{ll}\text { Chapter 7. Discussion } & 97\end{array}$

$\begin{array}{lll}7.1 & \text { Overall goals } & 97\end{array}$

7.2 Cell stress signaling in HA and TCP scaffolds and surfaces 98

7.3 Cell adhesion and stress response on scaffolds with ultrasound 99

7.4 Long term cell culture in HA scaffolds with fluid perfusion 101

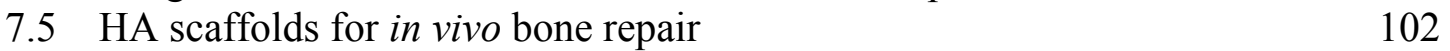

$\begin{array}{lll}7.6 \text { Conclusion } & 103\end{array}$

$\begin{array}{ll}\text { Chapter 8. Future directions } & 105\end{array}$

$\begin{array}{ll}\text { List of references } & 106\end{array}$ 


\section{LIST OF TABLES}

Table 3.1 Scaffold histomorphometry parameters compared to human vertebral bone of the second lumbar.

Table 6.1 Histomorphometry parameters of HA scaffold compared to newly formed trabecular bone in the defect location 3 weeks post surgery.

Table 6.2 Total tissue area and mineralized bone area percentages in M-HA and N-HA scaffolds at 3 and 12 weeks post surgery.

Table 6.3 Relative mineralized tissue formation compared to total tissue in M-HA and N-HA scaffolds at 3 and 12 weeks post surgery.

Table 6.4 Blood vessel distribution (per mm) and diameter $(\mu \mathrm{m})$ within 12 week M-HA, N-HA scaffolds and natural cortical bone. 


\section{LIST OF FIGURES}

Figure 1.1 Histology cross section of (a) trabecular and (b) cortical bone, 200X.

Figure 1.2 Illustration of anatomical osteon and trabecular arrangement in a long bone based on Martin (1998).

Figure 3.1 Representation of parallel MAPK cascade consisting of ERK1/2, P38 and JNK members and the cell survival signal AKT/PKB.

Figure 3.2 SEM photographs of (a) HA and (b) TCP surface micro structure with crystal size closely matched while scale bars differ demonstrating the smaller tightly bound crystals of HA and larger crystals of TCP with small micro-pores.

Figure 3.3 HEPM cell attachment behavior on (white bars) HA and (black bars) TCP surfaces over 6 hours.

Figure 3.4 Phospho-immunoreactivity of ERK1/2 using HEPM cells on tissue culture plastic, calcium phosphate surfaces and scaffolds.

Figure 3.5 Phospho-immunoreactivity of p38 using HEPM cells on tissue culture plastic, calcium phosphate surfaces and scaffolds.

Figure 3.6 Phospho-immunoreactivity of JNK using HEPM cells on tissue culture plastic, calcium phosphate surfaces and scaffolds.

Figure 3.7 Phospho-immunoreactivity of AKT using HEPM cells on tissue culture plastic, calcium phosphate surfaces and scaffolds.

Figure 4.1 SEM photographs of (a) HA and (b) TCP scaffold surfaces showing the smaller crystal size of HA with more grain boundaries and (c) macro calcium phosphate scaffolds representative of both HA and TCP bulk structure and (d) rounded triangular strut design of the scaffold.

Figure 4.2 Calcium release behavior from HA and TCP scaffolds.

Figure 4.3 Ultrasound induced selective increase for cellular protein markers.

Figure 4.4 Scaffold and ultrasound stimulations of intra-cellular stress signal markers.

Figure 4.5 Scaffold and ultrasound stimulations of cell attachment and adhesion signal markers.

Figure 5.1 Acrylic perfusion blocks with HA scaffolds. 
Figure 5.2 SEM pictures of (a) micro surface HA (mHA) and (b) nano coated surface HA (nHA) scaffolds.

Figure 5.3 Cumulative calcium release behavior from micro and nano HA scaffolds demonstrating (a) short term release behavior over 24 hours and (b) long term release over 30 days, reported as ug calcium per scaffold dry weight per mL PBS.

Figure 5.4 Early HEPM cell response to M-HA and N-HA scaffolds. 68

Figure 5.5 Protein expression of HEPM cells in scaffolds over 21 days. 70

Figure 6.1 Cylindrical, interconnected $5 \times 5 \mathrm{~mm}$ HA scaffolds for defect repair in the dog mandible.

Figure 6.2 Representative image of the dog mandible showing; (a) the location of the introduced defects below the premolar teeth and (b) coronal or frontal cross section of the mandible with defect traversing the lateral aspect of the cortical bone based on Boyd (2001).

Figure 6.3 Histological preparation scheme showing cross sections through an implanted scaffold with assignment of quantitative slides from the center and qualitative descriptions from the outer sections.

Figure 6.4 SEM photographs of the HA scaffolds; (a) bulk macroporisity, (b) N-HA scaffold strut morphology, (c) M-HA surface features and (d) N-HA scaffold demonstrating nano-scale surface features.

Figure 6.5 Coronal orientation, micro-CT images; (a,d) control defect, (b,e) implanted M-HA (c,f) and N-HA scaffolds after 3 and 12 weeks postsurgery in the canine mandible.

Figure 6.6 Bone tissue cross section of control defect stained with Paragon for connective tissue (violet) and Alizarin Red for mineralized bone tissue (red) after (a) 3 and (b) 12 weeks post surgery and N-HA scaffold shown after (c) 3 and (d) 12 weeks with scaffold in black, 80X original magnification.

Figure 6.7 Bone tissue cross section of N-HA scaffold under phase contrast after (a) 3 and (c) 12 weeks post surgery with corresponding cross-polarized light micrographs shown in $(b, d)$ representing birefringence of collagen strands, 200X ( $\mathrm{S}=$ scaffold, $\mathrm{M}=$ mineralized bone, $\mathrm{C}=$ collagen birefringence, $\mathrm{V}=$ vessel). 


\section{Chapter 1. Introduction}

Regeneration of bone tissue is often supported by artificial scaffolds providing a platform for cell adhesion and matrix production. Scaffolds are essential to shorten the healing time of large defects or span critical size defects where natural bone fails to bridge an injury. Tissue damage and loss can be the result of disease states or physical injury resulting in diminished quality of life and considerable socioeconomic cost [Chapekar 00]. Despite the improvements in joint replacement techniques and traditional segmental defect repair by marketed products, material and design failure continue to influence biomaterials and often necessitate replacement surgery over time [Spector 92]. In addition to implants, the current therapeutic techniques for treatment of orthopedic damage include auto and allografting of cancellous bone and the use of partially vascularized grafts from the iliac crest [Perry 99]. However, harvesting from donor locations can be associated with site morbidity, provide limited quantities of bone and remains an expensive procedure. Allografting adds the complication of disease and infection that may cause further harm to the patient [Burg 00]. These factors and the clinical demand for therapies that promote bone regeneration throughout a patient's lifetime provided the initial interest in scaffold use for improved integration with native bone tissue [Rose 02].

\section{$1.1 \quad$ Bone background}

Bone is a unique living tissue that dynamically reacts to changes in its physiological environment. The complexity of bone is defined from its multifunctional 
role as the mechanical and structural framework of the body, its ion buffering system for metabolic function and its generation of blood cells by hematopoiesis. As the main mechanical structure of the body, bone withstands the high forces associated with natural motion and protects internal organs and soft tissues from injury [Martin 98]. Bone also has a significant role as the body's ion buffer system for mineral metabolism, acid-base balance and detoxification predominantly regulated by the hormonal system.

\subsection{Bone cells}

Regulation of bone formation and maintenance is governed at the cellular level by a combination of cell types. Four common cells regulate this environment: osteoblasts, osteoclasts, osteocytes and bone lining cells [Marks 02]. Bone sustains a nearly continuous rate of remodeling with osteoblasts depositing and mineralizing new matrix, osteocytes maintaining this structure and osteoclasts resorbing damaged matrix. Lining cells often cover exposed bone surfaces and are considered to be a source of osteoblast precursor cells [Marks 02]. Osteoblastic activity deposits new collagen and mineralizes the matrix. These cells become embedded into circular tube-like structures called osteons. At the completion of this process the cells are called osteocytes and are surrounded inside capsules called lacunae. Embedded osteocytes can receive chemical signals via dendrite processes and represent the communication system of the bone environment [Bulkwalter 96, Martin 98]. These two cell types act in concert to change the shape and repair damage of bone through the activity of basic multicellular units (BMUs) [Martin 98]. These multi-cell structures continuously remodel bone over an individual's lifetime and control the shape and structure of bones. 


\subsection{Bone composition and classification}

Researchers model bone as a composite structure containing both organic and inorganic components [Ascenzi 72, Carter 77, Wang 02]. Collagen fibers in a saline fluid are considered the organics while the mineral hydroxyapatite $\left[\mathrm{Ca}_{10}\left(\mathrm{PO}_{4}\right)_{6}(\mathrm{OH})_{2}\right]$ is the inorganic [Ascenzi 72, Martin 98, Reilly 75]. The arrangement of these components in the overall structure determines the mechanical characteristics of bone.

Categorized by porosity, bone is termed as cortical and trabecular as shown in Figure 1.1. Compact or cortical (from the cortex) bone ranges in porosity from 5 to 20 percent while trabecular bone ranges from 75 to 90 percent [Ascenzi 72, Martin 98]. Trabecular bone is composted of small struts known as trabeculae and is typically located at the ends of long bones. Cortical bone is the primary support of long bones and represents nearly 80 percent of the adult skeleton [Buckwalter 96].

At the microstructural level, bone can be defined as lamellar or woven. Lamellar bone is an exceptionally organized arrangement of collagen and mineral sheets stacked with altering collagen fiber orientation. Lamellar sheets are produced in $0^{\circ}$ and $90^{\circ}$ rotations or as a continuous rotation through $180^{\circ}$. By using this arrangement, a plywood-like structure with exceptional mechanical strength is created [Martin 98]. Woven bone is a rapidly formed tissue that does not display the high degree of organization characteristic of other bone types, but can be formed with great speed in response to injury or during extreme growth. With its near random distribution of collagen fibers and subsequent mineralization, woven bone is a mechanically weak structure especially in elasticity although it does allow higher levels of mineralization, thus increasing material stiffness. 

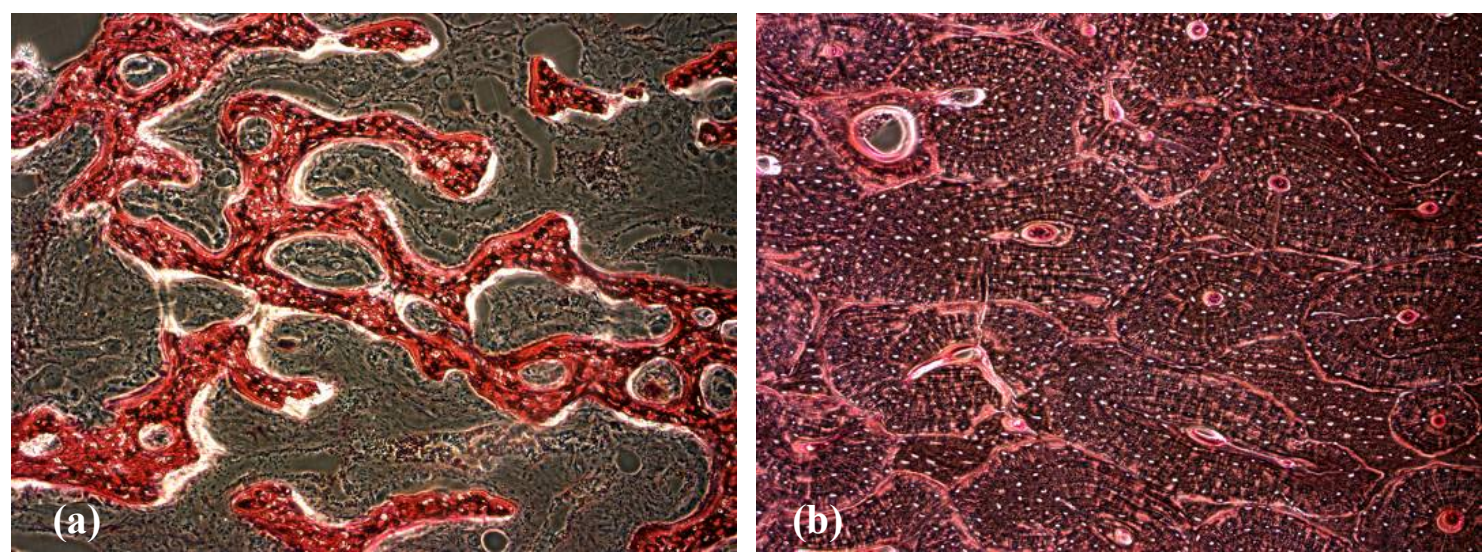

Figure 1.1 Histology cross section of (a) trabecular and (b) cortical bone, 200X. Mineralized tissue stained in red using Alizarin red. 
At the macroscopic level, dense cortical bone contains haversian canals that run longitudinal to the axis of long bones containing blood vessels and nerves as shown in Figure 1.2 following previously reported classifications [Martin 98]. Around these porous spaces, circumferential lamellae are woven to build a functional osteon. Volkmann's canals are located within cortical bone and create a bridge between haversian canals and the periosteum through connecting channels. Through osteoclast activity, hollow spaces are created during remodeling and repair activities [Buckwalter 96].

The osteon arrangement initially forms in response to the blood vessel organization. Cortical bone is further characterization as either primary or secondary bone. Primary bone contains osteons embedded within a less organized matrix and can be deposited on surfaces such as the periosteum. The result is a quickly formed and dense bone often created during fast growth. Secondary bone results from the remodeling activity of osteoclasts and the development of an optimized haversian system.

\subsection{Scaffold design}

In the last 40 years a remarkable quantity of biomaterials have been proposed as scaffolds for bone regeneration, however, very few have proven clinical success. Since natural bone is composted of a substituted hydroxyapatite $\left[\mathrm{Ca}_{10}\left(\mathrm{PO}_{4}\right)_{6}(\mathrm{OH})_{2}\right](\mathrm{HA})$ within an organic matrix ( $\sim 95 \%$ type I collagen) [Ascenzi 72 , Marks 02 ], many scaffolds attempt to duplicate these material components. In addition to natural materials, biodegradable composites based on poly (lactic acid) (PLA), poly (glycolic acid) (PGA) and ratio blends of the two have been used [Freed 94, Peter 98]. These materials have been successfully applied clinically with prior FDA approval and can have their surface 


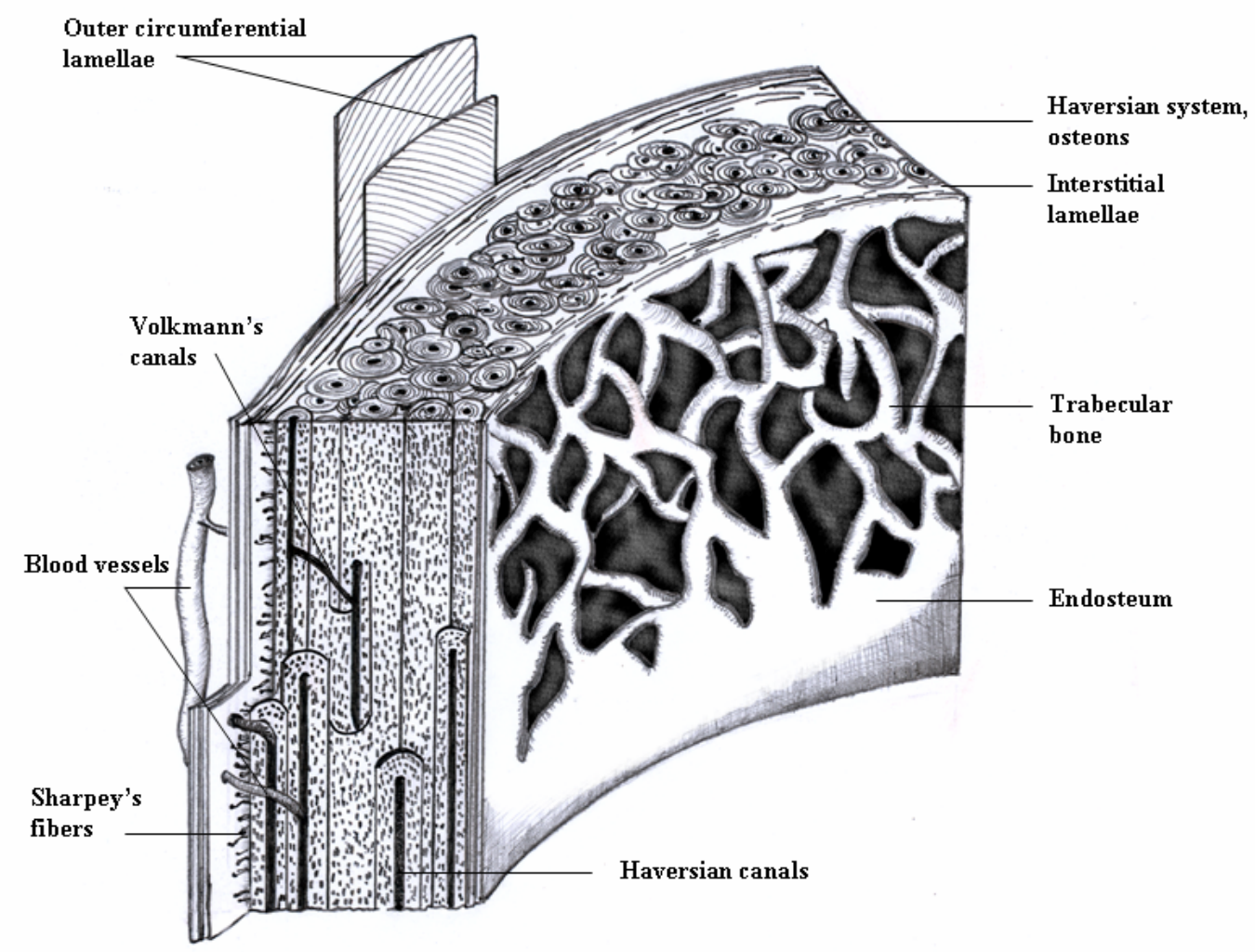

Figure 1.2 Illustration of anatomical osteon and trabecular arrangement in a long bone based on Martin (1998). 
and bulk properties modified for improved characteristics. However, polymer scaffolds of the above or other compositions usually lack mechanical strength and can release acidic byproducts to cells ultimately hindering implant integration and inducing inflammatory reactions [Agrawal 97, 01, Schugens 96].

Among the many biomaterials used for manufacturing scaffolds, hydroxyapatite has a proven performance for bone reconstruction [Arinzeh 05, Dong 01, Flautre 99, Gauthier 05, Kon 99, Koshino 01, Lu 98, Mastrogiacoma 06]. Because of its resemblance to the natural apatite of bone, HA demonstrates a strong bio-mechanical interlock with host tissue [Posner 73, Richard 98]. This material also has limited immunoreactivity while also providing a source of calcium and phosphorous for surrounding cells.

\subsection{Scaffold porosity}

In addition to material composition, pore morphology and overall architecture has been of interest in the development of scaffolds to improve clinical behavior [Arts 06, De Oliveira 03, Lu 99, Mankani 01, Sepulveda 00]. A variety of techniques including porogen leaching, textile, solid free-form fabrication and template coating have been employed to create ceramic scaffolds. Each of these methods has its own unique characteristics with current research especially aimed at the identification of a minimum pore size necessary for tissue infiltration [Chang 00 , Gauthier 98]. The arrangement and shape of pore structures are particularly relevant to cell activities such as proliferation and differentiation of bone precursor cells into the osteoblast lineage [Habibovic 05].

Open, highly porous configurations take advantage of natural bone in-growth to 
enhance the osteoconduction and integration between scaffold implants and bone [Karageorgiou 05]. A number of criteria have been established for scaffold properties including; material composition, surface features, pore morphology and architecture that influence the success of implants. Careful control of these factors can permit scaffolds to be biocompatible, osteo and angioconductive while encouraging a natural bone arrangement during the infiltration of new bone [Chang 00, Groeneveld 99]. Long term clinical success of these designs has been linked with the creation and maintenance of a functional blood supply [Boyde 99]. The result of limited scaffold interconnectivity can lead to an obstruction in vascular infiltration ultimately limiting new tissue formation. Blood vessels also have a role in the coordination of biochemical activity which guides cell response especially during bone remodeling [Barou 03]. The clinical success of scaffolds requires that each of these factors be considered and balanced to support new tissue formation and maintenance.

\subsection{Scaffolds as platforms for cell study}

In addition to their clinical application for regenerative medicine, scaffolds also offer a unique platform for the study of biological pathways. Their bone-like geometry and curvatures permit detailed investigations closely matched to a natural environment. Current research has already established the importance of scaffold surface area and shape of ceramic substrates for preosteoblast cell differentiation into mature osteoblasts [Habibovic 00]. Scaffolds provide a reproducible environment to identify and isolate the specific biological signals that occur during this process and during adhesion and proliferation. Similar to their clinical application, scaffold structures give a stable 
support network for cell adhesion, migration and proliferation as osteoconductive platforms [Chang 00]. Through the careful control of geometry, trabecular structures can be formed to match the architecture of natural tissue.

\subsection{Bone stress signaling}

Cells respond to their three dimensional environment by coupling external stimulations through signaling mechanisms resulting in phenotype changes. One of the most common pathways engaged by bone-like cells in response to the environment are the mitogen-activated protein kinase (MAPK) pathways. These signaling systems mediate many cell reactions to external stimuli such as cytokines, G-protein coupled receptors, growth factors and integrin-based cell adhesion [Morino 95, Robinson 97]. This signaling system has also been identified in committing human mesenchymal stem cells to osteogenic or adipocyte lineages [Jaiswal 00]. Within this family are three subpathways; the extracellular signal-regulated kinases (ERK1/2), c-Jun N-terminal kinases, (JNK), and p38 kinases, the latter two are collectively termed the stress-activated protein kinases (SAPKs). Coupling cell environment changes with survival also activates a diverse regulator of proliferation, growth and anti-apoptosis called AKT / protein kinase B. Coordination of these signals regulates a variety of transcriptional events including survival, glycogen synthesis, glucose transport [Hajduch 01], cell cycle regulation [Diehl 98] and growth by several mechanisms [Inoki 02, Manning 02, Nave 99]. AKT's control over cell survival is of particular interest as physiological stress could be reflected by an increase in AKT activation. Downstream, AKT acts to inhibit apoptosis by inactivation of regulators such as forkhead transcription factors [Brunet 99], c-Raf [Zimmerman 99], 
and caspase-9 [Cardone 98]. AKT exerts substantial influence over cell function and its activity may lead to management of high stress responses from the MAPK cascade observed during cell adhesion to implant materials.

\subsection{Mechanical stimuli}

Scaffolds represent a significant environmental change for cells traditionally cultured on surfaces, however, to accurately represent the native bone environment further mechanical stimuli are necessary. A variety of mechanical factors influence natural bone development including direct compression and associated strains, torsion, bending, fluid pressure and fluid shear. While each of these components acts on natural tissue, the selection of mechanical stimulations for in vitro work is often hindered because force and displacement stimuli are inherently destructive. For this reason, the latter two techniques of applying fluid based pressure waves by acoustic energy or fluid shear by perfusion are often used for tissue engineering.

Bone cells respond to mechanical forces through a process called mechanotransduction. Environmental stimuli are linked with biological signals causing a change in genetic regulation and cellular adaptation [Moalli 00]. At the cell membrane, integrins are responsible for mediating these events through tyrosine phosphorylation of signaling proteins [Ingber 03] forming focal adhesions. Within the cell membrane, focal points engage a variety of structural proteins to connect integrins with signaling pathways such as the mitogen-activated protein kinase (MAPK) cascades [Morino 95, Schlaepfer 98]. 


\subsection{Ultrasound}

Therapeutic ultrasound has proven a valuable tool for the treatment of pathological and trauma fractures particularly with the development of low intensity pulsed ultrasound (LIPUS) [Duarte 83]. Ultrasound has been described as a pressure or sound wave capable of transferring mechanical energy into biological tissues [Williams 83]. This acoustic energy has demonstrated the capability to increase fracture healing both in vitro [Azuma 01, Gebauer 02] and in vivo [Heckman 94]. For laboratory-based cell behavior studies, ultrasound represents a near ideal mechanical stimulation of the cell membrane since the technique is non-destructive and will not adversely affect the scaffold structure.

\subsection{Flow perfusion}

Similar to acoustic ultrasound, perfusion induces local pressure and shear forces at the cell membrane. Fluid shear stimulation has been well characterized in previous studies and has a substantial role in inducing cell differentiation in a bone environment [Cartmell 03, Goldstein 01, Holtorf 05]. Additionally, perfusion offers the added advantage of enhanced nutrient transport for in vitro tissue engineering. This added transport mechanism is especially required when nutrient supply based on diffusion becomes insufficient to meet the metabolic needs of cells. In large 3-D volumes of functional tissue and for long term study of tissue organization, particularly where uniform cell growth is necessary to prevent regions of necrosis, perfusion becomes critical [Holy 00, Ishaug 97]. These strategies for developing and maintaining large 
volumes of tissue with improved nutrient conditions have demonstrated enhanced cell viability, rates of proliferation and protein production [Dunkelman 94, Glowacki 98]. 


\section{Chapter 2. Objectives and hypothesis testing}

\subsection{Overall goals}

The primary objective of this research was to identify cell behavior changes that occur in response to three dimensional features in bone formation and maturation. A significant disparity often occurs between laboratory-based biomaterial testing and in vivo clinical results. The studies included in this work represent an attempt to bridge these fields by using biomaterials and in vitro conditions closely matched to their in vivo counterparts. Hydroxyapatite (HA) and tricalcium phosphate (TCP) represent the two materials studied in this research and reflect the mineral component of natural bone apatite encountered by bone cells. A scaffold design, with natural trabecular bone as the model, represented the platform for cell studies carried out in these experiments.

Scaffolds matched to the true organization of natural bone allowed for biomaterial testing in an environment similar to in vivo architecture. True bone forms under a combination of mechanical forces two of which were investigated herein and included media-based perfusion, simulating the blood-based perfusion flow of natural bone and ultrasound or acoustic-based pressure waves, representing a non-destructive mechanical force similar to the fluid pressure changes resulting from mechanical deformations in natural bone.

The first section of this research compares HA and TCP materials in two dimensions (2-D) and three dimensions (3-D) in terms of cell stress behavior and gives especial emphasis to the role of architecture on cell response. This work is continued in the second section focusing exclusively on 3-D scaffolds with the application of ultrasound mechanical stimuli. While the first two sections emphasize the behavior of 
HA and TCP designs, the last two sections focus on surface modification to HA only. The rationale for the selection of HA relates to the stability of the material. In short term studies the resorbtion activity of TCP can be ignored, however, in longer term studies they introduce a new variable that would alter the focus of this research. To replace the TCP groups, a nano sol-gel based HA was used to evaluate differences in calcium release and surface structure. In the third section, micro and nano surface HA scaffolds are explored in long term cell culture to observe the specific effect of media perfusion on cell differentiation. Finally, in the last section, micro and nano HA scaffolds were evaluated in a canine model for mandible defect repair demonstrating the potential of the scaffold design for successful bone regeneration with emphasis on the osteo and angioconductive capability of the design.

\subsection{Specific hypotheses}

\subsubsection{Osteoblast precursor stress signaling in trabecular HA and TCP scaffolds} compared to 2-D surfaces

- Hypothesis 1: Scaffolds create three-dimensional curvatures not represented in two-dimensions causing an activity increase in the members of the mitogen activated protein kinase cascade.

- Hypothesis 2: Activation of the MAPK cascade corresponds with an increase in the anti-apoptosis signal AKT, rescuing cells from programmed cell death in 3-D scaffolds. 


\subsubsection{Adhesion and stress response of osteoblast precursors in trabecular HA and TCP}

scaffolds in response to ultrasound

- Hypothesis 3: Calcium release from scaffold designs is responsible for the increase in cell stress signaling and adhesion protein activation.

- Hypothesis 4: Ultrasound stimulation significantly increases activity of the MAPK cascade and adhesion proteins on 3-D scaffolds.

\subsubsection{Osteoblast precursor response to fluid perfusion in trabecular nano and micro} surface HA scaffolds

- Hypothesis 5: Nano coating of HA scaffolds increases local surface roughness for improved cell attachment and viability.

- Hypothesis 6: Nano surface HA scaffolds increases calcium release stimulating HEPM cell differentiation both in static and media perfused conditions.

\subsubsection{Trabecular nano and micro surface HA scaffolds for in vivo bone repair}

- Hypothesis 7: In vivo bone formation in scaffolds will match the differentiation time of perfusion studies confirming the use of in vitro perfusion in scaffolds as a platform for bone evaluation.

- Hypothesis 8: Nano surface HA scaffolds increase the total tissue, blood vessel and bone formation capacity compared to micro surface scaffolds while generating tissue morphology similar to natural cortical bone. 


\section{Chapter 3. Effects of trabecular calcium phosphate scaffolds on stress-signaling in osteoblast precursor cells*}

\subsection{Abstract}

The objective of this research was to investigate stress-signaling patterns in response to two dimensional (2-D) and three dimensional (3-D) calcium phosphate (CP) materials using human embryonic palatal mesenchyme cells (HEPM, CRL-1486, ATCC, Manassas, VA), an osteoblast precursor cell line. Control discs and scaffolds were fabricated from hydroxyapatite (HA) and $\beta$ tri-calcium phosphate (TCP) ceramics. Phospho-specific antibody cell-based ELISA (PACE) technique was utilized to measure the activities of the mitogen-activated protein kinase (MAPK) cascades including; the extracellular signal-regulated kinases (ERK1/2), p38, c-Jun N-terminal kinase (JNK), and the anti-apoptosis mediator protein kinase B (AKT). Quantification of these signals was evaluated during the early attachment phase of osteoblast precursor cells. In this study, it was observed that cell culture on 3-D CP scaffolds significantly activated the stress mediators p38 and JNK but not ERK1/2. This signal trend was matched with an increase in AKT, suggesting the ability of cells to manage high stress signals in response to 3-D $\mathrm{CP}$ architecture and that 3-D CP scaffolds are necessary for studies simulating a natural trabecular bone organization. The absence of these signals in 2-D CP surfaces indicated the importance of local architecture conditions on cell stress responses. It was concluded from this study that osteoblast precursor cells cultured in 3-D CP scaffolds experience

\footnotetext{
*Reprinted from Biomaterials, 28, Appleford MR, Oh S, Cole JA, Carnes DL, Lee M, Bumgardner JD, Haggard WO, Ong JL. Effects of trabecular calcium phosphate scaffolds on stress signaling in osteoblast precursor cells, 2747-2753, 2007, Elsevier permissions.
} 
greater stress-signaling patterns when compared to 2-D CP surfaces.

\subsection{Introduction}

Regeneration of bone tissue assisted by ceramic scaffold grafts has shown excellent capability in recent bone regenerative therapeutic techniques [Arinzeh 05 , Boyde 99, Dong 01, Dong 03, Flautre 99, Gauthier 05, Kon 99, Livingston 02, Lu 98, Mastrogiacoma 06, Uemura 03]. Additionally, the development of artificial scaffolds for bone reconstruction offers several distinct advantages for cell studies. In particular, the use of calcium phosphate $(\mathrm{CP})$ ceramics for scaffold development exhibits a variety of useful properties; strong mechanical characteristics closely matched to bone, negligible immunoreactivity and the availability of local calcium and phosphorous for surrounding cells. At the protein and cellular level, $\mathrm{CP}$ materials are directly bound to the collagen matrix forming a strong mechanical interlock between bone and implant [Richard 98]. In addition to material composition, research has also established the importance of specific surface area and shape of ceramic substrates for cell differentiation into the osteogenic lineage [Habibovic 05]. These scaffolds offer a reproducible platform for the identification and isolation of specific biological signals as well as their clinical use in regenerative orthopedics [Koshino 01, Mangano 03, Zyman 98]. Their structures provide a stable support network for cell adhesion, migration, and proliferation as osteoconductive platforms [Chang 00]. Their strong resemblance to trabecular bone also permits investigation of cell signaling patterns in an environment analogous to natural tissue. As bone cells identify and react to the environment by means of a mechano- with transduction system, it is of interest to distinguish changes in intracellular communication 
respect to 3-dimensional (3-D) curvatures.

Intracellular pathways such as mitogen-activated protein kinase (MAPK) family of serine/theonine kinases drive many cell reactions to external stimuli including cytokines, G-protein coupled receptors, growth factors, and integrin-based cell adhesion [Morino 95, Robinson 97]. This signaling system has also been identified in committing human mesenchyme stem cells to osteogenic or adipocyte lineages [Jaiswal 00]. Within this family are three sub-pathways; the extracellular signal-regulated kinases (ERK1/2), c-Jun N-terminal kinases, (JNK), and p38 kinases [Widmann 99], the latter two are collectively termed the stress-activated protein kinases (SAPKs). Cell survival signaling also involves a mediator termed $\mathrm{AKT} / \mathrm{PKB}$, protein kinase $\mathrm{B}$, originally named from an AKR/J thymoma mouse cell line [Staal 77], with involvement in a diverse set of cell functions. A general outline of the various inputs and outputs from the MAPK and AKT members are shown in Figure 3.1.
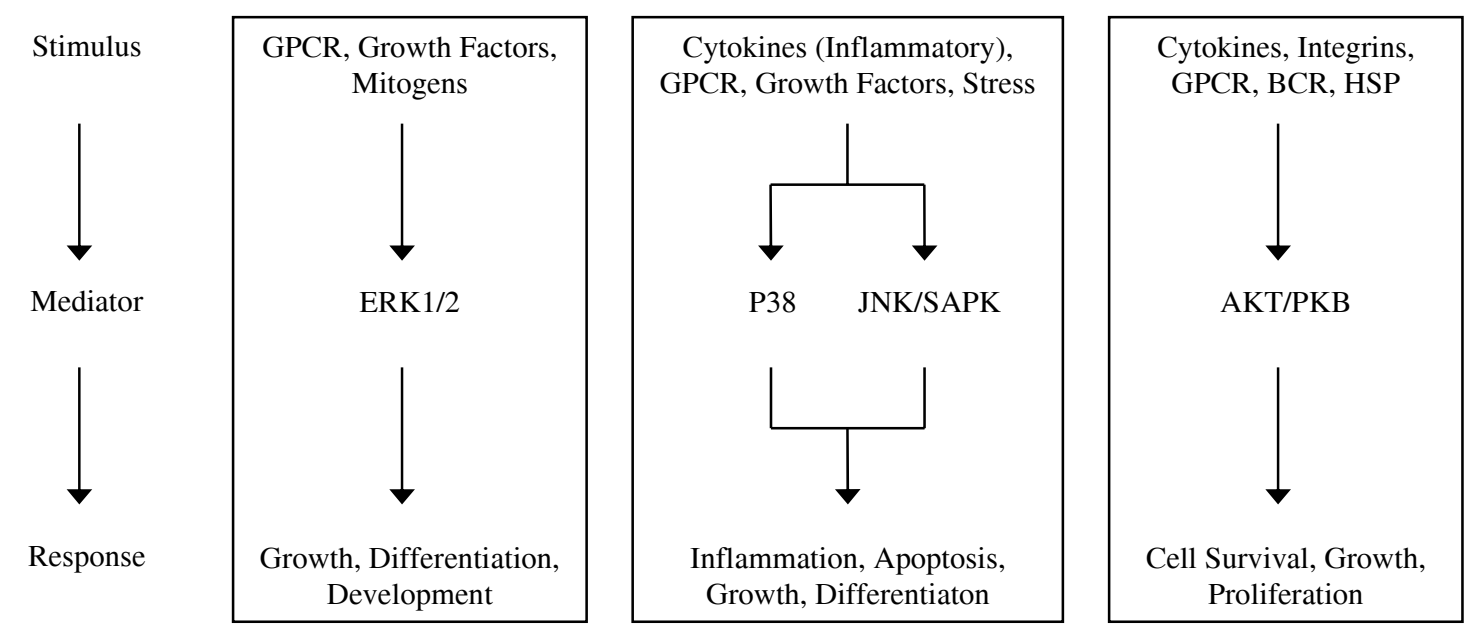

Figure 3.1 Representation of parallel MAPK cascade consisting of ERK1/2, P38 and JNK members and the cell survival signal AKT/PKB. Stimulations, mediators and generalized responses are illustrated in flow diagram form. 
The objective of this study was to determine pre-osteoblast responses to scaffold architecture during the cell adhesion-phase through the mitogen-activated protein kinase (MAPK) cascade and anti-apoptosis mediator AKT signaling. Testing was performed on hydroxyapatite (HA) and tri-calcium phosphate (TCP) scaffolds using human embryonic palatal mesenchyme cells (HEPM, CRL-1486, ATCC, Manassas, VA), an osteoblast precursor cell line. Specifically, phospho-activation of extracellular signal-regulated kinases (ERK1/2), p38, c-Jun N-terminal kinase (JNK), and AKT on 3-D and 2dimensional (2-D) HA and TCP surfaces were measured.

\subsection{Materials and methods}

\subsubsection{Sample preparation}

Disc shaped specimens (controls) were produced from micro particulate HA and TCP (TAL Materials, Ann Arbor, MI) using a hydraulic press and stainless steel mold with diameter of $6 \mathrm{~mm}$. The materials were sintered in air at $1230^{\circ} \mathrm{C}$ for 3 hours. HA and TCP scaffolds were prepared using a foam-dipping technique. Polyurethane sponges (EN Murray, Denver, CO) were coated with HA or TCP slurry. Binders were used with the slurry to improve sintering and to stabilize the scaffold structure and included $3 \%$ high molecular weight polyvinyl alcohol, $1 \% \mathrm{v} / \mathrm{v}$ carboxymethylcellulose, $1 \% \mathrm{v} / \mathrm{v}$ ammonium polyacrylate dispersant, and 3\% v/v N,N-dimethylformamide drying agent. Coated sponges were vacuum-dried overnight before sintered. Scaffolds were twice coated with $\mathrm{CP}$ slurry and re-sintered to $1230^{\circ} \mathrm{C}$. Purity of the composition was validated using X-ray diffraction analysis. Final scaffold dimensions were ø $5 \mathrm{~mm}$ and length of 5

$\mathrm{mm}$, discs were prepared with $\varnothing 6 \mathrm{~mm}$ and height of $1.5 \mathrm{~mm}$. All samples were placed 
into non-binding 96 well plates (Corning, Acton, MA) and ethylene oxide gas sterilized before analysis.

\subsubsection{Sample characterization}

Calcium phosphate disc-controls and scaffolds were imaged by scanning electron microscopy. Histomorphometric measures of the scaffold were performed on crosssectional slides. Scaffolds were embedded in one-component photo-curing resin (Exakt 7200 VLC, Oklahoma City, OK), and thin sectioned using a precision microsaw (Buehler, Lake Bluff, IL). Sections were progressively polished on 600, 800, 1000, 1200 grit paper and adhered to glass slides using a methyl methacrylate resin (Surgipath Medical Ind., Richmond, IL). Sections were imaged at 100X magnification with a digital camera (QImaging, Burnaby, Canada) on a Nikon TE300 microscope (Nikon, Melville, NY). An analysis of the scaffold was performed using bone histomorphometry software, Osteo v.7 (Bioquant, Nashville, TN). A total of four cross-sections were prepared from each scaffold and parameters were defined using traditional histomorphometry guidelines for trabecular bone structures as follows:

- Percentage of scaffold volume [SV / TV = scaffold volume / total volume $\mathrm{x}$ $100 \%]$

- Ratio of scaffold surface perimeter to total volume [SS / TV = surface length / total volume]

- Ratio of scaffold surface perimeter to scaffold volume [SS / SV = surface length / scaffold volume]

- Trabecular thickness [Tb.th. $=(4 / 1.199) \times(S S / S V)]$ 
- $\quad$ Trabecular number [Tb.n. $=((4 / \pi) \times(\mathrm{SV} / \mathrm{TV}))^{-0.5} /($ Tb.th. $\left.)\right]$

- $\quad$ Trabecular separation [Tb.sp. $=((4 / \pi) \times(\mathrm{TV} / \mathrm{BV})-1) \times(\mathrm{Tb}$. th. $)]$

The formulae shown above were derived with respect to trabecular bone tissue that includes both rod- and plate-like geometry. Consequently, these formulae may not be ideally suited to the isotropic character of these scaffolds. The incorporation of these properties herein permits a comparison with known values with the human lumbar spine, a predominantly rod-like trabecular structure [Hildebrand 99].

\subsubsection{Cell culture and adhesion}

Human embryonic palatal mesenchyme cells (HEPM, CRL-1486, ATCC, Manassas, VA), an osteoblast precursor cell line, were cultured in Dulbecco's modified eagle medium (DMEM, Invitrogen, Carlsbad, CA) supplemented with 7\% fetal bovine serum (FBS, Invitrogen) and 1\% antibiotic/antimycotic (PSA, $100 \mathrm{U} / \mathrm{mL}$ penicillin, 100 $\mu \mathrm{g} / \mathrm{mL}$ streptomycin, $0.25 \mu \mathrm{g} / \mathrm{mL}$ amphotericin $\mathrm{B}$, MP Biomedicals, Solon, $\mathrm{OH}$ ) at $37^{\circ} \mathrm{C}$ with 5\% $\mathrm{CO}_{2}$. Cells were cultured in TC-75 flasks with biweekly media changes and passaged at confluence using TrypLE, a trypsin-like enzyme (Invitrogen). HEPM cells were counted using a coulter counter (Beckman Coulter Z2, Fullerton, CA), and 20,000 cells in total were seeded onto tissue culture treated plates, CP discs or scaffolds.

Attachment behavior of HEPM cells to CP surfaces was evaluated in a time course study with cells plated and attached for 1, 2, 4 or 6 hours. The cell media was collected along with two washes of PBS to count unattached cells at the selected time points. The percent cell attachment was calculated as $(\% \mathrm{Att}=($ cells seeded - unattached cells) / cells seeded x 100\%). This methodology was confirmed by detaching the 
remaining cells from the material to ensure count equivalence. Percent attachment values were used to determine a suitable time point for remaining studies such that an equivalent cell number could be assumed between HA and TCP materials.

\subsubsection{Material phospho-specific antibody cell-based ELISA (PACE)}

HEPM cells were attached to CP surfaces for 6 hours followed by washing twice with ice-cold PBS. Cells were fixed with 4\% Carson's Millonig formaldehyde in PBS for 30 minutes at room temperature then endogenous peroxidase activity was quenched using $0.3 \% \mathrm{H}_{2} \mathrm{O}_{2}$ in PBS - $0.1 \%$ Triton X-100 (PBS-T) for 30 minutes. Cells were washed three times with PBS-T, followed by blocking with $10 \%$ fetal calf serum (FCS, Invitrogen) in PBS-T for 1 hour. Primary rabbit antibodies against phospho-p44/42 (ERK1/2, Thr202/Tyr204), phospho-p38 (Thr180/Tyr182), phospho-SAPK/JNK (Thr183/Tyr185), and phospho-AKT (Ser 473, Cell Signaling Technology, Danvers, MA) were added in 5\% FCS-PBS-T and incubated overnight at $4{ }^{\circ} \mathrm{C}$ with $20 \mathrm{rpm}$ rocking. Dilutions of primary antibodies were set at 1:1000 except for pp38, at 1:500. Antibody dilutions were established from titer-controls with a minimum absorbance signal to noise ratio of 8 using non-stimulated cells on tissue culture treated plastic. Signal inhibitors for

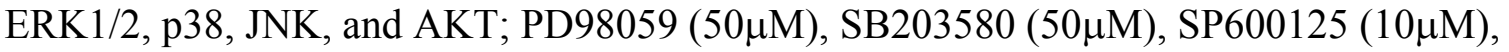
Wortmannin $(2 \mu \mathrm{M})$, respectively, were added 30 minutes before test completion. After primary antibody incubation, cells were washed three times with PBS-T for 5 minutes and incubated with secondary anti-rabbit IgG, HRP-linked antibody (horseradish peroxidase) with a 1:1000 dilution in 5\% FCS-PBS-T for 1 hour at room temperature with rocking. The cells were then washed three times with PBS-T, and twice with PBS 
for five minutes. One-Step Ultra TMB substrate (Pierce Biotechnology, Rockford, IL) was added to the wells and color developed for 30 minutes at room temperature in the dark. The oxidation reaction was stopped and color changed and stabilized using an equal volume of $2 \mathrm{M} \mathrm{H}_{2} \mathrm{SO}_{4}$. The colored products were transferred to new 96 well plates and absorbance measured at $450 \mathrm{~nm}$ with reference at $620 \mathrm{~nm}$ on a Beckman Coulter AD34C plate reader (Fullerton, CA).

\subsubsection{Statistical analysis}

Statistical calculations were performed with SigmaStat software (Systat, Point Richmond, CA). Validity of signal inhibition with each material was compared by paired t-test. Significance between groups was analyzed by one-way ANOVA with Tukey pairwise multiple comparisons. Significance levels were set at $\mathrm{p}<0.05$.

\subsection{Results}

\subsubsection{Material characterization}

Calcium phosphate control surfaces imaged by SEM are shown in Figure 3.2(a-b) revealing the micro surface structure. While surface roughness was normalized by bulk fabrication, differences in the chemical composition are reflected in the surface character of HA and TCP materials. Sintered HA surfaces consisted of smaller crystals with tight junctions while TCP surfaces exhibited larger crystal size with loosely bound junctions and infrequent micro-scale pores. These characteristics were also preserved in 3-D where strut-surfaces reflect the morphology differences of HA and TCP materials. 

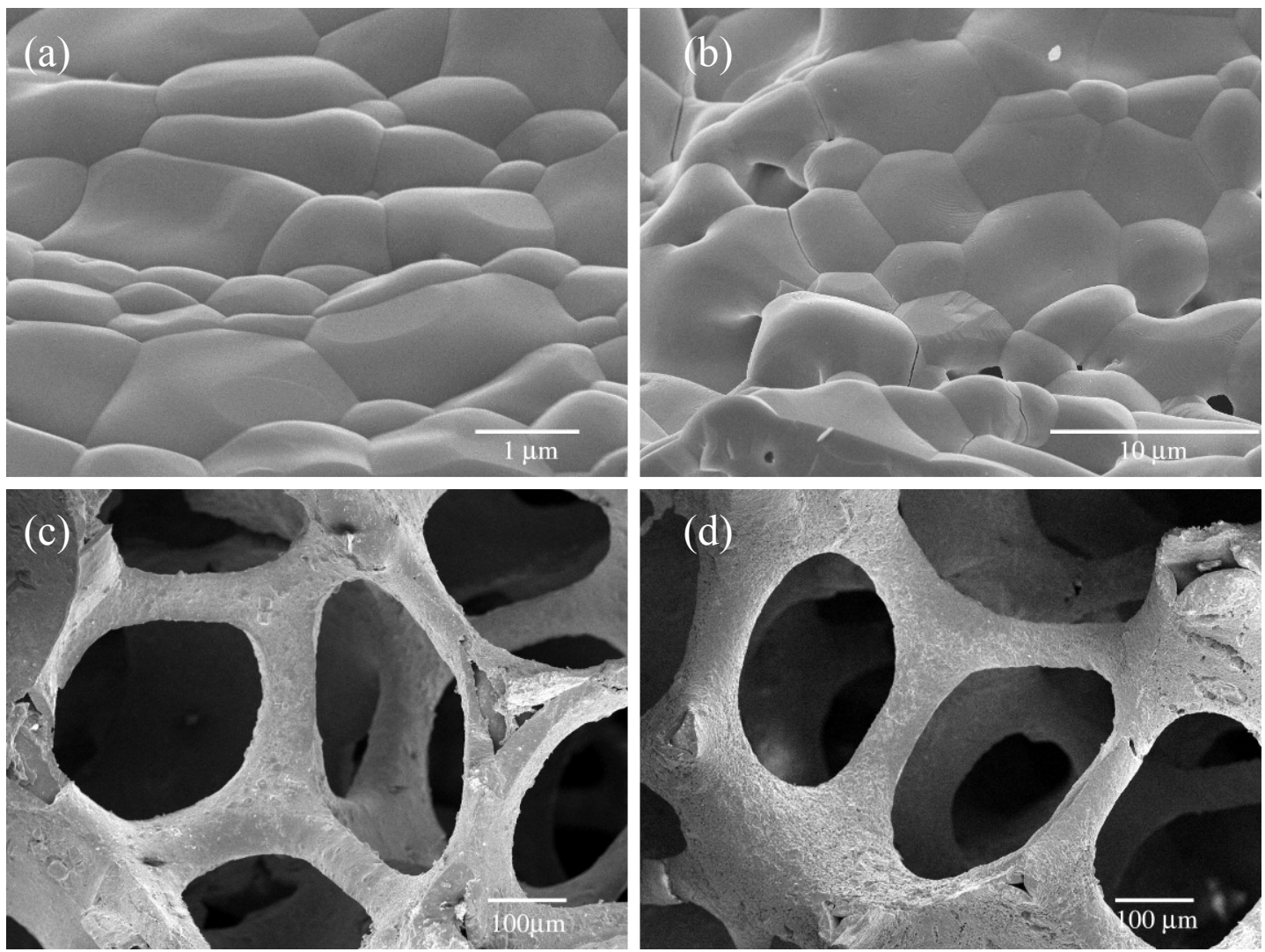

Figure 3.2 SEM photographs of (a) HA and (b) TCP surface micro structure with crystal size closely matched while scale bars differ demonstrating the smaller tightly bound crystals of HA and larger crystals of TCP with small micro-pores. Bulk scaffold architecture of (c) HA and (d) TCP materials show little differences in structure. 
Bulk scaffold architecture, defined by the original polyurethane template, is nearly identical for the two CP materials studied (Figure 3.2c-d). Small variations were seen in the percent shrinkage between HA and TCP after heat treatments, however, the differences were not significant as measured by histomorphometry. Average scaffold values were obtained for the previously mentioned parameters with comparisons to vertebral bone structure as shown in Table 3.1. The architecture of the scaffold consisted of a rod-like arrangement with morphological similarity to human vertebral, trabecular bone [Hildebrand 99].

\subsubsection{Cell adhesion}

Cells attached to HA and TCP at a rapid rate with approximately $80 \%$ binding

within the first hour. As variations in attachment could affect the ELISA measurements, a time point was selected where differences were no longer significant between the two materials, but before changes in cell number by proliferation could influence the data. The cell attachment rate on HA and TCP surfaces indicated no significant differences between the two surfaces at each time point as shown in Figure 3.3. By 4 to 6 hours of cell culture a stable plateau is reached where time differences are no longer significant (93\% binding). The 6 hour time point was subsequently used for all ELISA testing. Scaffold attachment rates equaled or exceeded that of surfaces and also normalized to 95\% by 6 hours with 2-D data representative of 3-D attachment behavior. 
Table 3.1 Scaffold histomorphometry parameters compared to human vertebral bone of the second lumbar.

\begin{tabular}{lllll}
\hline Parameter & Abbreviation & Scaffold & Vertebra* & Units \\
\hline Scaffold Volume/Total Volume & SV/TV & $32.51 \pm 6.65$ & $8.3 \pm 2.4$ & $\%$ \\
Scaffold Surface/Total Volume & SS/TV & $3.19 \pm 0.27$ & $1.87 \pm 0.49$ & $\mathrm{~mm}-1$ \\
Scaffold Surface/Scaffold & SS/SV & $10.26 \pm 2.32$ & $23.73 \pm 3.41$ & $\mathrm{~mm}-1$ \\
Volume & & & & \\
Trabecular Number & Tb.N & $1.93 \pm 0.25$ & $0.93 \pm 0.25$ & $\mathrm{~mm}-1$ \\
Trabecular Separation & Tb.Sp & $1.00 \pm 0.11$ & $1.07 \pm 0.33$ & $\mathrm{~mm}$ \\
Trabecular Thickness & Tb.Th & $0.34 \pm 0.08$ & $0.09 \pm 0.01$ & $\mathrm{~mm}$ \\
\hline
\end{tabular}

*Source: Hildebrand T, Laib A, Muller R, Dequekker J, Ruegsegger P. Direct threedimensional morphometric analysis of human cancellous bone: microstructural data from spine, femur, iliac crest, and calcaneus. J Bone Miner Res 1999;14:1167-1174. 


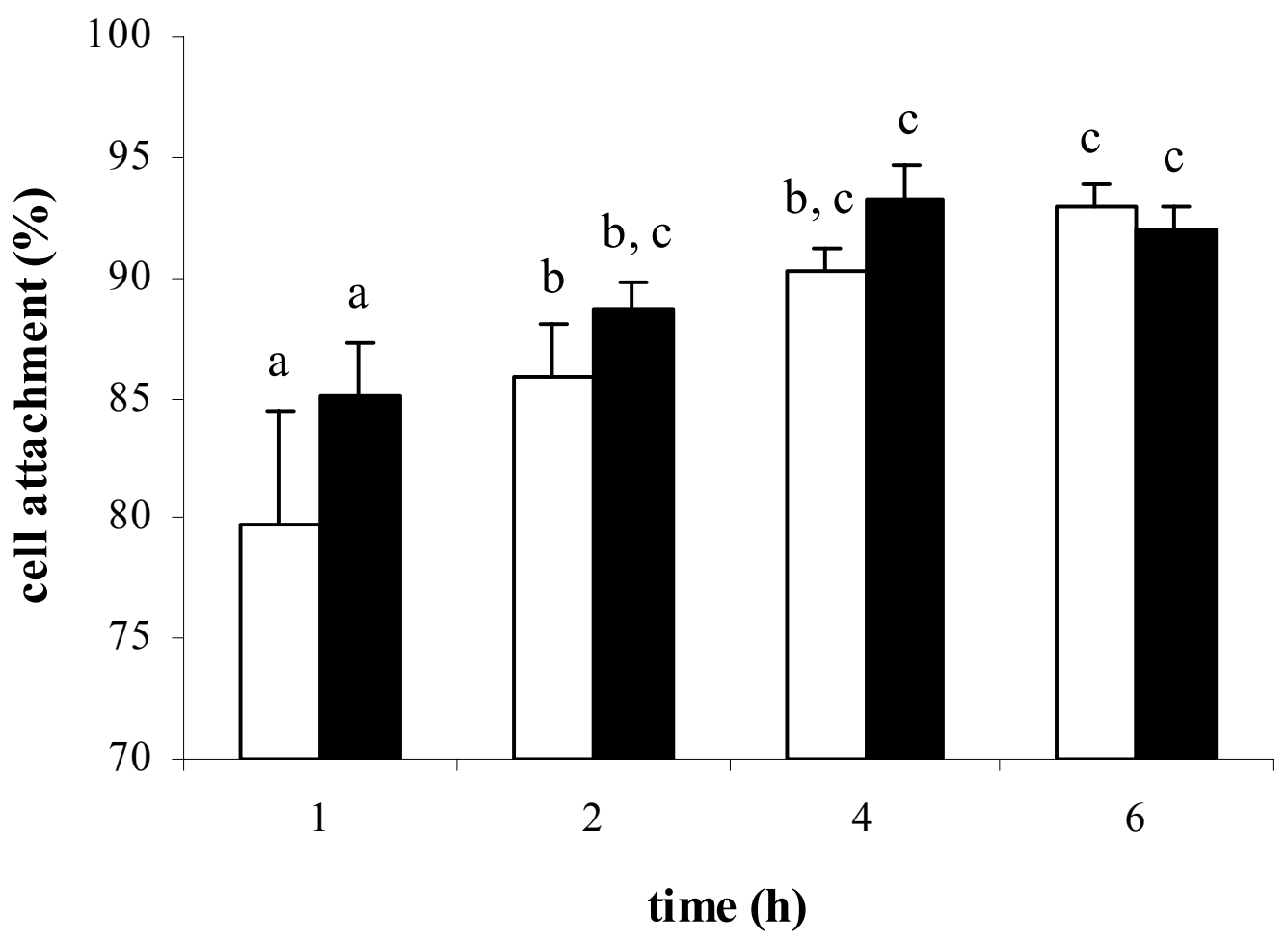

Figure 3.3 HEPM cell attachment behavior on (white bars) HA and (black bars) TCP surfaces over 6 hours. More than $80 \%$ of cells attached to CP surfaces within 1 hour, and attachment stabilized to approximately $93 \%$ by 6 hours. Letters denote significant between group differences by Tukey pairwise multiple comparisons $\mathrm{p}<0.05, \mathrm{n}=4$ / time point, error bars + S.D. 


\subsubsection{Activation of ERK1/2 on CP's}

The effects of surface material and architecture on the phosphorylation of ERK1/2 was investigated during the early attachment phase of HEPM cells to HA and TCP substrates as shown in Figure 3.4. A high basal level of ERK activity was observed with cells cultured on tissue culture plastic and was significantly reduced with cells cultured on 2-D TCP and 3-D HA materials. A significant increase in signal was also seen in 3-D TCP scaffolds over 2-D TCP and 3-D HA. Signal was inhibited using PD98059 (a binder of MEK1 inactive forms), limiting activation by upstream signalers. Inhibition of MEK1 significantly reduced $\mathrm{pERK} 1 / 2$ activity in all groups $(\mathrm{p}<0.005)$.

\subsubsection{Activation of $p 38$ on $C P$ 's}

The activation of the stress signal mediator $\mathrm{p} 38$ was evaluated in response to material surface and architecture as shown in Figure 3.5. A moderate difference was identified between tissue culture plastic and 2-D HA and TCP surfaces with both 3-D

groups significantly greater than all other materials. The highest activation of p38 occurred in 3-D HA and was significantly greater than 3-D TCP. Selective inhibition was performed with SB203580, and significantly reduced all material responses $(\mathrm{p}<0.05)$ except for tissue culture plastic indicating that $\mathrm{p} 38$ was not activated in response to this surface.

\subsubsection{Activation of JNK on CP's}

Phospho-activation of the JNK environmental stress mediator on CP materials is shown in Figure 3.6. On 2-D surfaces, a difference was recognized between HA and 


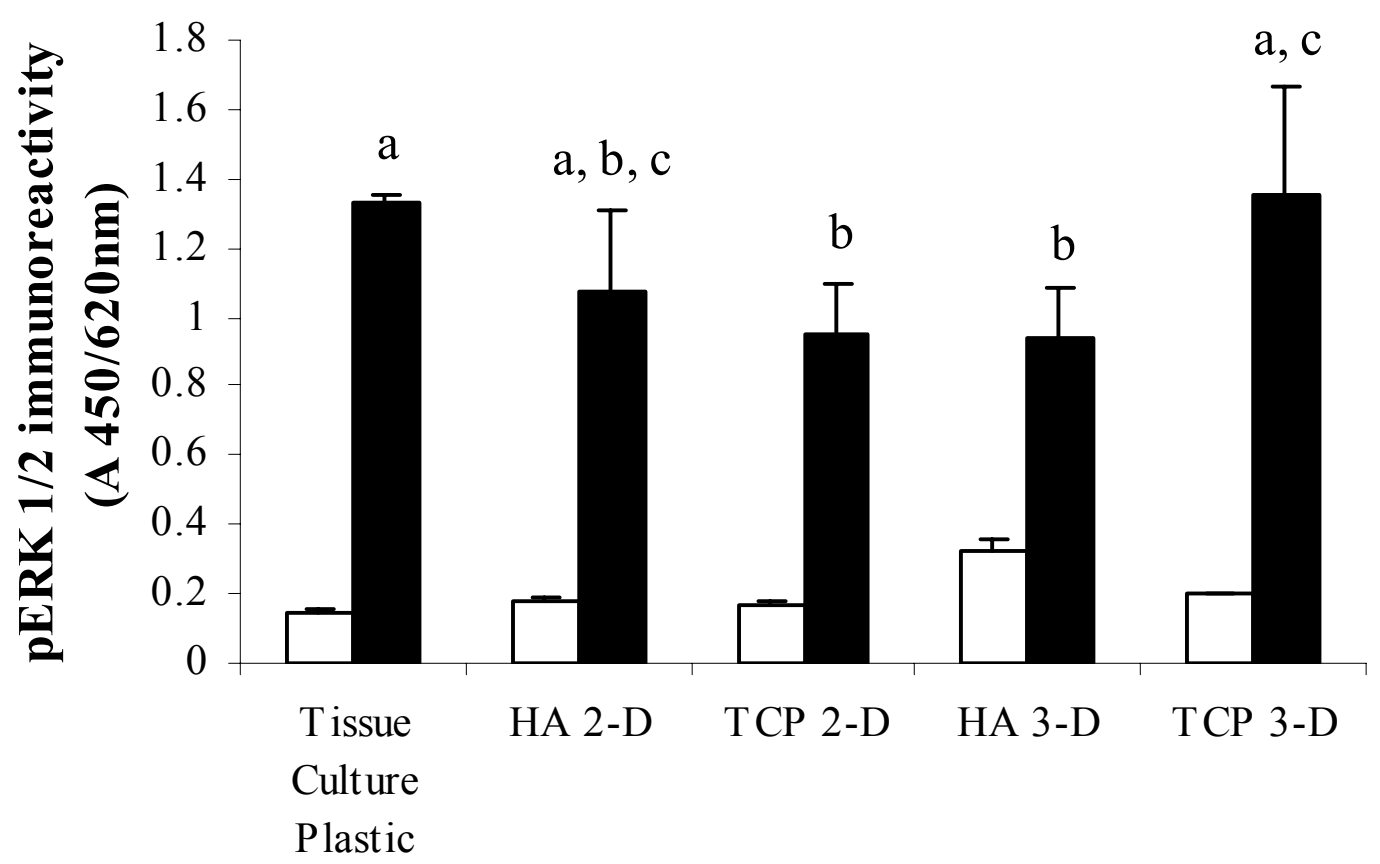

Figure 3.4 Phospho-immunoreactivity of ERK1/2 using HEPM cells on tissue culture plastic, calcium phosphate surfaces and scaffolds. White bars represent signal inhibition for 30 minutes with PD98059, black bars represent actual signal. Selective inhibition was significantly different from signal in each material by paired $t$-test, $p<0.005$. Letters denote significant differences by Tukey pairwise multiple comparisons $\mathrm{p}<0.05, \mathrm{n}=6$, data representative from 2 independent experiments. ERK, extracellular-signal-regulated kinase. 


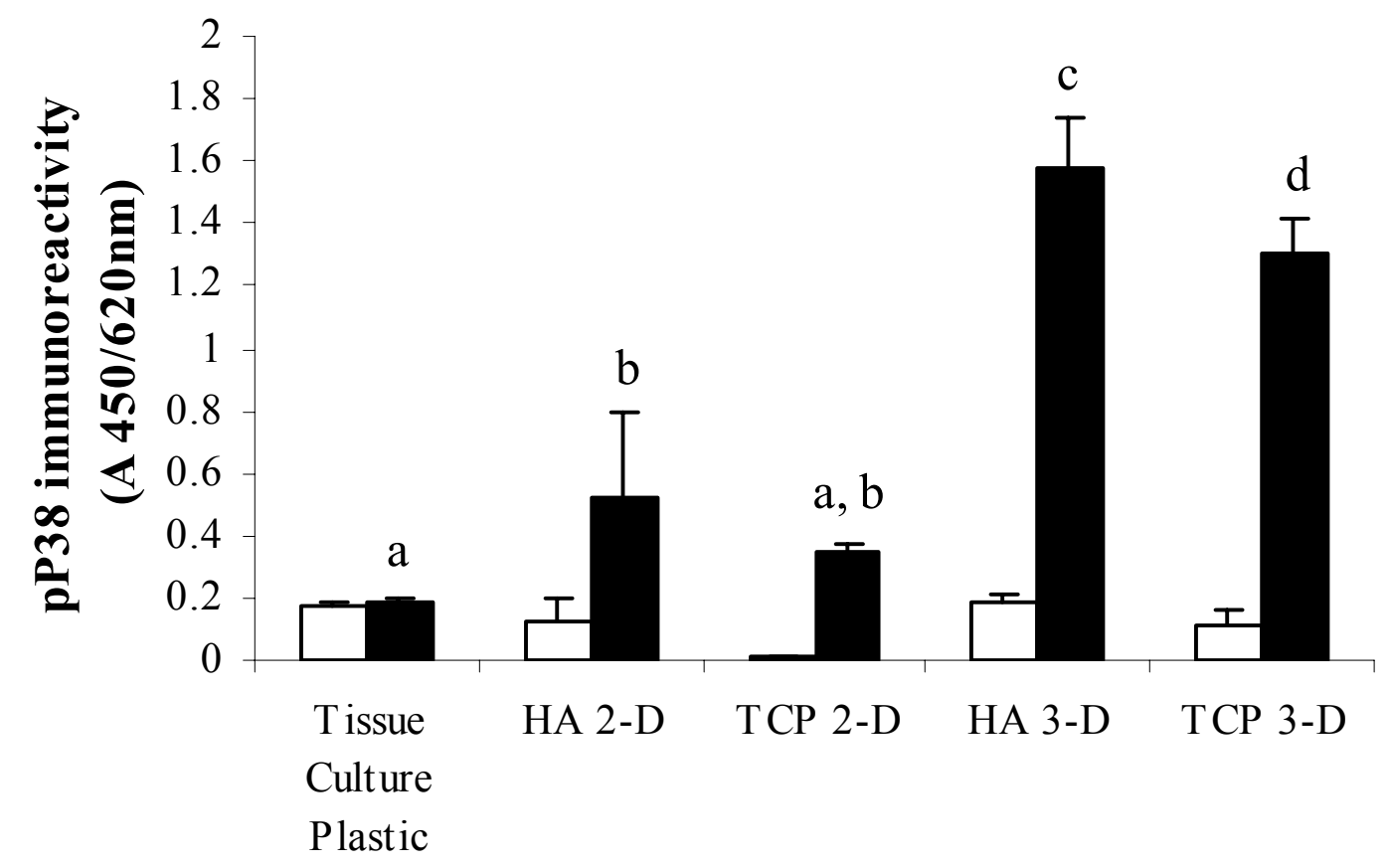

Figure 3.5 Phospho-immunoreactivity of p38 using HEPM cells on tissue culture plastic, calcium phosphate surfaces and scaffolds. White bars represent signal inhibition for 30 minutes with SB203580, black bars represent actual signal. Selective inhibition was significantly different from signal in each material, except tissue culture plastic by paired t-test, $p<0.05$. Letters denote significant differences by Tukey pairwise multiple comparisons $\mathrm{p}<0.05, \mathrm{n}=6$ from 2 independent experiments. $\mathrm{p} 38$ from cytokine suppressive anti-inflammatory drug binding protein (CSBP). 


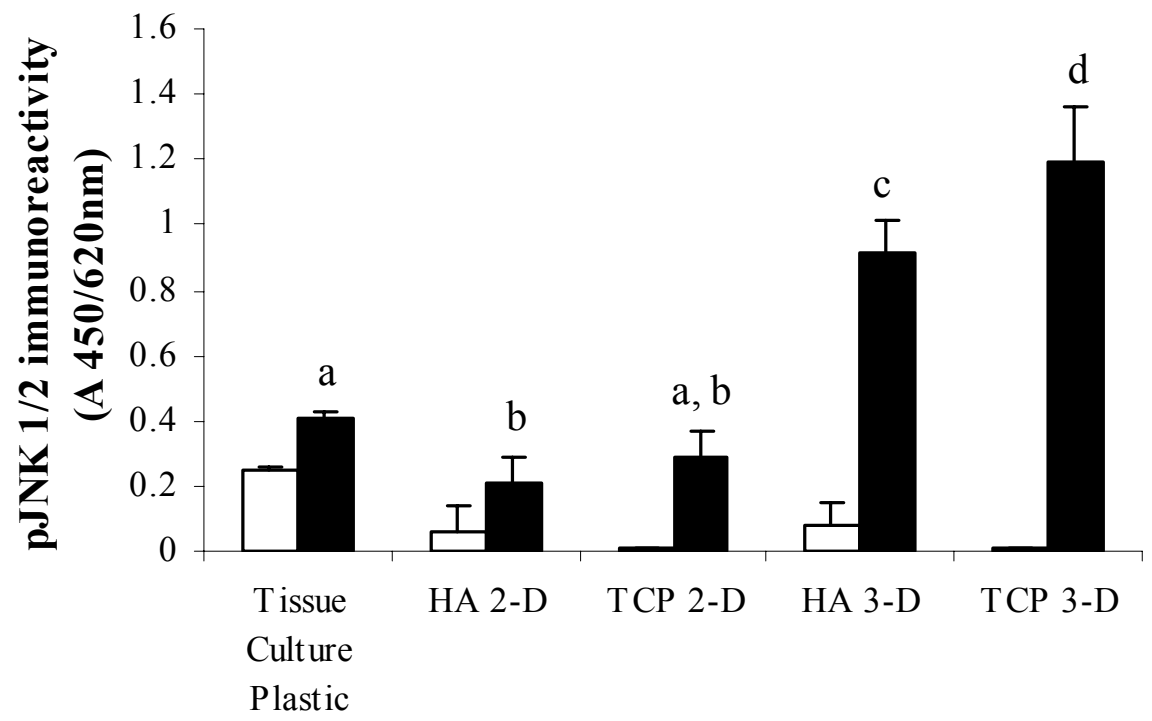

Figure 3.6 Phospho-immunoreactivity of JNK using HEPM cells on tissue culture plastic, calcium phosphate surfaces and scaffolds. White bars represent signal inhibition for 30 minutes with SP600125, black bars represent actual signal. Selective inhibition was significantly different from signal in each material by paired t-test, $p<0.05$. Letters denote significant differences by Tukey pairwise multiple comparisons $\mathrm{p}<0.05, \mathrm{n}=6$ from 2 independent experiments. SAPK/JNK, stress-activated protein kinase/c-Jun-aminoterminal kinase. 
elevated values on tissue culture plastic, however, this difference may not be a true signal change due to the high background of the inhibited signal on tissue culture plastic.

Similar to the trend seen with $\mathrm{p} 38$, 3-D JNK signals were elevated with significant differences over all other materials but with highest signal strength in TCP rather than HA scaffolds. Selective signal inhibition was performed using SP600125, resulting in significant reductions $(\mathrm{p}<0.05)$ in all materials.

\subsubsection{Activation of AKT on CP's}

The cell survival signal AKT/PKB was evaluated in response to CP materials with results illustrated in Figure 3.7. Signal strength was elevated in 2-D HA over tissue culture plastic and no difference was identified between 2-D and 3-D HA although the trend suggests higher activation in 3-D. TCP scaffolds elicited the greatest signal response significantly greater than all other groups. The pAKT pathway was wortmannin sensitive and selective inhibition of phosphatidylinositol 3-kinase significantly reduced $(p<0.05)$ the values in all materials. Similarities were observed between the activation of AKT and JNK with regard to material dependant 3-D response and between AKT and p38 in 2-D response.

\subsection{Discussion}

Cells translate environmental signals into physiological responses through intracellular pathways linking genetic regulation with changes in phenotype. The MAPK cascade plays a substantial role in environmental signaling. Herein, the importance of material substrate and 3-D architecture on the regulation of stress and apoptosis 


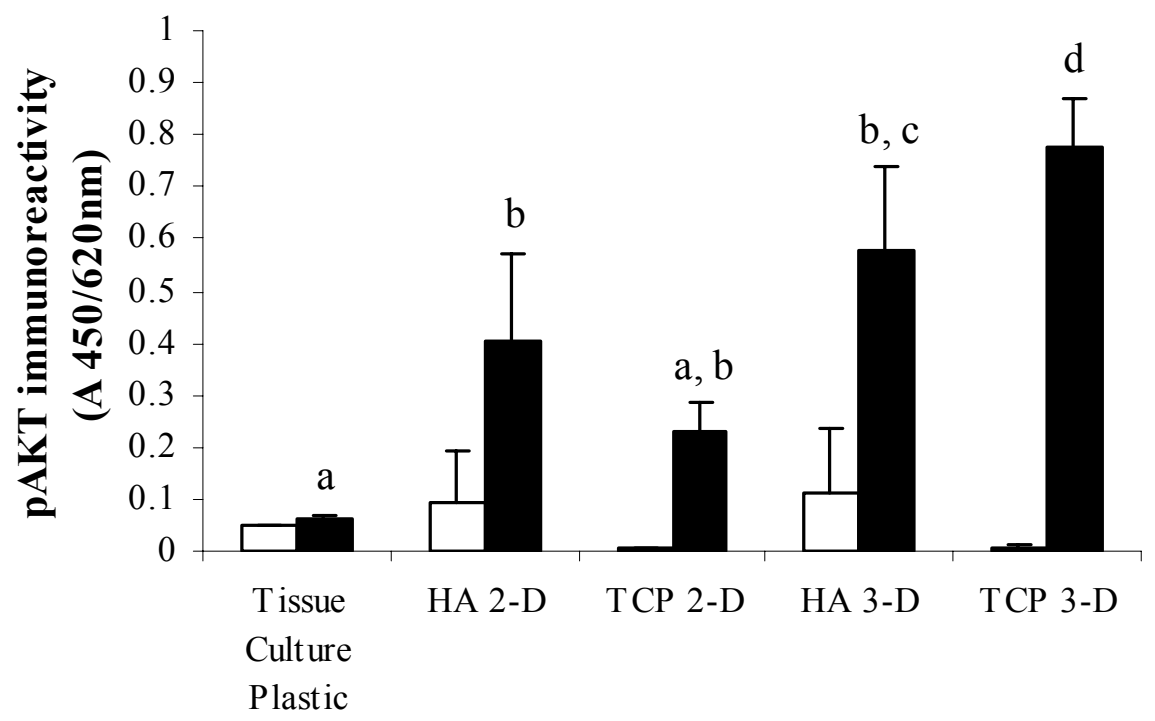

Figure 3.7 Phospho-immunoreactivity of AKT using HEPM cells on tissue culture plastic, calcium phosphate surfaces and scaffolds. White bars represent signal inhibition for 30 minutes with Wortmannin, black bars represent actual signal. Selective inhibition was significantly different from signal in each material by paired t-test, $p<0.05$. Letters denote significant differences by Tukey pairwise multiple comparisons $\mathrm{p}<0.05, \mathrm{n}=6$ from 2 independent experiments. AKT/PKB, AKR/J thymoma mouse cell line derived/protein kinase B. 
mediators were examined by PACE in vitro testing of a mesenchyme cell line.

\subsubsection{Scaffold architecture}

Hydroxyapatite scaffolds mimicking the natural inorganic composition of bone were fabricated with careful attention to the local organization of trabecular bone. An interconnected rod-like structure was prepared closely matching the histological arrangement of the lumbar spine. It was postulated that cells respond differently to structures found in vivo compared to traditional methods of maintaining cells on tissue culture treated plastic. The rationale for developing this structure as a model platform relates to its use for tissue-engineering. It is known that $\mathrm{CP}$ materials provide a local supply of calcium and phosphorous minerals [Gross 97] in addition to a large surface to volume area for cell adhesion. During scaffold manufacture, emphasis was placed on matching the local architecture of trabecular bone particularly the characteristics of the struts; trabecular number, separation and thickness [Feldkamp 89]. The unique curvatures of these surfaces provide substantial micro and nano-based surface characteristics that are not represented by 2-D surfaces. It is known that during bone formation, osteoblasts deposit new matrix in circular curvatures, namely the lamellar organization of haversian osteons and trabeculae. The presence of these curvatures may influence adhesion-based integrin distribution in turn altering sub-cellular signaling organization and biological response [Chen 97]. 


\subsubsection{PACE testing for cell-biomaterial constructs}

For statistical significance in biomaterial testing, a large number of samples are required which eliminates many techniques for signal-transduction analysis. Phosphospecific antibody cell-based ELISA (PACE) has previously been derived for investigations where large sample numbers prohibit comparative western blotting or time intensive kinase assays [Versteeg 00]. Additionally, traditional western blotting is hindered by fast signal saturation and non-linearity causing difficulty with samples where divergent response is anticipated. The enzymatic reaction in PACE testing was of a linear character permitting quantifiable comparisons when diverse signal ranges were tested. Application of this technique to biomaterials provided reproducible signals with low background noise. Selective inhibition at or upstream of the signal of interest allowed for significant signal reductions on every material tested with the exception of basal levels seen on tissue culture plastic with p 38 demonstrating the specificity of the response. The use of PACE was well-suited for high throughput biomaterial applications.

\subsubsection{Intracellular stress pathways in a physiological simulated environment}

Phospho-activation of $\mathrm{p} 38$, JNK but not ERK1/2 were increased when cultured on 3-D CP's compared to 2-D surfaces, particularly tissue culture treated plastic. This leads us to postulate that traditional cell culture may be drastically underestimating the stress signal responses found in large tissue constructs. While the cross-talk between up-stream members in the MAPK cascade prohibit identification in this study of which or if a single pathway mediates the 3-D stress response, it appears that both p38 and JNK are principal players while ERK1/2's role remains unclear. With the elevated levels of ERK1/2 
observed on all materials and its known involvement with integrin-mediated cell attachment and migration [Klemke 97], the data obtained from this study reinforces the idea that ERK1/2 is upregulated during the attachment phase [Chen 94, Schlaepfer 94, Zhu 95] and may not demonstrate material or architecture dependence except in relation to adhesion sites. Additional evidence has suggested that with respect to osteogenic cell types, ERK1/2 may have a more significant role during differentiation and mineralization [Simmons 03].

\subsubsection{Anti-apoptosis signaling}

Both ERK1/2 and AKT have been implicated in activation of cell survival pathways. As observed in this study, few differences were found between tested materials with respect to ERK1/2 activation. CP materials have not been shown to induce apoptosis [Sepulveda 00], and it was not anticipated to see substantial changes in ERK1/2 or AKT. Thus, it was of interest to note the similarities in activation between the stress-activated protein kinases and AKT. Previous cell signaling studies involving the upstream MEKKs in the MAPK family demonstrated that apoptosis regulation could not be predicted exclusively by the activation of ERK or JNK pathways [Bonvin 02]. The high signal and correlation of AKT with $\mathrm{p} 38$ and JNK in this case suggest its involvement as an early anti-apoptosis regulator when cells are confronted with high stress signaling in response to curvatures not normally experienced in vitro. As both HA and TCP materials do not induce cell death, the AKT signal could be considered a management pathway of elevated SAPK levels observed in 3-D cell culture. Future scaffolds designed to match the exact curvature of trabecular bone and additional time- 
based signaling analysis will help to isolate the mechanisms of bone-material interaction for regenerative orthopedics.

\subsection{Conclusion}

In summary, significant activation of stress mediators p38 and JNK was observed on 3-D CP scaffolds, whereas these signals were absent on 2-D CP surfaces.

Additionally, a significant up-regulation of AKT, an anti-apoptosis signal was also observed on 3-D CP surfaces. It was concluded from this study that osteoblast precursor cells cultured in 3-D CP scaffolds experience greater stress-signaling patterns when compared to 2-D CP surfaces. 


\section{Chapter 4. Ultrasound effect on osteoblast precursor cells in trabecular calcium phosphate scaffolds}

\subsection{Abstract}

This study investigated the in vitro effect of low intensity pulsed ultrasound (LIPUS) on human embryonic palatal mesenchyme cells (HEPM, CRL-1486, ATCC, Manassas, VA), an osteoblast precursor cell line, during early adhesion to calcium phosphate scaffolds. Hydroxyapatite (HA) and $\beta$-tricalcium phosphate (TCP) ceramic scaffolds were produced by a template coating method. Phospho-specific antibody cellbased ELISA (PACE) technique was utilized on stress activation proteins including; the extracellular signal-regulated kinase (ERK1/2), P38, c-Jun N-terminal kinase (JNK) and the anti-apoptosis mediator protein kinase B (PKB/AKT). Cell-based ELISAs were also performed on the membrane anchoring protein vinculin and $\alpha 6 \beta 4$ integrin. LIPUS stimulated activation of ERK 1/2, JNK, P38 and vinculin in traditional 2 dimension (2-D) culture. Calcium release from the scaffolds was partially involved in the activation of ERK 1/2 when cell response was compared between culture on 2-D surfaces and 3 dimension (3-D) HA and TCP scaffolds. Effects of calcium from scaffolds cultured in media could not account for the full activation of JNK, P38, AKT, vinculin and $\alpha 6 \beta 4$ integrin. LIPUS stimulation further increased ERK activity on TCP scaffolds corresponding with an increase in both vinculin and $\alpha 6 \beta 4$ integrin levels. It was concluded from this study that LIPUS treatment can significantly affect stress signaling mediators and adhesion proteins in osteoblast precursor cells during the early cellattachment phase to trabecular patterned scaffolds. 


\subsection{Introduction}

Therapeutic ultrasound has proven a valuable tool for the treatment of pathological and trauma fractures particularly with the development of low intensity pulsed ultrasound (LIPUS) [Duarte 83]. Ultrasound has been defined as a pressure or sound wave with the ability to transfer mechanical energy into biological tissues [Williams 83]. This acoustic energy has demonstrated improved fracture healing with in vivo studies [Azuma 01, Gebauer 02] and in controlled clinical trials [Heckman 94]. However, identification of the cellular signals stimulated by ultrasound still remains to be fully understood especially with respect to 3 dimensional (3-D) environments.

Bone cells react to mechanical forces by mechanotransduction of biological signals linking environmental forces with genetic regulation and cellular adaptation [Moalli 00]. At the cell surface, integrins mediate these events through tyrosine phosphorylation of signaling proteins [Ingber 03] forming focal adhesions. Inside the cell, these focal points recruit a variety of structural proteins such as vinculin connecting integrins with signaling pathways such as the mitogen-activated protein kinase (MAPK) cascade [Morino 95, Schlaepfer 98]. The MAPK pathway also has a role during the transition of mesenchyme stem cells into the osteogenic lineage [Jaiswal 00]. Within this family are three sub-pathways; the extracellular signal-regulated kinases (ERK1/2), c-Jun N-terminal kinases, (JNK), and P38 kinases [Widmann 99], the latter two termed the stress-activated protein kinases (SAPKs). Cell stress and survival signaling also involves a mediator termed $\mathrm{AKT} / \mathrm{PKB}$, protein kinase $\mathrm{B}$. AKT regulates an assorted set of cell functions including survival, glycogen synthesis, glucose transport [Hajduch 01] and can inhibit apoptosis [Cardone 98, Zimmerman 99]. 
Ultimately, investigations of cell signaling behavior have clinical application, and in the case of bone repair, regeneration is often assisted by scaffold grafts. Identification of signaling mechanisms can be profoundly affected by 3-D culture with surface area and shape influencing cell stress responses and differentiation [Appleford 07, Habibovic 05]. Ceramic scaffolds have provided an excellent platform for bone regeneration in recent studies [Arinzeh 05, Boyde 99, Dong 01, Gauthier 05, Kon 99, Mastrogiacoma 06, Uemura 03]. Scaffolds prepared from calcium phosphate (CP) ceramics permit a stable platform for cell adhesion, migration, and proliferation [Chang 00] with surface properties very similar to natural bone apatite. In addition to exhibiting negligible immunoreactivity, these materials induce direct binding to the cell-collagen matrix creating a strong mechanical interlock between bone and implant [Richard 98]. Scaffolds offer a reproducible stage for the identification of specific biological pathways as well as their use in regenerative medicine [Mangano 03, Zyman 98]. Careful attention to material and architectural properties permits investigation of cell signaling patterns in an environment analogous to natural tissue.

In the present study, the effect of LIPUS treatment on osteoblast precursor cell signaling and adhesion behavior was explored in 3-D culture on HA and TCP scaffolds. The identification of both environment and ultrasound induced changes in MAPK and AKT activation as well as the membrane associated proteins vinculin and $\alpha_{6} \beta_{4}$ integrin was performed using in vitro culture of human embryonic palatal mesenchyme cells (HEPM, CRL-1486, ATCC, Manassas, VA) on HA and TCP trabecular patterned scaffolds. 


\subsection{Materials and methods}

\subsubsection{Sample preparation}

Scaffolds were prepared from micro particle HA and TCP (TAL Materials, Ann Arbor, MI) as previously reported using a template coating technique [Appleford 07]. Briefly, polyurethane sponges (EN Murray, Denver, CO) were coated with HA or TCP distilled water-based slurry containing $1 \% \mathrm{v} / \mathrm{v}$ ammonium polyacrylate dispersant and $3 \% \mathrm{v} / \mathrm{v}$ N,N-dimethylformamide drying agent during initial mixing and overnight vacuum drying. 3\% high molecular weight polyvinyl alcohol and 1\% v/v carboxymethylcellulose binders were added to provide specific temperature burn out stages during sintering. Scaffolds were twice coated with CP slurry and heat-sintered to $1230^{\circ} \mathrm{C}$ for 3 hours. Purity of the composition was validated using X-ray diffraction analysis. Scaffold dimensions for all in vitro studies were diameter and length of $5 \mathrm{~mm}$. Samples were placed into non-binding 96 well plates (Corning, Acton, MA) and ethylene oxide gas sterilized before testing.

\subsubsection{Sample characterization}

Calcium phosphate scaffolds were observed by scanning electron microscopy.

Calcium release profiles were generated by time immersion into $250 \mu \mathrm{L}$ phosphate buffered saline (PBS) at $37{ }^{\circ} \mathrm{C}, 5 \% \mathrm{CO}_{2}$ by calcium reduction to a colored product. A $10 \mu \mathrm{l}$ volume of saline was removed and added to $240 \mathrm{uL}$ of calcium reagent based on the 2-cresolphthalein complexone method (Raichem Hemagen, Columbia, MD).

Determinations were obtained from a standard curve generated using a calcium standard 
with absorption measurements made at 550nm on a Beckman Coulter AD34C plate reader (Fullerton, CA). An initial release rate was identified by measuring calcium every 3 minutes up to 15 minutes with direct media replacement.

\subsubsection{HEPM cell culture}

Human embryonic palatal mesenchyme cells (HEPM, CRL-1486, ATCC, Manassas, VA), an osteoblast precursor cell line, were cultured in Dulbecco's modified eagle medium (DMEM, Invitrogen, Carlsbad, CA) supplemented with 7\% fetal bovine serum (FBS, Invitrogen) and 1\% antibiotic/antimycotic (PSA, $100 \mathrm{U} / \mathrm{mL}$ penicillin, 100 $\mu \mathrm{g} / \mathrm{mL}$ streptomycin, $0.25 \mu \mathrm{g} / \mathrm{mL}$ amphotericin B, MP Biomedicals, Solon, $\mathrm{OH}$ ) at $37^{\circ} \mathrm{C}$ with $5 \% \mathrm{CO}_{2}$. Cells were maintained in culture flasks with media changes every two days and passaged at confluence using trypsin (Invitrogen). Cell passages 10-12 were used in the course of this experiment. HEPM cells were counted using a coulter counter (Beckman Coulter Z2, Fullerton, CA), and 20,000 cells were seeded onto tissue culture treated plates or $\mathrm{CP}$ scaffolds. Calcium containing media extracts were prepared by incubating scaffolds in culture media for 6 hours with an identical volume to that used for cell studies. Media were removed from scaffolds $(n=6)$ and used to resuspend cells at the same start time used for direct cell-scaffold studies. Early attachment time was identified from a previously reported study with a time point of 6 hours identified where cells equally attached to HA and TCP materials with greater than 90\% cell binding [Appleford 07]. 


\subsubsection{Stimulation with ultrasound}

To stimulate cells on tissue culture plastic and scaffolds the Exogen low intensity pulsed ultrasound (LIPUS) system was utilized (Smith \& Nephew, Memphis, TN). This system is configured with six independent ultrasound transducers that each produce a 1.5Mhz ultrasound wave, $200-\mu$ s pulse modulated at $1 \mathrm{kHz}$ using an output intensity of $30 \mathrm{~mW} / \mathrm{cm}^{2}$. Ultrasound transducers were fitted on a plastic frame to stimulate specific regions of a 96 well plate where samples were located. Coupling gel was placed between the transducer and culture plates. Untreated controls were maintained in identical conditions to ultrasound stimulated plates. Following a 6 hour cell attachment time, ultrasound groups were stimulated for 20 minutes and given a 30 minute recovery time before test completion.

\subsubsection{Phospho-specific antibody cell-based ELISA (PACE)}

Cells were attached to all surfaces and scaffolds for 6 hours and 50 minutes followed by washing twice with ice-cold PBS. Fixation was performed with 4\% Carson's Millonig formaldehyde in PBS for 30 minutes at room temperature and endogenous peroxidase activity was quenched using $0.3 \% \mathrm{H}_{2} \mathrm{O}_{2}$ in $\mathrm{PBS}-0.1 \%$ Triton X100 (PBS-T) for 30 minutes. PACE testing was performed as previously reported [Versteeg 00]. Briefly, cells and scaffolds were washed three times with PBS-T, followed by blocking with $10 \%$ fetal calf serum (FCS, Invitrogen) in PBS-T for 1 hour. Primary rabbit antibodies against phospho-p44/42 (ERK1/2, Thr202/Tyr204), phosphoP38 (Thr180/Tyr182), phospho-SAPK/JNK (Thr183/Tyr185), and phospho-AKT (Ser 473, Cell Signaling Technology, Danvers, MA) were added in 5\% FCS-PBS-T and 
incubated overnight at $4^{\circ} \mathrm{C}$ with $20 \mathrm{rpm}$ rocking. Dilutions of primary antibodies were set at 1:1000 except for P38, at 1:500. As reported previously signal inhibitors for ERK1/2, P38, JNK, and AKT included PD98059 $(50 \mu \mathrm{M})$, SB203580 (50 $\mu \mathrm{M})$, SP600125 $(10 \mu \mathrm{M})$, Wortmannin $(2 \mu \mathrm{M})$, respectively, were used to check validity of signal generation and were added 30 minutes before test completion. Following primary antibody incubation, cells were washed three times with PBS-T for 5 minutes and incubated with secondary anti-rabbit IgG, HRP-linked antibody (horseradish peroxidase) with a 1:1000 dilution in 5\% FCS-PBS-T for 1 hour at room temperature with rocking. The cells and scaffolds were then washed three times with PBS-T and twice with PBS for five minutes. One-Step Ultra TMB substrate (Pierce Biotechnology, Rockford, IL) was added to the wells and color developed for 30 minutes at room temperature in the dark. The oxidation reaction was stopped and color changed and stabilized using an equal volume of $2 \mathrm{M} \mathrm{H}_{2} \mathrm{SO}_{4}$. Volumes of $100 \mu$ l of the colored product were transferred to new 96 well plates and absorbance measured at $450 \mathrm{~nm}$ with reference at $620 \mathrm{~nm}$ on a plate reader.

\subsubsection{Adhesion protein immuno-detection}

Similar to PACE testing, cells and scaffolds were prepared for immuno-detection of membrane proteins using mouse primary antibodies against vinculin (Sigma, St Louis, MO) and $\alpha_{6} \beta_{4}$ integrin (Chemicon Int, Inc., Temecula, CA). Primary antibodies were added in $5 \%$ FCS-PBS-T and incubated over night at $4{ }^{\circ} \mathrm{C}$ with $20 \mathrm{rpm}$ rocking. Dilutions of primary antibodies were set at 1:1000 for vinculin and $\alpha_{6} \beta_{4}$ integrin and were established from antibody titer-controls with signal to noise ratio of 10 using cells 
cultured on tissue culture treated plastic. Secondary anti-mouse IgG HRP linked antibody was used with the One-Step Ultra TMB substrate to generate color for detection.

\subsubsection{Statistical analysis}

Statistical calculations were performed with SigmaStat software (Systat, Point Richmond, CA). Validity of signal inhibition with each material, and ultrasound stimulations on culture plastic were compared by paired t-test. Significance between media and scaffold groups were analyzed by two-way ANOVA using material and condition as factors with Tukey multiple comparison procedure. Significance levels were set at $\mathrm{p}<0.05$.

\subsection{Results}

\subsubsection{Material characterization}

Calcium phosphate surfaces and scaffolds imaged by SEM are shown in Figure 4.1(a-d) demonstrating the micro structure of HA (Figure 4.1a) and TCP (Figure 4.1b) surfaces and the overall architecture and rounded triangular strut configuration of the scaffolds as shown in Figure 4.1(c, d).

No significant morphological difference was identified between HA and TCP materials in terms of bulk design, however, micro and nano scale differences do exist between these materials as previously reported [Appleford 07], with HA crystals significantly smaller than TCP creating a greater number of grain boundaries available for calcium release. Additionally, TCP surfaces also contained small micro-pores. 

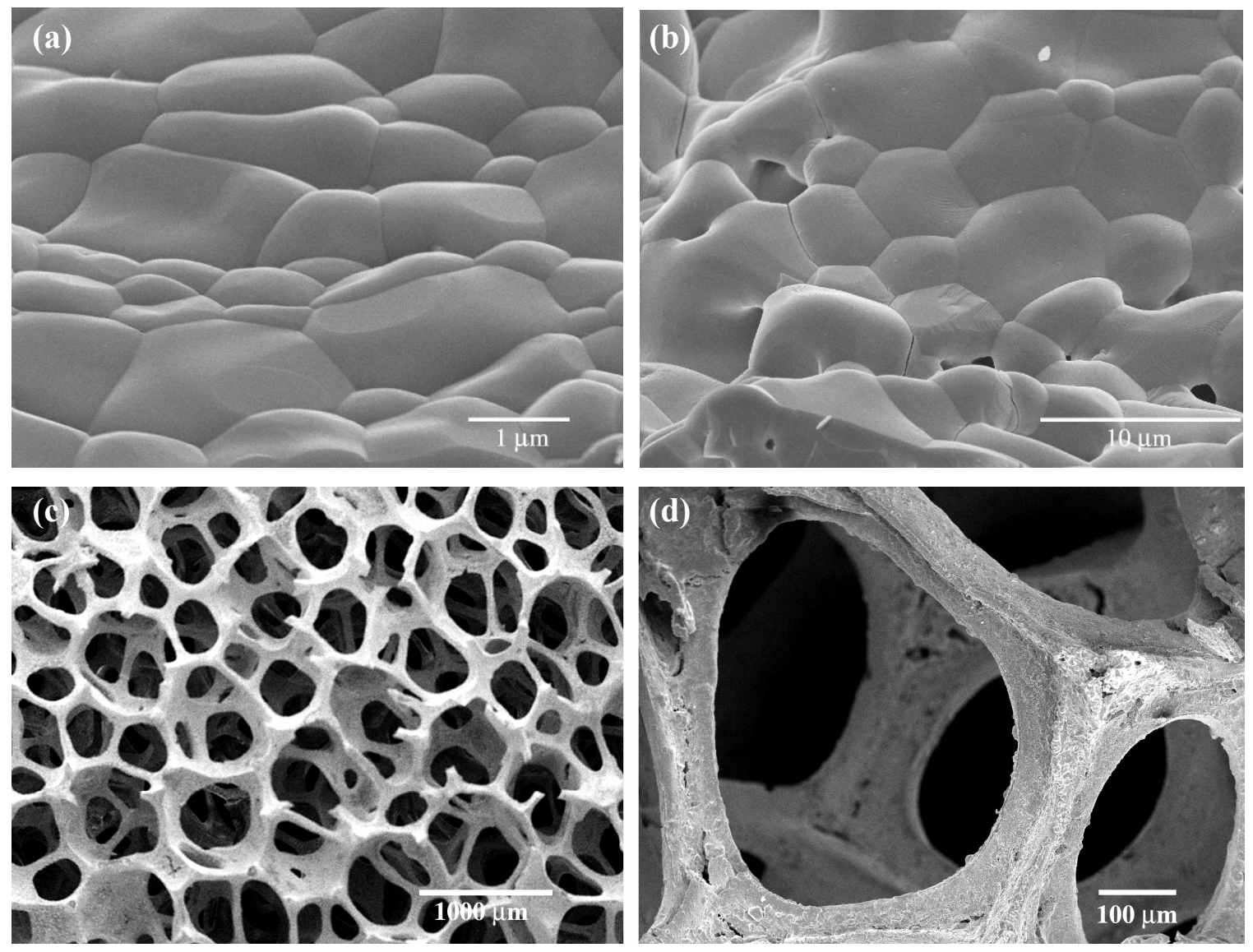

Figure 4.1 SEM photographs of (a) HA and (b) TCP scaffold surfaces showing the smaller crystal size of HA with more grain boundaries and (c) macro calcium phosphate scaffolds representative of both HA and TCP bulk structure and (d) rounded triangular strut design of the scaffold. 
Overall scaffold arrangement was designed with complete channel interconnections throughout the scaffold design.

Calcium release behavior from HA and TCP scaffolds was characterized over 2 days with attention to the initial release rate from the scaffolds. As shown in Figure 4.2, HA scaffolds initially released a greater amount of calcium into PBS at physiological conditions. The initial release rates were 1.22 and $0.64 \mu \mathrm{g}$ calcium per mg scaffold per mL PBS per hour, respectively. After two days the dissolved calcium reached maximum values in both HA and TCP materials corresponding to 1.94 and $0.66 \mathrm{mM}$, respectively.

\subsubsection{Ultrasound stimulations of cellular protein markers in 2-D}

Cells cultured on tissue culture treated plastic after 6 hours were exposed to ultrasound for 20 minutes and given a 30 minute recovery time. Control timeexperiments identified 30 minutes as a minimum time necessary for activation of intracellular proteins studied in this experiment. As shown in Figure 4.3, significant increases were identified in ERK 1/2, JNK, P38, and vinculin proteins $(\mathrm{p}<0.05)$, however, the activations of the stress activated protein kinases; JNK and P38 were extremely low. No differences were found for $\mathrm{pAKT}$ and $\alpha_{6} \beta_{4}$ integrin.

\subsubsection{Activation of cell protein markers with scaffold extract media, cell-scaffolds and LIPUS}

The activation of the stress signal mediators ERK 1/2, P38, JNK, and AKT were evaluated in response to cells exposed to scaffold media extracts, HA and TCP scaffolds 


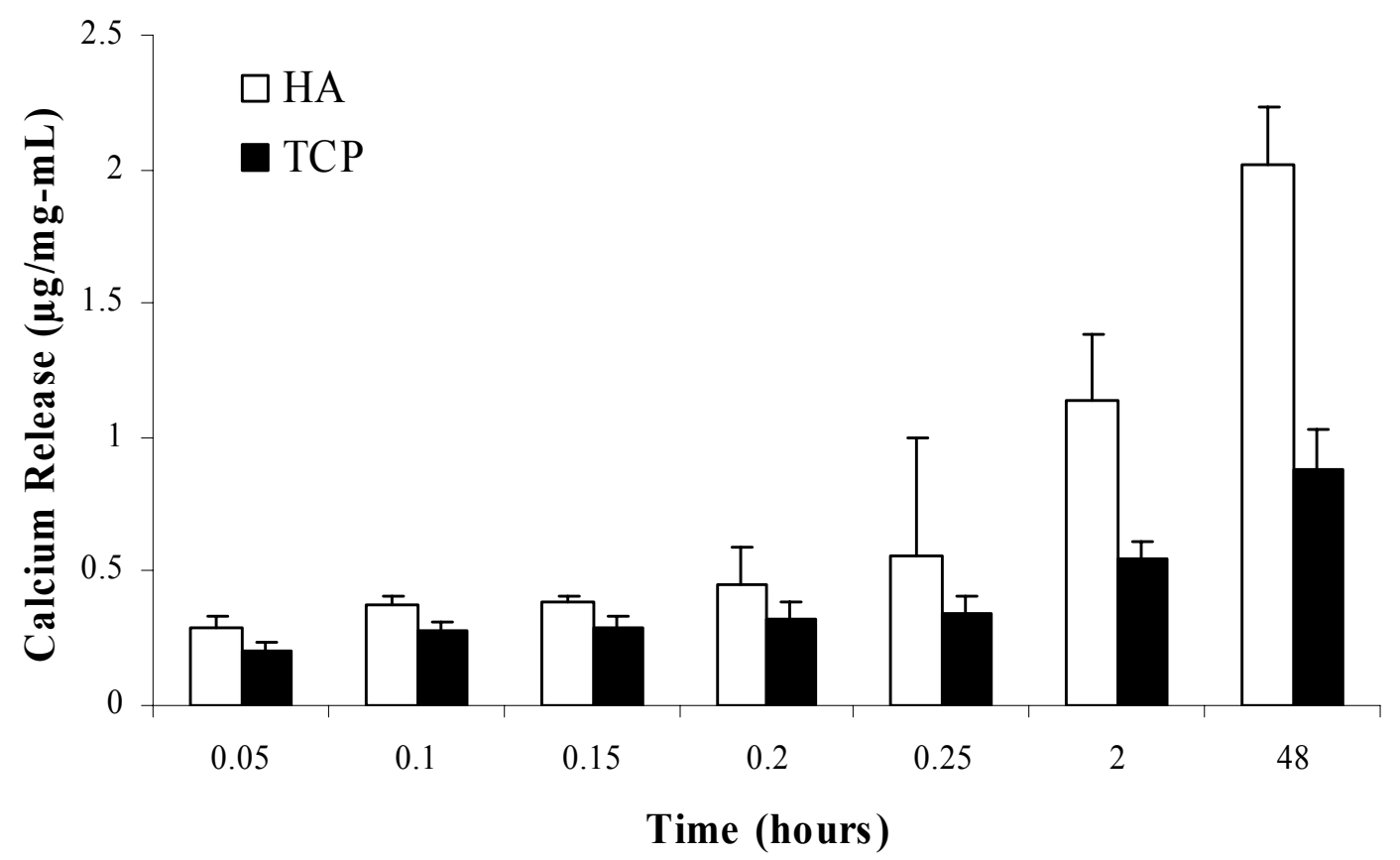

Figure 4.2 Calcium release behavior from HA and TCP scaffolds. Calcium release reported at selected times after immersion in $\mathrm{PBS}$ at $37^{\circ} \mathrm{C}, 5 \% \mathrm{CO} 2$, reported as $\mu \mathrm{g}$ calcium / (mg scaffold dry weight, $\mathrm{mL}$ PBS). Data represents average values + S.D., $\mathrm{n}=4$. 

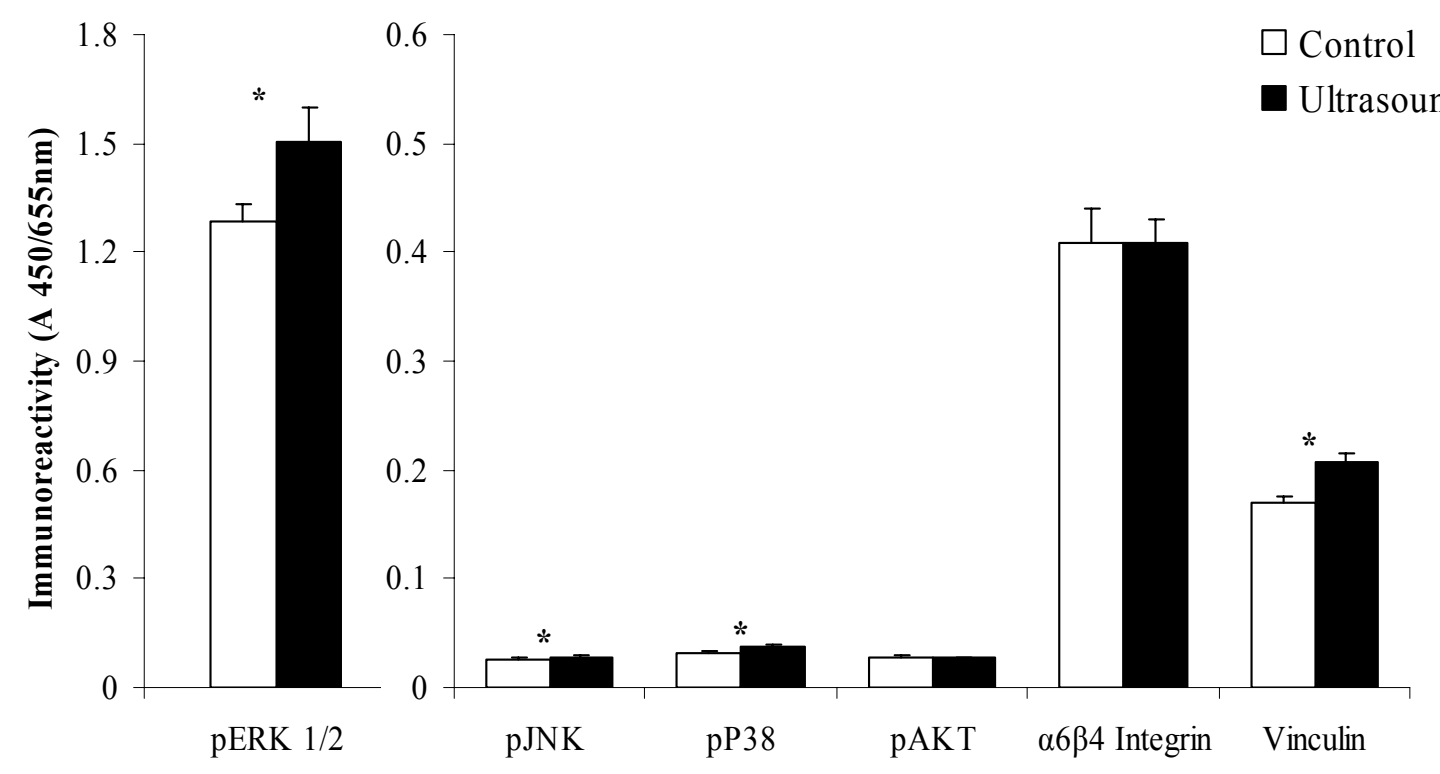

Figure 4.3 Ultrasound induced selective increase for cellular protein markers.

Immunoreactivity of six proteins measured with HEPM cells cultured on tissue culture plastic after 6 hours 50 minutes (control, white bars) or stimulated with ultrasound for 20 minutes with 30 minute recovery prior to test completion (black bars). The data shown represent average values $(n=6)+$ S.D., $* \mathrm{p}<0.05$ by paired $\mathrm{t}$-test. 
directly and with applied LIPUS as shown in Figure 4.4. Media extracts were prepared from culturing control scaffolds in media for the same time period as remaining groups. This provided a control condition where the variability and effect of soluble calcium release from scaffolds could be identified.

Phospho-activation of ERK 1/2 demonstrated equal activation between HA scaffold extracts and cell-scaffold groups. Application of LIPUS significantly increased ERK $1 / 2$ activation only on the TCP scaffold. No differences were identified within the HA group (Figure 4.4a) and both TCP scaffolds experienced significantly greater ERK activity compared to HA $(\mathrm{p}<0.05)$. Phospho-activation of the JNK stress mediator is shown in Figure 4.4b. In contrast to the ERK activity, JNK was minimal from media supplementation demonstrating differences in both scaffold groups. One between group difference was identified between HA and TCP scaffolds not exposed to ultrasound, with TCP greater than HA $(\mathrm{p}<0.05)$. The same trends were observed with phospho-activation of the P38 mediator with the exception that TCP was significantly less than the corresponding HA scaffold value $(\mathrm{p}<0.05)$ as shown in Figure 4.4c. The final phosphoprotein selected for study, AKT, also a multifunctional anti-apoptosis signal, demonstrated significant increases in response to ultrasound in HA but not TCP. Similar to ERK and JNK activation, AKT was higher on TCP compared to HA scaffolds $(\mathrm{p}<0.05)$ as shown in Figure $4.4 \mathrm{~d}$.

\subsubsection{Stimulation of adhesion proteins}

The stimulation of the cytoskeleton attachment and adhesion proteins vinculin and $\alpha_{6} \beta_{4}$ integrin were evaluated with cells exposed to scaffold media extracts, HA and TCP 

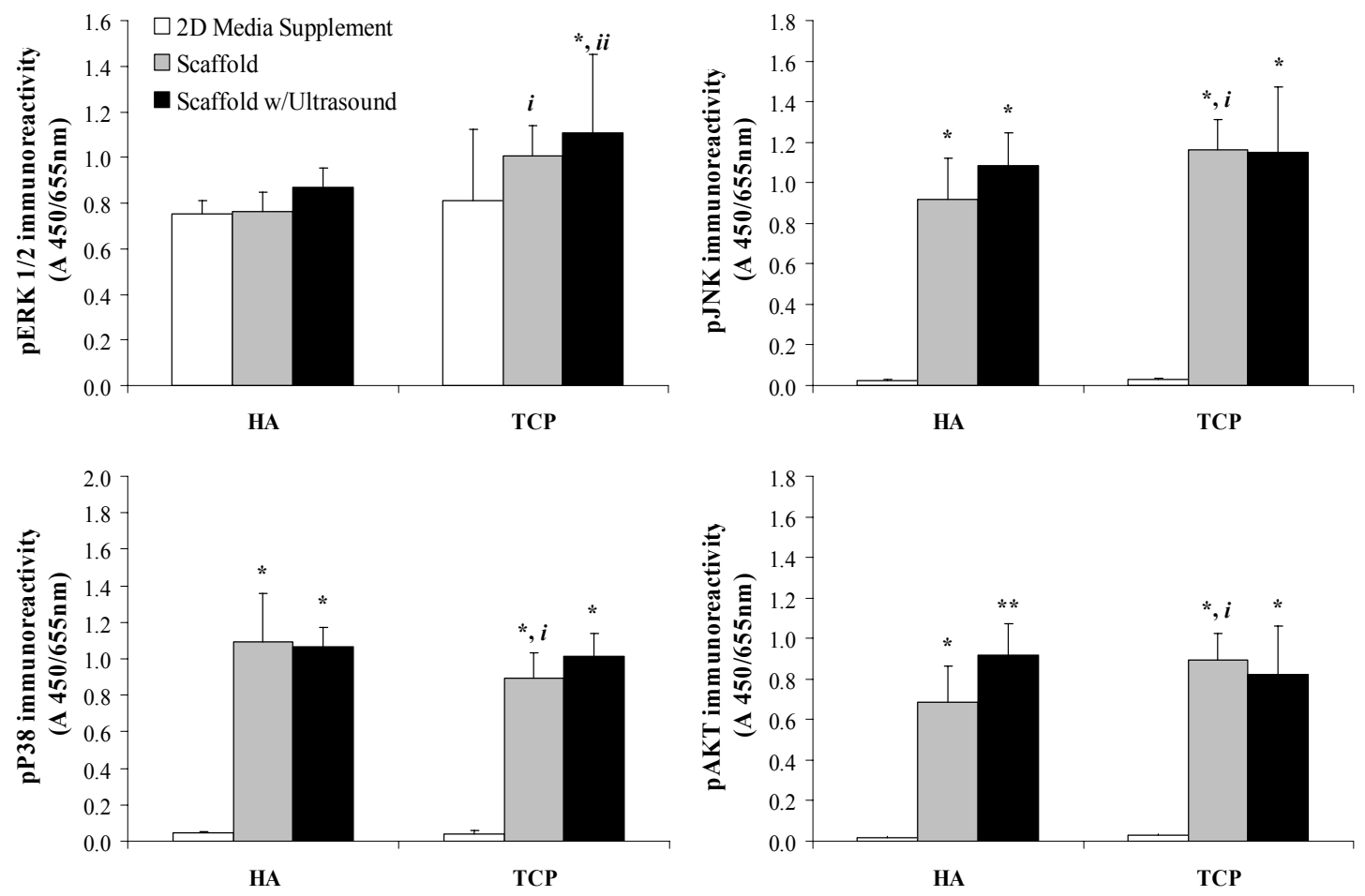

Figure 4.4 Scaffold and ultrasound stimulations of intra-cellular stress signal markers. Phospho-immunoreactivity of ERK1/2, JNK, P38 and AKT for HEPM cells cultured on 2D tissue culture surfaces exposed to calcium containing media from incubated control scaffolds (control white bars), cells cultured directly on scaffolds (grey bars) and cells cultured on scaffolds stimulated with ultrasound for 20 minutes with 30 minute recovery prior to test completion (black bars). The data shown represent average values, $(\mathrm{n}=6)+$ S.D., * denotes differences from control within material groups (HA or TCP), i denotes differences between material groups per condition, $p<0.05$ by two factor ANOVA with Tukey pairwise multiple comparisons. 
scaffolds directly and with applied LIPUS as shown in Figure 4.5. Increases in vinculin were identified for cells cultured on scaffolds compared to 2-D surfaces in both HA and TCP. Ultrasound significantly increased vinculin levels in TCP but not HA scaffolds $(\mathrm{p}<0.05)$ as shown in Figure 4.5a. An identical trend was observed with $\alpha_{6} \beta_{4}$ integrin levels with high levels in scaffolds with and without ultrasound only significantly affecting the TCP group shown in Figure 4.5b.

\subsection{Discussion}

The clinical application of ultrasound to damaged bone has found application to accelerate healing time and prevent loss of bone during the healing period [Kristiansen 97]. As these systems are increasingly used clinically, knowledge of the biological effects of ultrasound is required to identify safe guidelines for use and to help develop these systems for effective mechanisms of action. In this study, the importance of material and 3-D design in conjunction with LIPUS was explored on the regulation of stress, apoptosis and adhesion mediators with an osteoblast precursor cell line.

\subsubsection{Scaffold design and calcium release}

The structural composition of natural bone consists of an apatite mineral with strut or rod-like organization in trabecular bone. Calcium phosphate scaffolds fabricated with similar material and structural characteristics make cell behavior studies more reflective of an in vivo environment. The scaffold architecture employed in this study was carefully matched to the histological parameters of the human lumbar spine. This arrangement of surface curvature provides characteristics not represented in 2-D that may 

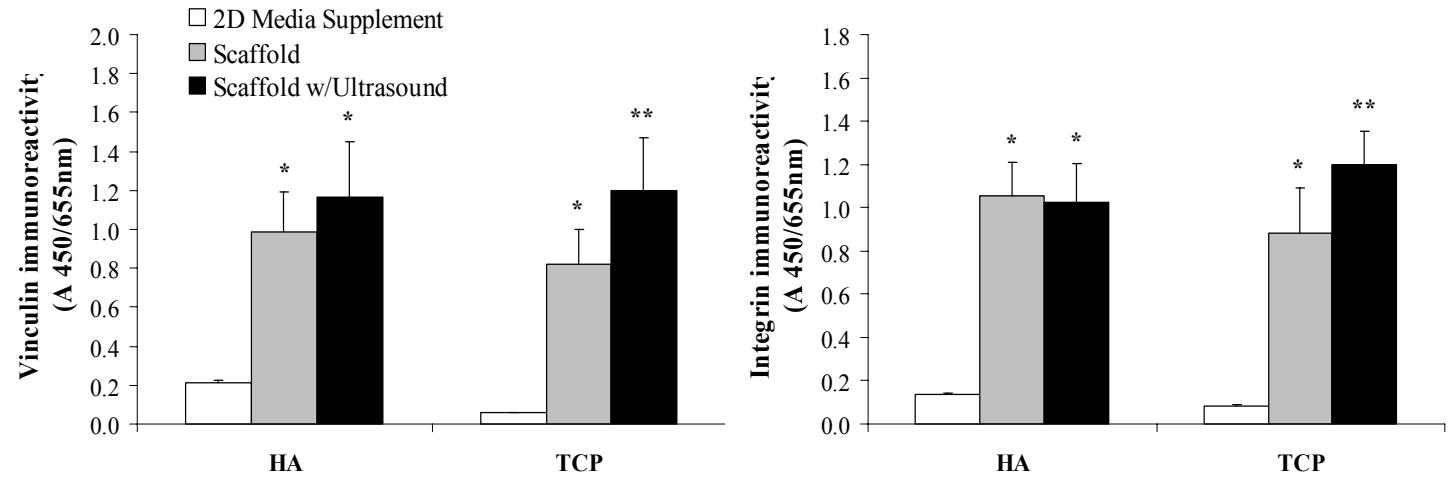

Figure 4.5 Scaffold and ultrasound stimulations of cell attachment and adhesion signal markers. Immunoreactivity of vinculin and $\alpha 6 \beta 4$ integrin proteins for HEPM cells cultured on 2D tissue culture surfaces exposed to calcium containing media from incubated control scaffolds (control, white bars), cells cultured directly on scaffolds (grey bars) and cells cultured on scaffolds stimulated with ultrasound for 20 minutes with 30 minute recovery prior to test completion (black bars). The data shown represent average values, $(n=6)+$ S.D., * denotes differences from control within material groups (HA or TCP), ** denotes differences between treatment groups by two factor ANOVA with Tukey pairwise multiple comparisons. 
alter signaling patterns reported using traditional cell culture. Specifically, 3-D structure may influence integrin adhesion and subcellular protein distribution thus changing biological response [Chen 97]. Calcium release profiles demonstrated greater levels in HA compared to TCP scaffolds, a result contrary to the known high dissolution behavior of TCP, however, equal sintering temperatures were used in this study resulting in small tightly bound HA crystals as shown in Figure 4.1a. Crystal size of TCP was approximately 10X larger as shown in Figure 4.1b, resulting in fewer grain boundaries and lower calcium release over the short time period of this study. Calcium release has been implicated in the activation of many biological pathways including the MAPK cascade [Katz 06] and in the course of this study did not exceed $2 \mathrm{mM}$, well below the cytotoxic safe limit [Maeno 05]. The preparation of media extracts from control scaffolds also allowed for the identification of calcium effects on cell signaling and adhesion behavior. An additional characteristic not normalized in this study was the effect of micropores in TCP materials creating a different surface profile compared to HA.

\subsubsection{Ultrasound stimulation of HEPM cells in 2-D}

Low intensity pulsed ultrasound (LIPUS) using a commercially available product already applied in a clinical setting supplied the acoustic stimulations of $30 \mathrm{~mW} / \mathrm{cm}^{2}$ in this study. Application of ultrasound to HEPM cells in 2-D traditional culture stimulated the activation of ERK 1/2, JNK, P38 and production of the cell membrane cytoskeleton protein vinculin over control non-stimulated HEPM cells. These findings, with respect to ERK activity, match recently reported observations of a Gai protein-ERK-Runx2- 
osteocalcin pathway involved in osteogenic transition behavior [Chen 03]. While the SAPK's; JNK and P38 demonstrated low activity in 2-D, ultrasound was able to significantly increase these values demonstrating that other MAPK members may be involved in this signal transduction. While no significant change was identified with $\alpha 6 \beta 4$ integrin activity in response to ultrasound, the membrane cytoskeleton protein vinculin was increased. A previous reported study identified mechanosensitive molecules including integrin activation occurring with physical stimulation of the membrane [Lee 00]. Activation of these proteins demonstrates that multiple mechanosensitve pathways can be engaged during membrane stimulation.

\subsubsection{Scaffold and ultrasound stimulation of HEPM cells}

HEPM cells were cultured in 2-D with calcium media extracts prepared from scaffolds to serve as a calcium control for the variable release behavior of HA and TCP scaffolds. Signaling from cells exposed to extracts demonstrated a substantial level of ERK activity independent of HA scaffold configuration or ultrasound. This effect was only identified for ERK and was completely absent on the other MAPK members; JNK, P38 and the cell survival signal AKT. In TCP scaffolds, ultrasound significantly increased the activation of ERK over media control. In all other measured signals, calcium media extracts with cells in 2-D showed minimal activation with both scaffold groups in HA and TCP significantly greater than controls. In addition to the ERK activation on TCP scaffolds, ultrasound stimulated an increase in pAKT on HA scaffolds and both vinculin and $\alpha 6 \beta 4$ integrin expression on TCP scaffolds. 
It was of particular interest to note that of the MAPK proteins evaluated in this study only ERK 1/2 was significantly increased in response to ultrasound and only on TCP scaffolds. This result matched the increases in vinculin and $\alpha 6 \beta 4$ integrin, once again only on TCP scaffolds. This result appears in conflict with the lower calcium release from the TCP materials at this early time period, however as previously reported, TCP surfaces at the micro and nano scale have small micro-pores that may supply locally high calcium concentrations especially during ultrasound that are not detectable by bulk media testing in addition to their surface roughness and morphological differences. As LIPUS treatment has been shown to redistribute actin stress fibers and focal adhesions [Zhou 04], the described results could be masked by the specific characteristics of TCP scaffolds and the selection of adhesion-phase timing chosen in this study. Direct visualization of calcium activity through the cell membrane in addition to matching the crystalline features of these materials may provide greater insight to identify the contribution of local calcium influx during LIPUS treatments.

\subsection{Conclusion}

Low intensity pulsed ultrasound stimulated phospho-activation of the MAPK proteins ERK 1/2, JNK and P38 in addition to the membrane anchoring protein vinculin. Calcium release from the scaffolds was partially involved in the activation of ERK 1/2 when cell response was compared between culture on 2-D surfaces and 3-D HA and TCP scaffolds. Effects of calcium extracted media from scaffolds alone were not responsible for activation of the stress activated protein kinases; JNK and P38. LIPUS stimulation further increased ERK activity on TCP scaffolds corresponding with an increase in both 
vinculin and $\alpha 6 \beta 4$ integrin levels. It was concluded from this study that LIPUS treatment can significantly affect stress signaling mediators and adhesion proteins in osteoblast precursor cells during the early cell-attachment phase to trabecular patterned scaffolds. 


\section{Chapter 5. Flow perfusion of osteoblast precursor cells in trabecular nano-coated hydroxyapatite scaffolds}

\section{$5.1 \quad$ Abstract}

Fluid perfusion represents a mechanical stimulation capable of inducing the differentiation of bone precursor cells. This study investigated the in vitro effect of fluid perfusion on human embryonic palatal mesenchyme cells (HEPM, CRL-1486, ATCC, Manassas, VA), an osteoblast precursor cell line, in trabecular hydroxyapatite (HA) scaffolds over 21 days. Micro hydroxyapatite (M-HA) and sol-gel deposited nano HA (N-HA) scaffolds were fabricated using a template coating method. Calcium release and HEPM cell response including attachment, viability and bone differentiation markers were examined on scaffolds exposed to static or perfused conditions at $1.0 \mathrm{ml} / \mathrm{min}$. NHA scaffolds released greater quantities of calcium during the first 24 hours and stabilized with no difference from M-HA scaffolds over 30 days. Early cell attachment favored N-HA scaffolds up to 4 hours and equalized at 95\% binding with M-HA by 6 hours. Perfusion cell culture significantly increased the bone differentiation markers osteocalcin and osteopontin demonstrating the inductive potential of fluid perfusion. In contrast to attachment rates, M-HA osteocalcin levels peaked earlier than N-HA with no difference in osteopontin values. It was concluded from this study that perfusion serves a critical role in the differentiation of mesenchyme cells to an osteoblast phenotype in scaffold-based tissue engineering and while nano deposited coatings can be advantageous for early cell attachment they may delay the onset of differentiation. 


\section{$5.2 \quad$ Introduction}

Nutrient transport for in vitro tissue engineering has traditionally relied upon the limited transfer mechanism of diffusion. With studies performed in two dimension (2-D) cell culture or limited three dimension (3-D) structures, this mechanism is sufficient to supply the metabolic needs of cells. However, when large 3-D volumes of functional tissue are engineered in the laboratory, diffusion becomes a limiting factor requiring the use of dynamic culture systems. This is particularly relevant when uniform cell growth and performance are required to prevent regions of necrosis [Holy 00, Ishaug 97]. Perfusion based tissue engineering represents a strategy for developing and maintaining large volumes of tissue with improved nutrient conditions for enhanced cell viability, rates of proliferation and protein production [Dunkelman 94, Glowacki 98]. In addition to the improvements in nutrient transport, fluid perfusion stimulates cells mechanically by the application of fluid shear stress and strains applied to the cytoskeleton often assisting bone cell response including differentiation mechanisms [Cartmell 03, Goldstein 01, Holtorf 05].

Identification of cell behavior including the local signaling behavior responsible for long-term cell changes can significantly change in response to the environmental conditions in 3-D culture differentiation [Appleford 07, Habibovic 05]. The importance, not only of fluid perfusion, but of material choice and local architecture has driven the improvement of scaffolds that mimic natural bone. Ceramic scaffold designs continually prove their excellent capacity for bone regeneration in recent studies [Arinzeh 05, Boyde 99, Dong 01, Gauthier 05, Kon 99, Mastrogiacoma 06, Uemura 03]. Hydroxyapatite materials formed into scaffolds provide a secure platform for cell adhesion, migration, 
and proliferation [Chang 00] as this material shows close similarity with the natural bone mineral apatite. Bone cells are able to strongly bind calcium phosphate surfaces forming a strong cell-material interlock [Richard 98]. Scaffolds also offer a reproducible stage for the identification of specific biological pathways as well as their use in regenerative medicine [Mangano 03, Zyman 98]. Additionally, recent research on HA has shown that nano-based surfaces can offer improved characteristics for bone formation [Arts 06].

In the following study, interconnected HA scaffolds were evaluated in response to media perfusion with two surface characteristics; micro and nano crystal surface features. Using human embryonic palatal mesenchyme cells (HEPM, CRL-1486, ATCC, Manassas, VA) an osteoblast precursor cell line, interconnected trabecular scaffolds were investigated as platforms for cell attachment, viability and long term differentiation response with media perfusion over 21 days.

\subsection{Materials and methods}

\subsubsection{Sample preparation}

Scaffolds were prepared from micro particle HA (TAL Materials, Ann Arbor, MI) as previously reported using a template coating technique [Appleford 07]. Briefly, polyurethane sponges (EN Murray, Denver, CO) were coated with HA or TCP distilled water-based slurry containing $1 \% \mathrm{v} / \mathrm{v}$ ammonium polyacrylate dispersant and $3 \% \mathrm{v} / \mathrm{v}$ $\mathrm{N}, \mathrm{N}$-dimethylformamide drying agent during mixing and were vacuum dried overnight. Polymer binders; 3\% high molecular weight polyvinyl alcohol and 1\% v/v carboxymethylcellulose, were included to provide precise temperature burn out stages 
during sintering. Scaffolds were twice coated with CP slurry with heat-sintering to $1230^{\circ} \mathrm{C}$ for 3 hours. A sol-gel deposited coating of nano-size HA was prepared from calcium nitrate in methanol using a previously reported process [You 01]. A stoichiometric $\mathrm{Ca} / \mathrm{P}$ ratio of 1.67 was obtained and solution aged for 7 days before immersion coating onto scaffolds and sintered to $600^{\circ} \mathrm{C}$ for 1 hour. Composition purity was validated using X-ray diffraction analysis (D8 Advance, Bruker Axs Inc., Madison, WI). Scaffold dimensions for all in vitro studies were diameter and length of $8 \mathrm{~mm}$. Samples were placed into non-binding 24 well plates (Corning, Acton, MA) and ethylene oxide gas sterilized before testing.

\subsubsection{Sample characterization}

HA scaffolds were observed by scanning electron microscopy. Calcium release behavior was evaluated by immersing scaffolds into $1 \mathrm{~mL}$ phosphate buffered saline (PBS) at $37^{\circ} \mathrm{C}, 5 \% \mathrm{CO}_{2}$. At early time points within $24 \mathrm{~h}, 20 \mu \mathrm{L}$ of media was extracted and combined with $180 \mu \mathrm{L}$ of calcium reagent based on the 2-cresolphthalein complexone method (Raichem Hemagen, Columbia, MD). Calcium levels were quantified from a standard curve generated using a calcium standard with absorption measurements made at $550 \mathrm{~nm}$ on a Beckman Coulter AD34C plate reader (Fullerton, CA). After 24 hours, complete media was replaced every two days corresponding with the next time measurement up to 30 days. Cumulative release curves were reported as $\mu \mathrm{g}$ calcium released per mg original scaffold dry weight per mL PBS. 


\subsubsection{HEPM cell culture}

Human embryonic palatal mesenchyme cells (HEPM, CRL-1486, ATCC, Manassas, VA), an osteoblast precursor cell line, were cultured in Dulbecco's modified eagle medium (DMEM, Invitrogen, Carlsbad, CA) supplemented with 7\% fetal bovine serum (FBS, Invitrogen) and 1\% antibiotic/antimycotic (PSA, $100 \mathrm{U} / \mathrm{mL}$ penicillin, 100 $\mu \mathrm{g} / \mathrm{mL}$ streptomycin, $0.25 \mu \mathrm{g} / \mathrm{mL}$ amphotericin B, MP Biomedicals, Solon, $\mathrm{OH}$ ) at $37^{\circ} \mathrm{C}$ with $5 \% \mathrm{CO}_{2}$. Cells were maintained in culture flasks with media changes every two days and passaged at confluence using trypsin (Invitrogen). HEPM cells were predifferentiated for 6 days to an early osteoblast phenotype using $10 \mathrm{mM} \beta$ glycerophosphate, $50 \mathrm{ug} / \mathrm{mL}$ L-ascorbic Acid, and $10 \mathrm{nM}$ dexamethasone (Sigma, $\mathrm{St}$ Louis, MO). HEPM cells were counted using a coulter counter (Beckman Coulter Z2, Fullerton, CA), and were seeded onto 4 samples per time-point per group with 100,000 cells applied onto each scaffold.

\subsubsection{Cell adhesion and MTT viability}

Cell attachment performance to M-HA and N-HA scaffolds was quantified in a short time study of 1, 2, 4, and $6 \mathrm{~h}$. Media suspensions along with two PBS washes were collected from scaffolds at select time points and counted for cells remaining in suspension. A percent cell attachment was reported as (cells seeded - unattached cells) / cells seeded $* 100 \%$. Attachment values were also used to identify a time point where cell number was not significantly different between M-HA and N-HA scaffolds during the initial perfusion setup.

Early cell viability in the scaffolds was determined by MTT analysis. After $2 \mathrm{~d}$ of 
cell culture, media was removed and replaced with DMEM without phenol red. The tetrazolium compound MTT (3-[4, 5-dimethylthiazol-2-yl]-2, 5-diphenyltetrazolium bromide) was added to the wells and manufactures instructions were followed with appropriate scaling for sample dimensions in 24 well plates (Tacs, Trevigen, Gaithersburg, MD). MTT was reduced by metabolically active cells to insoluble purple formazan dye crystals that were solubilized in a detergent and transferred to a new plate for absorbance measurements at $550 \mathrm{~nm}$ with reference at $655 \mathrm{~nm}$. A positive and negative control was performed using HEPM cells plated to tissue culture treated plastic (+ control) or cells supplemented with $0.05 \%$ Triton X-100 (- control).

\subsubsection{Perfusion system}

A flow perfusion culture system was manufactured from acrylic blocks consisting of 6 flow chambers per block. Scaffolds were press fit into a Teflon cylinder and inserted into the flow chamber with an o-ring compression seal as shown in Figure 5.1.

Acrylic chambers were monitored visually for any leaks creating a media pathway not through the scaffold. Each chamber was connected in a continuous circuit with silicon tubing to a media reservoir consisting of a 6 well ultra-low binding plates and a 24 channel, 8 roller peristaltic pump (Ismatec, Glattbrugg, Switzerland). After 2 days of static culture each chamber was connected to the individual channels of the peristaltic pump and ramped to 0.1 and $0.5 \mathrm{ml} / \mathrm{min}$ for 12 hours each up to a final perfusion rate of $1.0 \mathrm{ml} / \mathrm{min}$. Connection to six well plates allowed media changes twice weekly with final perfusion rate performed for $1,7,14$, and 21 days. 


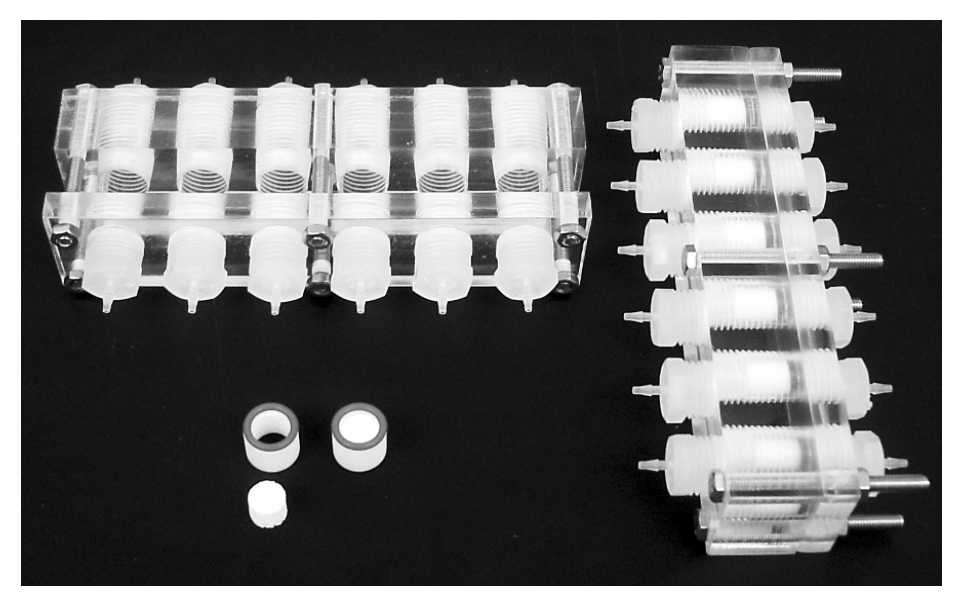

Figure 5.1 Acrylic perfusion blocks with HA scaffolds. Six HA scaffolds can be inserted into individual Teflon tubes and press fit into each chamber with compression Teflon oring and connected with tubing to a peristaltic pump. Perfusion blocks are maintained in an incubator at $37^{\circ} \mathrm{C}, 5 \% \mathrm{CO} 2$.

\subsubsection{Protein assay}

Cellular protein content was quantified using a BCA Protein Assay (Pierce, Rockford, IL) according to the manufactures protocol. Scaffolds were removed from the testing chamber and twice washed with PBS before immersion into a Triton X-100 (0.2\% in PBS) wash buffer. Three freeze-thaw cycles were performed in rapid succession to $-80{ }^{\circ} \mathrm{C}$. Samples were added to working reagent and incubated at $37^{\circ} \mathrm{C}$ in 96 well plates. The absorbance for the extracted cell suspension was read at $550 \mathrm{~nm}$, correlated to a standard curve, and normalized to nanograms of dsDNA using a PicoGreen dsDNA Kit (Molecular Probes, Eugene, OR).

\subsubsection{Osteocalcin and osteopontin assays}

At selected time points the secreted proteins osteocalcin and osteopontin were measured in culture media using commercially available sandwich immunoassays. 
Osteocalcin (OC) was measured using a MID-TACT Human Osteocalcin EIA Kit (Biomedical Technologies Inc., Stoughton, MA). The MID-TACT immunoassay measures both the intact human osteocalcin and the major fragment by employing two monoclonal antibodies; one immobilized to the plate and the second biotinylated. Osteopontin (OP) was measured using a TiterZyme Human Osteopontin EIA kit (Assay Designs, Ann Arbor, MI) by a similar antibody configuration. The OC and OP concentrations in the samples were correlated to a standard curve, and normalized to nanograms of dsDNA.

\subsubsection{Statistical analysis}

Statistical calculations were performed with SigmaStat software (Systat, Point Richmond, CA). Results are shown as means + S.D. Significance between materials was analyzed by paired t-test while significance between scaffold groups in static and perfused culture was analyzed by one-way ANOVA with Tukey multiple comparison procedure. Significance levels were set at $\mathrm{p}<0.05$.

\section{$5.4 \quad$ Results}

\subsubsection{Material characterization}

Trabecular HA scaffolds were imaged by SEM and are shown in Figure 5.2(a, b) illustrating the geometry and rounded triangular strut design of the scaffolds. A sol-gel HA coating of nano HA, as shown in Figure 5.2b, formed a thin layer of precipitated HA crystals over the bulk scaffold. The precipitation coating modified the surface character 

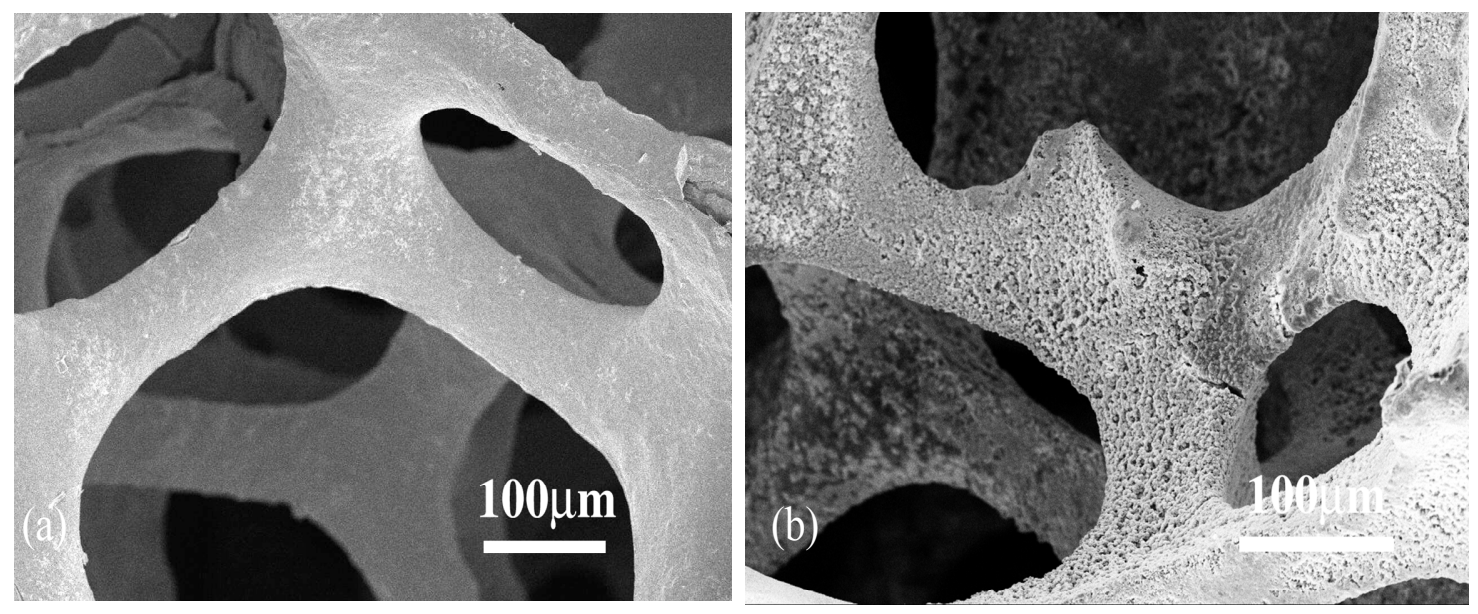

Figure 5.2 SEM pictures of (a) micro surface HA (mHA) and (b) nano coated surface HA (nHA) scaffolds. Nano coating increases the observed surface roughness without altering the fully interconnected open channels of the scaffold design with rounded edge triangular strut morphology.

by increasing the observed surface roughness of the scaffold with nano-texture.

The open channel configuration was arranged with isotropic geometry. Scaffolds averaged a porosity of $67.5 \%$ with strut internal porosity not included in this measurement as reported previously [Appleford 07]. Cumulative calcium release behavior from M-HA and N-HA scaffolds was quantified over 30 days with observed differences during the initial 24 hour release period as shown in Figure 5.3. N-HA scaffolds released significantly more calcium over the first 24 hours (Figure 5.3a) but matched M-HA calcium release rate over the following 30 days shown in Figure $6.3 \mathrm{~b}$.

\subsubsection{Cell attachment and viability}

HEPM cells attached to both M-HA and N-HA scaffolds at a fast rate with greater than $75 \%$ attachment within $1 \mathrm{~h}$ and $95 \%$ binding after $6 \mathrm{~h}$. Early attachment favored NHA scaffolds with significant differences between material types after 1, 2 and $4 \mathrm{~h}$ as 

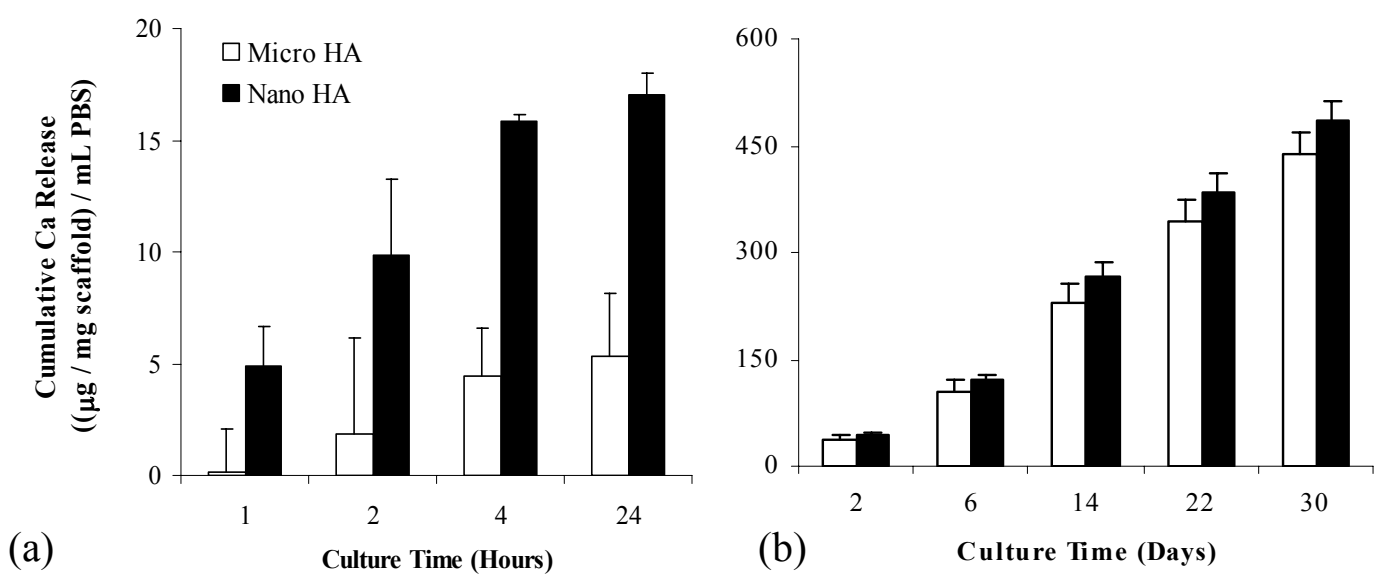

Figure 5.3 Cumulative calcium release behavior from micro and nano HA scaffolds demonstrating (a) short term release behavior over 24 hours and (b) long term release over 30 days, reported as $\mu$ g calcium per scaffold dry weight per mL PBS. Data represents average values + S.D., $n=4 *$ denotes significant difference, $\mathrm{p}<0.05$.

shown in Figure 5.4a. After 6 h, no significant difference was observed between materials with stabilized plateau binding thus representing the subsequent time point for initiation of perfusion.

To confirm the absence of cytotoxic effects of the scaffolds, an MTT viability study was performed after two days cell culture corresponding to the initiation of perfusion culture. At this time point, while M-HA trended lower compared to N-HA and positive control, there were no significant differences identified between groups $(p<0.05)$ as shown in Figure 5.4b.

\subsubsection{Cell total protein and differentiation markers}

Effects of media perfusion were evaluated over $21 \mathrm{~d}$ of cell culture with respect to total protein and osteoblast differentiation marker production normalized to the total cell count measured as the quantity of dsDNA. Total protein quantification is shown in 

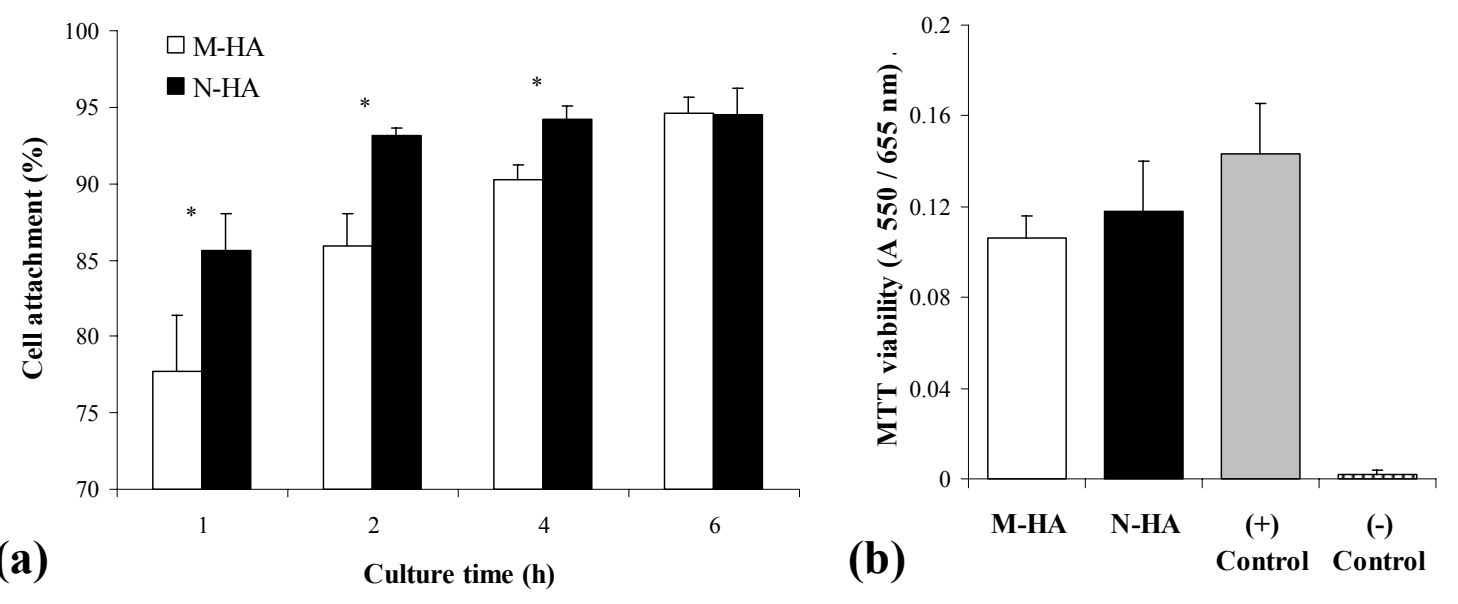

Figure 5.4 Early HEPM cell response to M-HA and N-HA scaffolds. Cell attachment behavior is shown (a) over $6 \mathrm{~h}$, with $75 \%$ or greater cell binding within $1 \mathrm{~h}$ and $95 \%$ binding after $6 \mathrm{~h}$. Cell viability (b) after $2 \mathrm{~d}$ culture compared to cells plated on tissue culture treated plastic, $(+)$ control, and supplemented with $0.05 \%$ Triton X-100 in culture media (-) control. 
Figure 5.5a for M-HA and N-HA scaffolds with perfused media or static conditions. Protein production between groups at each time point was not significantly different at 1 or $7 \mathrm{~d}$ after start of perfusion. Differences were identified only between M-HA static and N-HA perfused at 14 and $21 \mathrm{~d}$.

The secreted proteins osteocalcin and osteopontin were measured in culture media extracted at selected time points during perfusion. Minimal levels of osteocalcin were present in both static groups over the course of the experiment, with both groups significantly different from the perfused condition at all time points. Differences between M-HA and N-HA perfusion groups were identified at 1, 7 and $21 \mathrm{~d}$ after perfusion start with M-HA greater than N-HA at 1 and $7 \mathrm{~d}$ but not $21 \mathrm{~d}$. Osteopontin production showed significant differences between static and perfused condition only after $7 \mathrm{~d}$ culture, with only N-HA perfused different from M-HA static at $1 \mathrm{~d}$. No between-material differences were identified throughout the remainder of the experiment.

\subsection{Discussion}

The differentiation of mesenchyme precursor cells into an osteoblast phenotype is of significant interest for bone regeneration studies as this cell type represents a substance source for bone repair. The increasing use of perfusion culture combined with the development of porous scaffolding also offers a platform to study and fabricate newly formed bone in the laboratory. In this study, the importance of material surface features, scaffold architecture and perfusion culture on the attachment, viability and differentiation of osteoblast precursors was explored. 

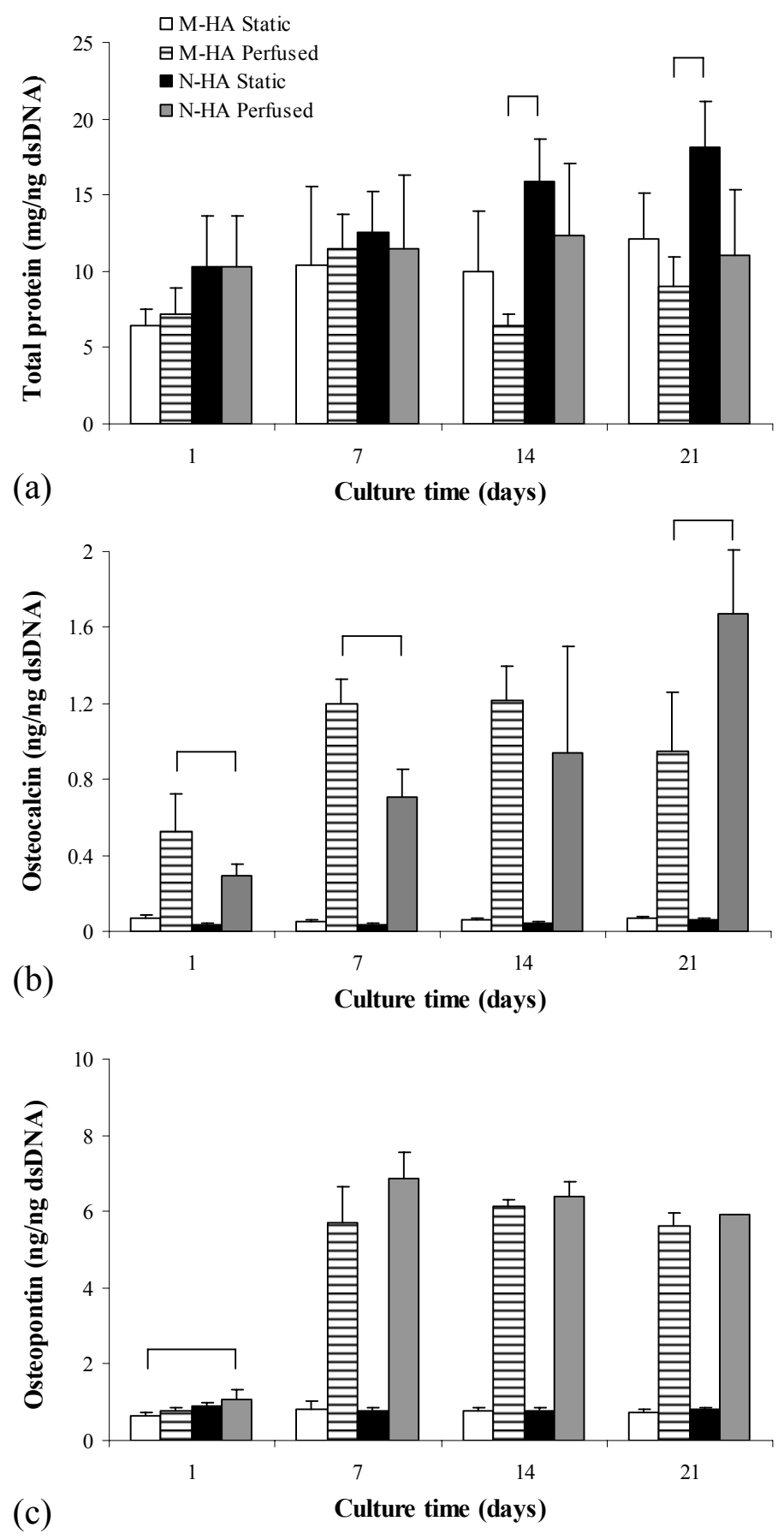

Figure 5.5 Protein expression of HEPM cells in scaffolds over 21 days. Total protein production (a) in ( $\mu \mathrm{g})$ by cells normalized to DNA content in (ng) on M-HA and N-HA scaffolds with and without perfusion, (b) osteocalcin secretion from cultured cellscaffolds in (ng) per (ng dsDNA) and (c) osteopontin secretion. Brackets denote $\mathrm{p}<0.05$. All osteocalcin perfused values were significantly greater than static values with no difference between static groups. All osteopontin perfused values were significantly different from static after day 1. Error bars represent means + S.D., $n=4$. 


\subsubsection{Scaffold design and calcium release}

The architectural arrangement and materials of natural trabecular bone demonstrate a strut-like organization with a mineral phase consisting of apatite. Hydroxyapatite scaffolds are closely matched in composition and can be fabricated to approximate the macroscopic arrangement of bone allowing in vitro experiments to better simulate an in vivo environment. The open, fully interconnected scaffolds fabricated from a template coating technique in this study were designed to simulate histological properties of the human lumbar spine [Appleford 07]. The addition of a nano based surface feature was postulated to increase the cellular attachment locations on the material and provide a greater early release of calcium. Calcium release has been implicated in the activation of many biological pathways including the MAPK cascade [Katz 06], with varying concentrations assisting osteoblast precursor differentiation [Maeno 05]. N-HA scaffolds increased the release behavior of calcium within 24 hours but did not significantly change the quantities over 30 days. In this experiment, HA materials were designed with full crystallinity, however, changes in sintering temperature could provide a less crystalline HA surface coat to increase calcium availability during initial bone formation in a clinical setting.

\subsubsection{Early cell behavior on HA scaffolds}

Early cell attachment to the scaffolds demonstrated the improved cell binding capacity of N-HA surfaces. Significantly greater cell binding occurred on N-HA compared to M-HA scaffolds at 1, 2, and $4 \mathrm{~h}$; however, both designs equally bound $95 \%$ of cells in suspension after $6 \mathrm{~h}$. This result is consistent with the observed increase in 
local surface roughness of the N-HA scaffold. To confirm that this increased roughness did not induce cell apoptosis, a viability study was performed at $2 \mathrm{~d}$ also corresponding with the start of perfusion studies. With no significant differences identified between MHA and N-HA at this time it can be assumed that equal cell loading had occurred prior to perfusion start and that neither material was cytotoxic, as previously reported from the literature [Sepulveda 00].

\subsubsection{HEPM differentiation in response to perfusion}

The application of fluid flow has previously shown activation of bone cell gene expression in vitro [Ogata 00, Owan 97, Reich 91]. The selection of fluid flow rate and rate of occurrence has been explored in relation to cell phenotypic response [Edlich 01, Jacobs 98] with postulated mechanisms of action including; mass transport and membrane based shear components or streaming potentials [Bakker 01, McAllister 99]. Confirmation of these signaling trends has also been observed in scaffold based tissue engineering strategies [Cartmell 03, Holtorf 05].

As observed in this study, total protein production was not significantly altered in response to perfusion flow on a per cell basis until d 14 and 21 and only between M-HA perfused and N-HA static groups. Interestingly, quantities favored static compared to perfused conditions, suggesting that perfusion may decrease net protein production. When the osteoblast differentiation markers; osteocalcin and osteopontin were quantified at these time points, a substantial increase in perfusion compared to static conditions was observed. Osteopontin represents a differentiation marker produced prior to and during matrix mineralization [Sandberg 93], and in contrast to cell adhesion patterns, peaked 
earlier on M-HA compared to N-HA scaffolds in perfusion. This indicates that while few identifiable differences in total protein within group levels were identified, a significant increase in differentiation had occurred in response to media perfusion. The earlier increase in M-HA compared to N-HA osteocalcin levels suggests that while attachment rate favored the N-HA scaffold, it may have hindered the differentiation response of HEPM cells. This result seems to contradict the increased calcium release behavior of the N-HA scaffold if calcium were the only difference between M-HA and N-HA scaffolds. Recent evidence has shown that the specific cell shape in response to surface features can substantially influence cell phenotype by changes in integrin expression [Chen 97]. A similar mechanism could be responsible for the observed results in this study as N-HA demonstrates significantly different surface features that may be recognized by cells.

The fluid flow rate utilized in this study represents a mid-range level as compared with other studies [Cartmell 03, Glowacki 98, Goldstein 01]. It should be noted that while perfusion rates are often reported, they make between study comparisons very difficult due to the inherent differences in scaffold architecture. Factors such as porosity, interconnectivity and local geometry have substantial influence over the shear stresses truly experienced by cells. These local forces can also vary significantly with time as the cells proliferate and modify the geometry of the scaffold. An approach is currently being developed to relate time-based architectural changes in the scaffold with varying perfusion rate. 


\subsection{Conclusion}

Trabecular CP scaffolds were manufactured with micro and nano-based surface

features to study HEPM cell behavior in static and perfused conditions. From this study N-HA scaffolds demonstrated greater calcium release and improved early HEPM cell attachment in vitro. Fluid perfusion stimulated the increase in bone differentiation markers osteocalcin and osteopontin. As the mechanism of action underlying fluid perfusion is local shear forces acting on the cell membrane it is reasonable to conclude that changes in cytoskeletal structure are changing intracellular pathways and gene regulation. These changes are ultimately reflected by the increased expression of bone differentiation markers. In contrast to the calcium and attachment behavior on N-HA scaffolds, a delay in osteocalcin based differentiation was observed in response to this scaffold surface. It was concluded from this study that perfusion fluid flow represents a substantial stimulation for the differentiation of bone cell precursors and while nano surface features can greatly improve early cell response, careful control over their structure is required to maintain the differentiation capability of this design. 


\section{Chapter 6. In vivo study on hydroxyapatite scaffolds with trabecular architecture for bone repair}

\subsection{Abstract}

The objective of this research was to investigate the bone formation and angioconductive potential of HA scaffolds closely matched to trabecular bone in a canine segmental defect after 3 and 12 weeks post implantation. Histomorphometric comparisons were made between naturally forming trabecular bone (control) and defects implanted with scaffolds fabricated from micro-size (M-HA) and nano-size HA (N-HA) ceramics. Scaffold architecture was similar to trabecular bone formed in control defects at 3 weeks. No significant differences were identified between the two HA scaffolds, however, significant bone in-growth was observed by 12 weeks with $43.9 \pm 4.1 \%$ and $50.4 \pm 8.8 \%$ of the cross-sectional area filled with mineralized bone in each scaffold type, respectively. Partially-organized, lamellar collagen fibrils were identified by birefringence under cross-polarized light at both 3 and 12 weeks post implantation. Substantial blood vessel infiltration was identified in the scaffolds and compared with the distribution and diameter of vessels in the surrounding cortical bone. Vessels were less numerous but significantly larger than native cortical Haversian and Volkmann canals reflecting the scaffold architecture where open spaces allowed interconnected channels of bone to form. This study demonstrated the potential of trabecular bone modeled, highlyporous, interconnected, HA scaffolds for regenerative orthopedics. 


\subsection{Introduction}

Bone regeneration supported by artificial scaffolding requires a substantial healing period before functional restoration of natural tissue is realized. Porous scaffold designs take advantage of natural bone in-growth to accelerate the osteoconduction and integration between implant and bone. Characteristics such as material composition, surface features, pore morphology and overall architecture are a few of the parameters that determine implant success. With careful control of these factors, scaffolds can be biocompatible, osteo- and angio-conductive while encouraging a natural bone arrangement with haversian-like features during bone regeneration.

Among the many biomaterials used for manufacturing scaffolds, the use of hydroxyapatite (HA) has demonstrated excellent performance for bone reconstruction [Arinzeh 05, Dong 01, Flautre 99, Gauthier 05, Kon 99, Koshino 01, Lu 98, Mastrogiacoma 06]. HA is a well established material for bone repair and very comparable to natural apatite providing a strong bio-mechanical interlock with host tissue [Posner 73, Richard 98]. The composition of HA exhibits a variety of useful properties such as closely matched composition to bone, negligible immunoreactivity, osteoconductivity and the availability of local calcium and phosphorous for surrounding cells. Additionally, recent research on HA has also shown that nano-based surfaces offer improved characteristics for bone formation [Arts 06].

In addition to material composition, the importance of pore morphology and architecture has been the focus of scaffold designs to improve clinical results [De Oliveira 03, Lu 99, Mankani 01, Navarro 04, Sepulveda 00]. Scaffolds have been manufactured from HA using techniques such as porogen leaching, textile, solid free 
form fabrication and template coating. Each of these methods offers advantages and disadvantages for scaffold design with ongoing research particularly aimed at the identification of a minimum pore size necessary for tissue infiltration [Chang 00 , Gauthier 98, Karageorgiou 05]. The macroscopic arrangement of pore designs and the importance of surface area and shape of ceramic materials have also been implicated in cell specific activities such as differentiation into the osteoblast lineage [Habibovic 05].

Open, interconnected porosity is essential for tissue infiltration as it guides cell migration, proliferation and bone cell differentiation to mechanically connect implant with bone. The long term success for clinically applied scaffolds may be assisted by the overall architecture of open channel designs since functional blood supply provides a foundation for tissue growth [Boyde 99]. Incomplete pore connections can obstruct vascular infiltration and ultimately constrain tissue formation in clinically-applied biomaterials. In addition to tissue survival, blood vessels have a substantial role in coordinating the biochemical activity that guide bone cell behavior including remodeling [Barou 02]. Successful scaffold designs must balance these factors to support vessel formation for functional bone tissue formation.

In this study, it was hypothesized that scaffolds coated with nano-size HA (NHA) would induce a different rate of bone regeneration when compared to scaffolds made of micro-size HA (M-HA). Bone formation and angio-conductive potential of a scaffold closely matched to trabecular bone was investigated in a segmental defect model of a canine after 3 and 12 weeks post implantation. Histological sections were compared between the naturally forming trabecular bone (control) and defects implanted with scaffolds. Additionally, collagen arrangement was identified and evaluated using cross- 
polarized microscopy to recognize lamellar fiber orientation.

\subsection{Materials and methods}

\subsubsection{Scaffold preparation}

HA scaffolds were produced using a template-coating technique. Polyurethane sponges (EN Murray, Denver, CO) were coated with HA powder (TAL Materials, Ann Arbor, MI), in a distilled water-based slurry. Binders used with the slurry to improve sintering and to stabilize the scaffold structure included 3\% high molecular weight polyvinyl alcohol, $1 \% \mathrm{v} / \mathrm{v}$ carboxymethylcellulose, $1 \% \mathrm{v} / \mathrm{v}$ ammonium polyacrylate dispersant, and 3\% v/v N,N-dimethylformamide drying agent. Coated sponges were vacuum-dried overnight before sintering to $1230^{\circ} \mathrm{C}$ for 3 hours in a high temperature furnace (Thermolyne, Dubuque, Iowa). Scaffolds were twice coated with HA slurry and re-sintered. A sol-gel coating of nano-size HA was prepared from calcium nitrate in methanol using a previously reported process [You 01]. A stoichiometric $\mathrm{Ca} / \mathrm{P}$ ratio of 1.67 was obtained and solution aged for 7 days before immersion coating onto scaffolds and sintered to $600^{\circ} \mathrm{C}$ for 1 hour. Composition purity was validated using X-ray diffraction analysis (D8 Advance, Bruker Axs Inc., Madison, WI). Final scaffold dimensions were $\varnothing 5 \mathrm{~mm}$ and length of $5 \mathrm{~mm}$ as shown in Figure 6.1. Samples were sterilized by ethylene oxide gas before implantation. 


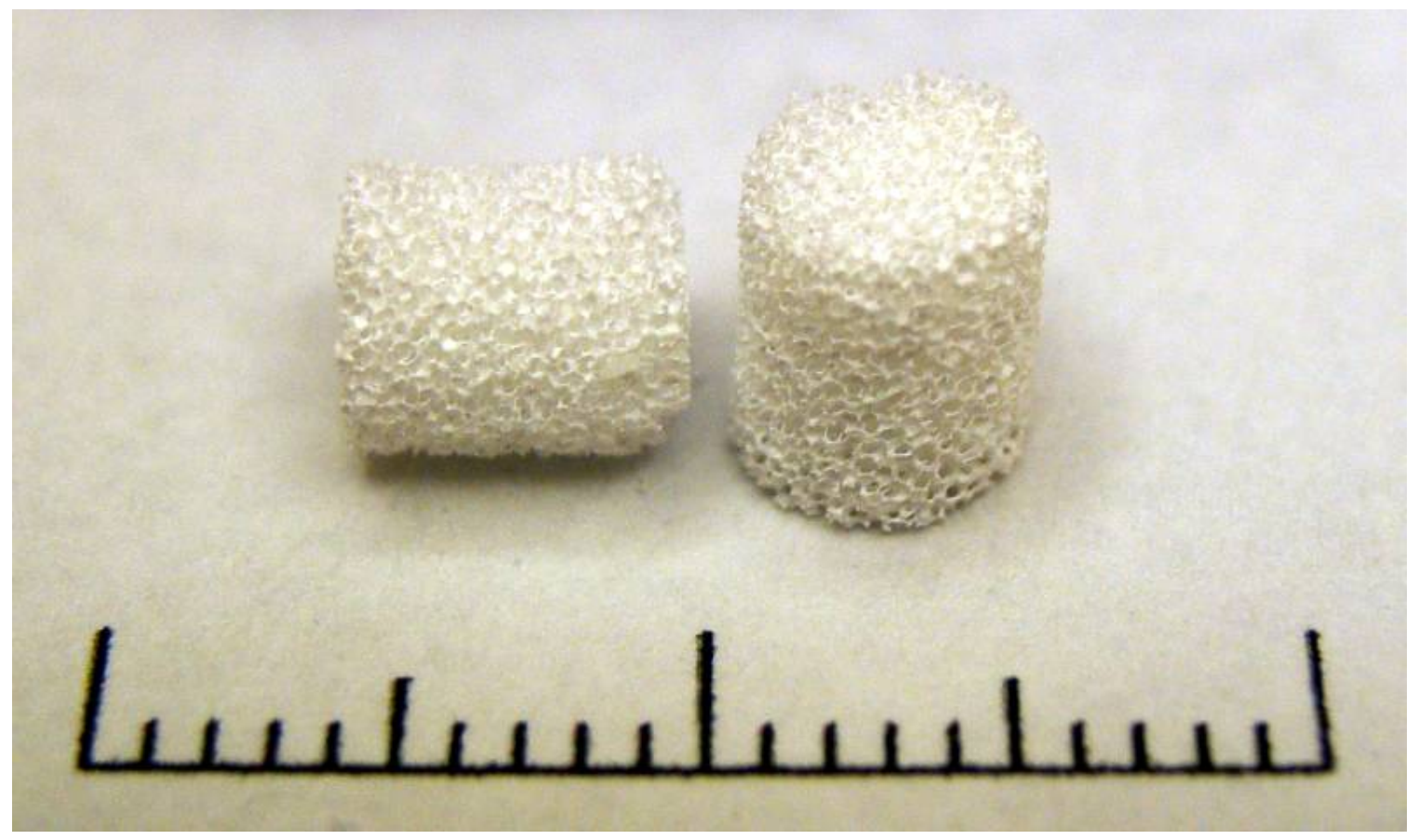

Figure 6.1 Cylindrical, interconnected 5 x $5 \mathrm{~mm}$ HA scaffolds for defect repair in the dog mandible. Scale bar measures $20 \mathrm{~mm}$. 


\subsubsection{Scaffold characterization}

Scaffolds were imaged by scanning electron microscopy (SEM) to observe macro and micro features. Histomorphometry was performed on cross-sectional slides prepared from representative samples. Embedding was performed in one-component photo-curing resin (Exakt 7200 VLC, Oklahoma City, OK) and thin sectioned using a precision microsaw (Buehler, Lake Bluff, IL). Sections were progressively polished to 1200 grit paper and adhered to glass slides using a methyl methacrylate resin (Surgipath Medical Ind., Richmond, IL). Sections were imaged at 80 and 200X magnification with a digital camera (QImaging, Burnaby, Canada) on a Nikon TE300 microscope (Nikon, Melville, NY). An analysis of the scaffold was performed using bone histomorphometry software (Bioquant Osteo, Nashville, TN). Two longitudinal cross-sections were prepared from each scaffold. Parameters were defined from traditional bone histomorphometry guidelines and the following characteristics were recorded: percentage of scaffold volume $[\mathrm{SV} / \mathrm{TV}=$ scaffold volume / total volume $\mathrm{x} 100 \%]$, ratio of scaffold surface perimeter to total volume [SS / TV = surface length / total volume, ratio of scaffold surface perimeter to scaffold volume [SS / SV = surface length / scaffold volume], trabecular thickness $[$ Tb.th. $=(4 / 1.199) \times(\mathrm{SS} / \mathrm{SV})]$, trabecular number $[\mathrm{Tb} . \mathrm{n} .=((4 / \pi)$ $\mathrm{x}(\mathrm{SV} / \mathrm{TV}))^{-0.5} /(\mathrm{Tb}$. th. $\left.)\right]$ and trabecular separation $[\mathrm{Tb} . s p .=((4 / \pi) \mathrm{x}(\mathrm{TV} / \mathrm{BV})-1) \mathrm{x}$ (Tb.th.)]. The formulae were derived with respect to trabecular bone tissue including both rod- and plate-like geometry [Parfitt 87]. The use of these measures allows for comparisons between known values of primarily rod-like trabecular structures from other anatomical locations [Hildebrand 99]. 


\subsubsection{Surgical procedure}

Ten, 2-year-old adult male foxhound dogs, weighing between 20 to $25 \mathrm{~kg}$ were used for this study. The 10 dogs were cared for in compliance with DOD programs and NIH publication \# 86-23, Guide for the Care and Use of Laboratory Animals. Prior to experimentation, the protocol was evaluated and approved by the IACUC of The University of Tennessee Health Science Center at Memphis to ensure that the policies, standards and guidelines for the proper use, care, handling and treatment of animals were observed.

Two defect locations were created in both the left and right aspects of the mandible. The periosteum was retracted to expose the mandible surgical locations below the forward premolar teeth which were removed in conjunction with a separate study. A trephine drill bit was used to create $5 \mathrm{~mm}$ defects through the buccal side of the cortical bone. Defects were left unfilled as an empty control, filled with mHA or nHA scaffolds. Randomization in the order of implant placement was performed in each animal. As illustrated in Figure 6.2, the defects were introduced into the mandible with image analysis performed in a coronal (frontal) plane of view [Boyd 01].

Animals were sacrificed at 3 and 12 weeks post surgery. Mandibles were collected and placed into 10\% neutral buffered formalin. Micro-CT sections were generated to observe macro tissue to implant integration and to assess any abnormalities in the surrounding tissue. Embedding and sectioning were performed following the same procedure for control scaffolds. Two sections of each implant representing the central region were used for quantitative histology as shown in Figure 6.3, while remaining sections were observed for qualitative features. 


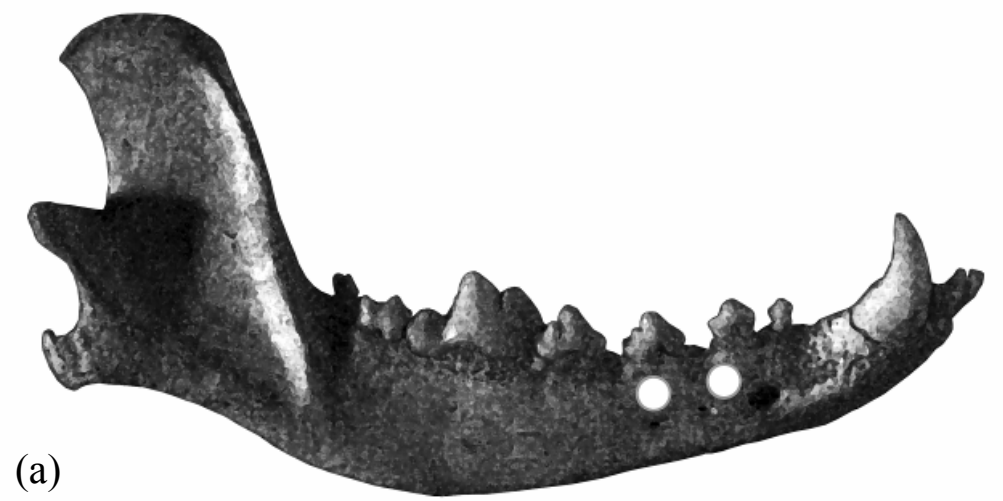

(b)

Figure 6.2 Representative image of the dog mandible showing (a) the location of the introduced defects below the premolar teeth and (b) coronal or frontal cross section of the mandible with defect traversing the lateral aspect of the cortical bone based on Boyd (2001). 


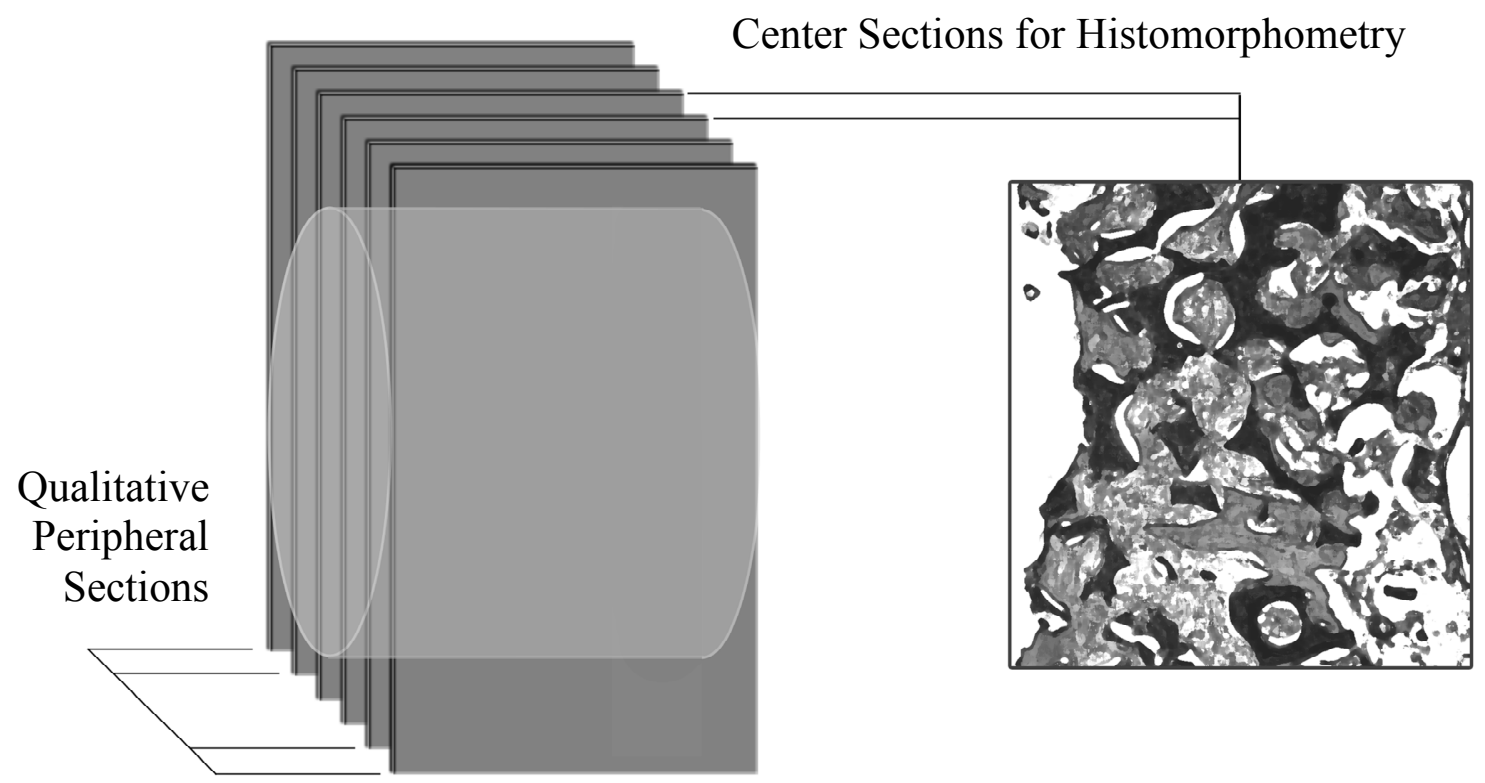

Figure 6.3 Histological preparation scheme showing cross sections through an implanted scaffold with assignment of quantitative slides from the center and qualitative descriptions from the outer sections. 
Thin sections were stained for connective tissues with Paragon (toluidine blue and basic fuchsin) and calcified bone tissue with Alizarin Red. Quantitative histomorphometry was performed on stained sections in Bioquant Osteo by color thresholds and direct measurement of area values. Tissue and bone formation data represent the percentage of those tissues within each total region of interest. Tissue was identified as inclusive biological structures identified by both stains while bone represented only mineralized tissue staining for Alizarin Red. As defined, partially mineralized osteoid was not included in the bone classification. All tissue-scaffold measurements were performed inside the perimeter of the scaffold. All porous spaces were excluded from tissue or bone measurements except for osteocyte lacunae and other features in the micron range. Vessels were identified in calcified sections within the scaffolds at 12 weeks. Vessel distribution and diameter were compared with vessels counted from the same histological section in cortical bone at a location greater than $5 \mathrm{~mm}$ from the defect. Haversian canals, Volkmann's canals, and small vessels were quantified with visibly interconnected channels counted as one. Currently forming osteons and resorbtion spaces were not included in the measurement.

\subsubsection{Statistical analysis}

Statistical calculations were performed with SigmaStat software (Systat, Point Richmond, CA). Significance between groups was analyzed by one-way ANOVA with Tukey pairwise multiple comparisons. Significance levels were set at $\mathrm{p}<0.05$. 


\subsection{Results}

\subsubsection{Material characterization}

Overall scaffold architecture shown in Figure 6.4(a,b) demonstrates the open interconnected features of the rod-like strut design. Open channels were arranged with isotropic geometry and rounded-edge triangular strut morphology. N-HA and M-HA surfaces were observed for scaffolds with and without sol-gel coatings, respectively as shown in Figure 6.4(c, d). Sol-gel coatings formed a thin layer of precipitated HA crystals on the bulk scaffold increasing the SEM visualized surface roughness and nanotexturing. Scaffolds averaged a density value of $22.6 \pm 5.6 \%$ leaving an average of $77.4 \%$ porous space for tissue infiltration.

\subsubsection{In vivo analysis}

Following surgical resection, mandible-block specimens imaged by micro-CT were examined for delayed- or non-union with the surrounding bone tissue. At the time of recovery, there was no evidence of inflammation or rejection around the scaffolds or open defects. An intact periosteum was found covering the surgery location and macroscopic bone formation could be identified in the specimens. Micro-CT, after 3 weeks, revealed soft and hard tissue within the control defect and both scaffold designs as shown in Figure 6.5(a-c). After 12 weeks, micro-CT observations indicated the formation of dense cortical bone within both scaffolds, whereas a thin cortical shell bridge was observed forming across the control defects as shown in Figure 6.5(d-f).

After three weeks, trabecular bone could be observed forming inside the control 

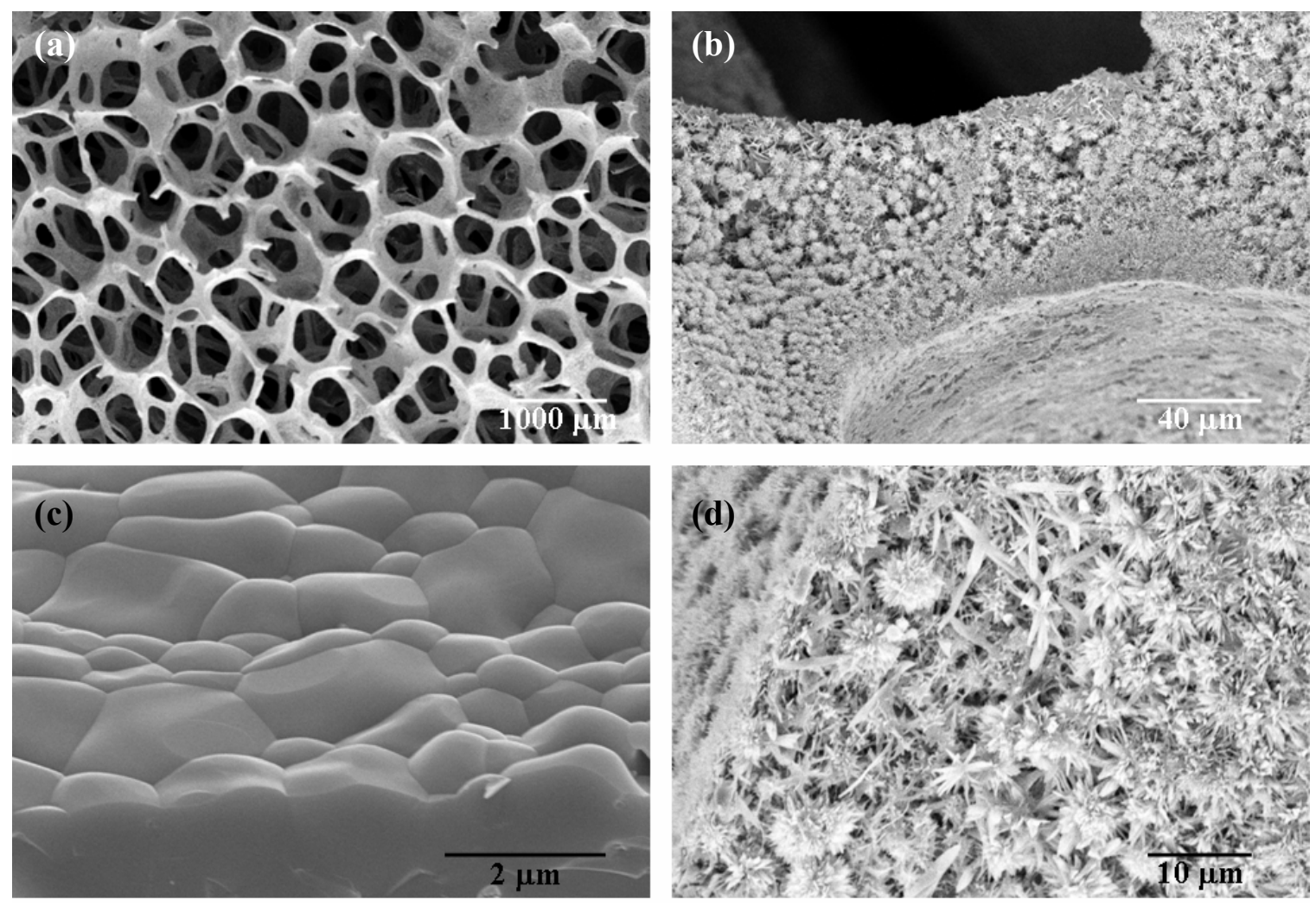

Figure 6.4 SEM photographs of the HA scaffolds; (a) bulk macroporisity, (b) N-HA scaffold strut morphology, (c) M-HA surface features and (d) N-HA scaffold demonstrating nano-scale surface features. Scale bar dimensions of 1000, 40, 2, and 10 $\mu \mathrm{m}$. 

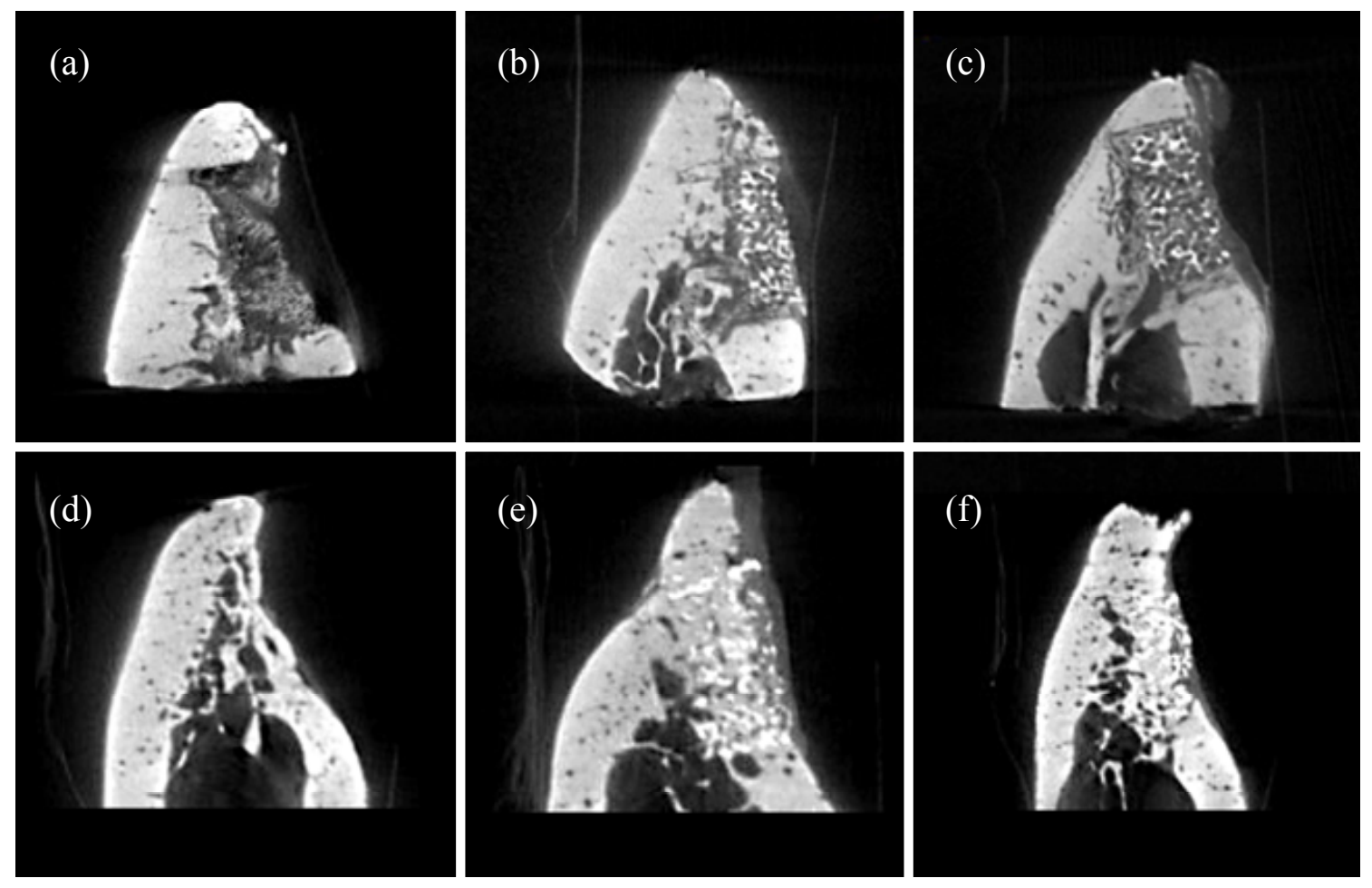

Figure 6.5 Coronal orientation, micro-CT images; (a,d) control defect, (b,e) implanted M-HA, and (c,f) N-HA scaffolds after 3 and 12 weeks post-surgery in the canine mandible. Radial defect was created from the lateral surface with control bone bridging initiated by 12 weeks. Scaffold groups show early union and bridging with dense cortical tissue found at 12 weeks. 
defect by histology. This bone was analyzed and compared with scaffold values with data represented in Table 6.1. It was observed that scaffold properties closely matched the properties of newly formed trabecular bone at 3 weeks with respect to bone surface to bone volume ratio $\left(35.6 \pm 5.6,25.4 \pm 7.6 \mathrm{~mm}^{-1}\right)$, trabecular number $(5.4 \pm 0.2,5.1 \pm 1.2$ $\left.\mathrm{mm}^{-1}\right)$, separation $(466 \pm 68,342 \pm 64 \mu \mathrm{m})$ and thickness $(98 \pm 15,138 \pm 36 \mu \mathrm{m})$, respectively.

Histomorphometry evaluation revealed tissue infiltration into both scaffolds at 3 weeks. New bone formation progressed from the original bone edge into the scaffold and from the marrow cavity. Newly formed and mineralized bone was observed infiltrating both scaffolds with semi-random collagen fiber orientation observed by cross-polarized light. Control and N-HA scaffolds after 3 weeks are shown in Figure 6.6(a,b) with N-HA demonstrating no morphological differences compared to M-HA scaffolds.

Quantification of this area showed an early majority of fibrous tissue, $61.8 \pm 6.0$ and $72.7 \pm 2.8 \%$, infiltrating the M-HA and N-HA scaffolds, respectively. At 3 weeks, $4.4 \pm 2.6 \%$ mineralized bone formation in M-HA scaffolds and $7.2 \pm 6.6 \%$ in N-HA scaffolds (Table 6.2) had occurred. Normalized percent values of mineralized to total tissue were recorded with $7.0 \pm 3.5 \%$ conversion in M-HA scaffolds and $10.1 \pm 9.5 \%$ conversion in N-HA scaffolds (Table 6.3). Collagen organization was also found in a partially lamellar organization coating the surface of the scaffolds as shown in Figure $6.7(a, b)$.

By 12 weeks post surgery, histomorphometry evaluations of the untreated defects concurred with the micro-CT observations indicating the formation of a thin cortical bridge across the opening. Tissue infiltration progressed throughout both scaffold 
Table 6.1 Histomorphometry parameters of HA scaffold compared to newly formed trabecular bone in the defect location 3 weeks post surgery.

\begin{tabular}{lcccc}
\hline Parameter & Abbreviation & HA Scaffold & 3 Week Bone & Units \\
\hline Bone Volume/Total Volume & BV/TV & $22.6 \pm 5.6$ & $36.4 \pm 5.4$ & $\%$ \\
Bone Surface/Total Volume & BS/TV & $7.6 \pm 0.7$ & $9.1 \pm 1.7$ & $\mathrm{~mm}^{-1}$ \\
Bone Surface/Bone Volume & BS/BV & $34.6 \pm 5.6$ & $25.4 \pm 7.6$ & $\mathrm{~mm}^{-1}$ \\
Trabecular Number & Tb.N & $5.4 \pm 0.2$ & $5.1 \pm 1.2$ & $\mathrm{~mm}^{-1}$ \\
Trabecular Separation & Tb.Sp & $466 \pm 68$ & $342 \pm 64$ & $\mathrm{~mm}^{-1}$ \\
Trabecular Thickness & Tb.Th & $98 \pm 15$ & $138 \pm 36$ & $\mu \mathrm{m}$ \\
\hline
\end{tabular}



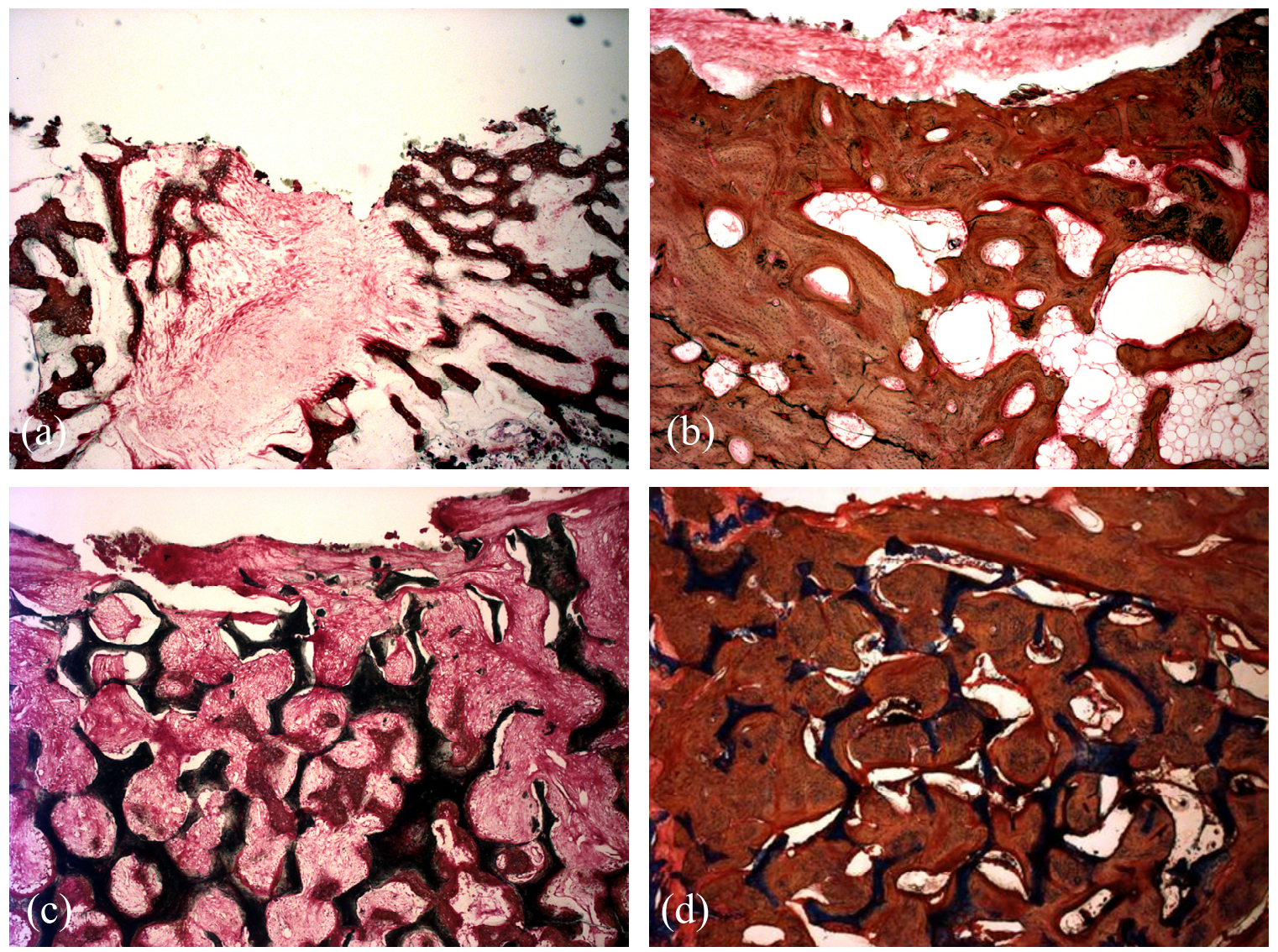

Figure 6.6 Bone tissue cross section of control defect stained with Paragon for connective tissue (violet) and Alizarin Red for mineralized bone tissue (red) after (a) 3 and (b) 12 weeks post surgery and N-HA scaffold shown after (c) 3 and (d) 12 weeks with scaffold in black, $80 \mathrm{X}$ original magnification. Lateral edge orientated upward. 
Table 6.2 Total tissue area and mineralized bone area percentages in M-HA and N-HA scaffolds at 3 and 12 weeks post surgery.

\begin{tabular}{lllll}
\hline \multirow{2}{*}{ Time } & \multicolumn{2}{l}{ Area of Total Tissue (\%) } & \multicolumn{2}{l}{ Area of Mineralized Bone (\%) } \\
\cline { 2 - 5 } Post Surgery (Weeks) & M-HA & N-HA & M-HA & N-HA \\
\hline 3 & $61.8 \pm 6.0$ & $72.7 \pm 2.8$ & $4.4 \pm 2.6$ & $7.2 \pm 6.6$ \\
12 & $74.4 \pm 3.1$ & $77.3 \pm 4.5$ & $43.9 \pm 4.1$ & $50.4 \pm 8.8$ \\
\hline
\end{tabular}

Table 6.3 Relative mineralized tissue formation compared to total tissue in M-HA and N-HA scaffolds at 3 and 12 weeks post surgery.

\begin{tabular}{lll}
\hline Time & \multicolumn{2}{l}{ Mineralized / Total Tissue (\%) } \\
\cline { 2 - 3 } Post Surgery (Weeks) & M-HA & N-HA \\
\hline 3 & $7.0 \pm 3.5$ & $10.1 \pm 9.5$ \\
12 & $59.0 \pm 3.5$ & $65.3 \pm 11.3$ \\
\hline
\end{tabular}



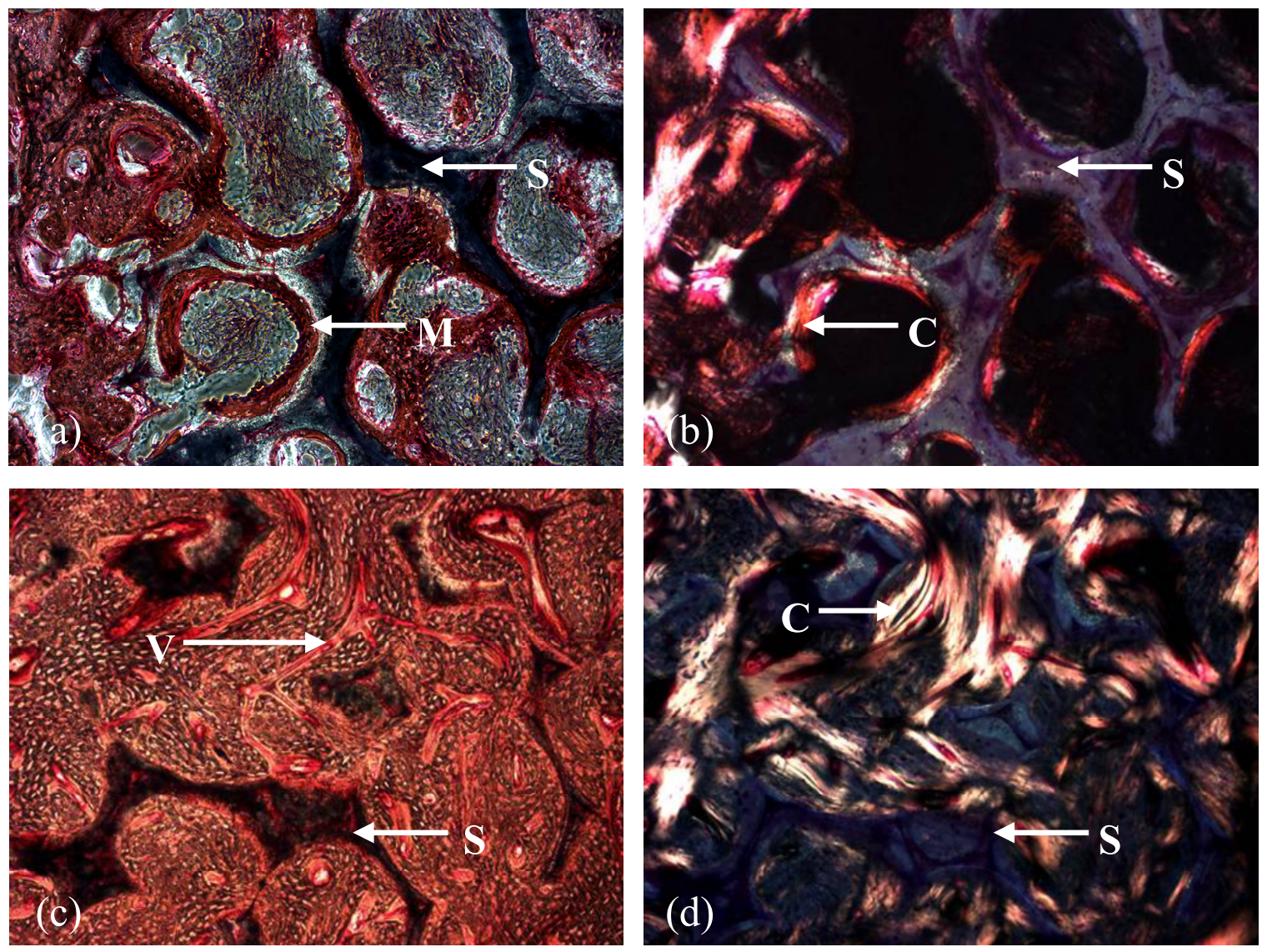

Figure 6.7 Bone tissue cross section of N-HA scaffold under phase contrast after (a) 3 and (c) 12 weeks post surgery with corresponding cross-polarized light micrographs shown in $(b, d)$ representing birefringence of collagen strands, 200X $(\mathrm{S}=$ scaffold, $\mathrm{M}=$ mineralized bone, $\mathrm{C}=$ collagen birefringence, $\mathrm{V}=$ vessel). 
designs with few pores left unfilled. Mineralized bone formation represented $43.9 \pm$ $4.1 \%$ of the M-HA scaffolds and $50.4 \pm 8.8 \%$ of the N-HA scaffolds (Table 6.2) and conversion from connective tissue into mineralized bone were correspondingly recorded at $59.0 \pm 3.5$ and $65.3 \pm 11.3 \%$ (Table 3). Figure $6.7(\mathrm{c}, \mathrm{d}$ ) shows the visible and crosspolarized light distribution of tissue formed inside a N-HA scaffold also representative of M-HA scaffold morphology. Open channels remain unfilled at the center of the scaffold pores representing the blood and nutrient supply to the newly formed tissues. Collagen patterning by 12 weeks has visibly organized into interlaced strands wrapping around the scaffold struts as shown in Figure 6.7(c,d).

Blood vessel conduction and diameter within the scaffolds were reported and compared with blood vessels found in the adjacent tissue at a distance of $5 \mathrm{~mm}$ from the defect site. Within the cortical bone tissue these consisted predominantly of Haversian and Volkmann's canals. The control bone averaged $16.9 \pm 3.4$ vessels $/ \mathrm{mm}^{2}$ with an average diameter of $19.0 \pm 0.7 \mu \mathrm{m}$. As shown in Figure 6.7c, vessels within HA scaffolds were observed.

Vessels found within the scaffolds had a less frequent distribution of $7.7 \pm 1.4$ and $7.6 \pm 2.7$ vessels $/ \mathrm{mm}^{2}$, with a larger average diameter of $23.3 \pm 2.7$ and $23.0 \pm 0.4 \mu \mathrm{m}$ in M-HA and N-HA scaffolds, respectively (Table 6.4), when compared with natural cortical bone. No significant differences were found between vessel distribution or diameter between the two HA scaffolds. However, significant difference in vessel distribution and diameter were observed between HA scaffolds and control bone $(\mathrm{p}<0.05)$. 
Table 6.4 Blood vessel distribution (per mm) and diameter $(\mu \mathrm{m})$ within 12 week M-HA, N-HA scaffolds and natural cortical bone. Values represent Haversian, Volkmann's canals and blood vessels only. *Denotes statistical difference from each scaffold group, $\mathrm{p}<0.05$.

\begin{tabular}{llll}
\hline Blood Vessel Parameter & M-HA & N-HA & Cortical Bone \\
\hline Vessels / mm & $7.7 \pm 1.4$ & $7.6 \pm 2.7$ & $* 16.9 \pm 3.4$ \\
Vessel Diameter $(\mu \mathrm{m})$ & $23.3 \pm 2.7$ & $23.0 \pm 0.4$ & $* 19.0 \pm 0.7$ \\
\hline
\end{tabular}

\subsection{Discussion}

This study investigated the bone forming and angio-conductive capability of a scaffold design closely approximating trabecular bone. A sol-gel coating of nanocrystalline HA was also investigated for improvements related to its nano-texturing and material properties at 3 and 12 weeks post implantation into the canine mandible. Although significant evidence exists in the literature defining the morphological properties of natural bone [Feldkamp 89, Navarro 04], it is seldom related to bone formation in scaffolds. As the natural process in segmental bone repair progresses through a woven and trabecular bone-like phase to a mature cortical structure, this research focused on using a scaffold patterned on trabecular bone. The presence of material curvatures is known to be a substantial influence on cell and tissue behavior and that careful control of these architectures may lead to enhanced bone formation [Chen 97]. As observed in this study, surface to volume ratio was designed to provide numerous locations for early cell attachment with strut dimensions (thickness, $98 \pm 15$ $\mu \mathrm{m})$ smaller than their in vivo counterparts $(138 \pm 36 \mu \mathrm{m})$. Rationale for this arrangement was to permit cell-layering around the struts with an organized collagen 
network. Although the defect size used in this study was not critical in character, as evidenced by the bridging in the control after 12 weeks, the use of this defect size was ideal for comparing the naturally formed trabecular bone with the replacement scaffold. Additionally, comparisons of tissue formation were not possible between control defects and scaffold groups because the original defect location could not be accurately located to ensure that controls would match the exclusive center-section criteria for quantitative histomorphometry.

At the early time point of 3 weeks post surgery, the interconnected scaffolds of $77.4 \pm 5.6 \%$ porosity were immediately filled with connective tissue. Generation of osteoid was already established at this time and $4.4 \pm 2.6$, and $7.2 \pm 6.6 \%$ fully mineralized tissue was observed in M-HA and N-HA scaffolds, respectively. Histology revealed that the mineralization front was initiated from contact with existing bone, from the marrow cavity and directly on the surface of the scaffold struts reflecting the strong osteoconductive characteristics of material and architecture. Osteoblasts were identified at 3 weeks making use of the scaffold arrangement by depositing newly formed bone in circular lamella from the scaffold surface. Cross polarized light revealed bundled collagen fiber organization by luminous birefringence that was characteristic of woven and partially lamellar bone at this early time point.

After 12 weeks post surgery, nearly complete mineralized bone formation was observed in both HA scaffolds. This represents the majority of the available space for bone tissue as the scaffold itself occupies $22.6 \%$ of the area. At 12 weeks, the mineralized bone showed full interconnection with the scaffold and small nutrient channels were observed tunneling throughout the tissue. When compared to the 
surrounding cortical bone tissue, intra-scaffold vessels were found to be less numerous but significantly larger than Haversian and Volkmann's canals. Since the scaffold design ultimately prevents complete osteon formation, mineralized bone must be supplied with nutrients by channels twisted around struts. This vessel arrangement could be related to the scaffold architecture where open spaces permit less numerous but larger, interconnected, bone-blocks to form.

Collagen organization within the scaffolds at 12 weeks showed lamellar-like organization with bundles woven around and between the struts. Visualized crosssections at the center of scaffold pores demonstrated a circular collagen arrangement with a Haversian-like vessel at its center. While the scaffold architecture cannot permit true osteons to form in a straight path, it was observed that osteocytes and their surrounding collagen matrix did form in concentric rings to the vessels. This arrangement allowed a semi-lamellar pattern to form although the distribution of collagen was partially random. With no evidence of necrosis within the scaffolds, this implant arrangement demonstrated the functionality of open-channel designs for both osteo- and angio-conduction.

\subsection{Conclusion}

This study demonstrated the potential of porous, interconnected, HA scaffolds with morphological similarity to trabecular morphology for bone regeneration. Distinct strut features and open channels allowed for successful mineralized bone and vascular infiltration throughout both scaffold designs. Partially-organized, lamellar collagen fibrils were identified by birefringence under cross-polarized light at both 3 and 12 weeks post implantation. 


\section{Chapter 7. Discussion}

\subsection{Overall goals}

The theme of this research was the characterization of cell response to bone-like materials with clinical application for the replacement or regeneration of native bone. It was hypothesized that a discontinuity exists in this field between laboratory based investigations and their clinical counterparts because of the substantial effect of environment on cell behavior. These investigations emphasized the substantial role of three-dimensional architecture on bone cell adhesion, stress signaling and differentiation in the development of a trabecular platform for bone regeneration.

In the following sections the specific findings of each major study is related to the original working hypotheses of Chapter 2. In section 7.2, the role of 3-D structure compared to 2-D surfaces are explored between HA and TCP materials. Section 7.3 adds the effect of a non-destructive mechanical force, ultrasound, on cell response in 3-D designs. These first two sections represented a screening method to reduce the number of groups tested in the final phase of this investigation for perfusion analysis and animal model studies. From the first sections, HA was identified as the material for testing in long term studies based on the early cell response and its degradation stability. In section 7.4, the effect of media perfusion on HEPM cell differentiation is evaluated in a longterm culture study on micro and nano HA scaffolds. Finally, in section 7.5, micro and nano HA scaffolds were implanted into a dog mandible model to demonstrate the clinical application of the scaffold material and configuration. 


\subsection{Cell stress signaling in HA and TCP scaffolds and surfaces}

It was hypothesized that bone cell precursors respond differently to structures found in vivo compared traditional tissue culture performed in a laboratory setting. Scaffolds and surfaces were prepared from HA and TCP ceramics in these studies to provide a substrate well recognized in the natural bone environment. Calcium phosphate materials provide an accessible supply of calcium and phosphorous minerals for bone cell metabolism [Gross 97] with scaffolds providing a large surface area for cell attachment. The scaffolds designed and manufactured in these studies were similar to natural trabecular bone [Feldkamp 89] as measured by histomorphometry. The unique curvatures of these scaffolds were hypothesized to increase stress signaling patterns that bone cells engage during adhesion [Chen 97]. Alterations in cell attachment proteins in the cell membrane are linked with the intracellular actin skeleton structure and can ultimately affect gene expression. This response was anticipated to assist bone cell differentiation through both the changes in membrane organization and through the activation of stress pathways. The ultimate targets of these changes include the master gene regulator RUNX2 capable of changing cell phenotype. Stress signaling through this controller could be responsible for differentiation related events.

A testing technique was employed using antibodies specific to particular members of the MAPK cascade following methodology for PACE testing [Versteeg 00]. The results of PACE testing on HEPM cells in 2- and 3-D environments demonstrated high activation of the stress signaling proteins, P38 and JNK in 3-D. Elevated levels of the MAPK protein ERK1/2 were already present in response to both 2- and 3-D materials, potentially related to its early activation during adhesion events independent of 
architecture [Chen 94, Klemke 97, Schlaepfer 94, Zhu 95]. As calcium phosphate materials due not induce cell apoptosis [Sepulveda 00], the observed activation of AKT, a strong anti-apoptosis control signal, demonstrated that bone precursor cells can manage the high stress response when conforming to 3-D curvatures. The potential of AKT rescue could signal through other proteins including blocking p73 and p53 mediated apoptosis, blocking apoptosis through XIAP, and driving cell growth through ERK, p70, or mTOR. These results were consistent with previous studies involving upstream members of the MAPK family where apoptosis regulation could not be predicted only by the activation of ERK and SAPK pathways [Bonvin 02].

From these results it could be concluded that bone cell precursors do activate stress signaling proteins in response to curvatures characteristic of natural bone supporting hypothesis 1 . This result indicates that traditional cell culture may be significantly underestimating cell stress response compared to natural bone organization. Furthermore, the increase in stress signaling corresponded with a 'rescue' from apoptosis through the AKT pathway thus supporting hypothesis 2 that cells can manage the elevated stress response.

\subsection{Cell adhesion and stress response on scaffolds with ultrasound}

In addition to the influence of scaffolds architecture discussed in section 7.2, a physical non-destructive force simulating natural bone environment was hypothesized to further activate stress and adhesion cell signals. Low intensity pulsed ultrasound represents a clinical tool used to help accelerate healing time and prevent bone loss during the healing period [Kristiansen 97]. It was postulated that in addition to 3-D 
curvature effect on cell response, ultrasound could also upregulate integrin adhesion during early cell attachment [Chen 97]. This may explain some of the clinical success with ultrasound systems if local application is improving cell adhesion thus increasing the pool of local cells to repair bone defects with or without scaffold replacements.

An inherent limitation of these theories is the influence of calcium release from the scaffolds affecting activation of the stress pathways studied, including the MAPK cascade [Katz 06]. Additionally, calcium release does have a cytotoxic limit that could influence cell viability [Maeno 05]. Preparation of media extracts from the scaffolds demonstrated that calcium was partly responsible for ERK activation combined with cell adhesion but did not influence the activation of the stress protein kinases or AKT. This result was consistent with the first study performed between 2- and 3-D materials and disproved hypothesis 3 that calcium alone could be responsible for the high levels of stress and adhesion activators.

A previous study isolated several mechanosensitive signals including integrin activation occurring with physical stimulation of the membrane [Lee 00]. Application of ultrasound was able to increase activation of ERK in addition to integrin and vinculin proteins but only on TCP scaffolds. This result appeared in conflict with the lower calcium release from TCP, however these surfaces have small micro-pores that may supply locally high calcium concentrations during ultrasound that are not detectable by bulk media testing. Since ultrasound treatment has been shown to redistribute actin stress fibers and focal adhesions [Zhou 04], the described results could be masked by the specific characteristics of TCP scaffolds and the selection of adhesion-phase timing chosen in this study. This result partially supported hypothesis 4 stating that ultrasound 
could further increase stress and adhesion based pathways as the result was valid for TCP but not HA scaffolds. Further research into matching the exact crystal surface features of these materials could clarify this result.

\subsection{Long term cell culture in HA scaffolds with fluid perfusion}

With the identification of stress and adhesion mediators identified from the first two sections, longer study of viability and differentiation effects were required to determine how 3-D stimulation would influence cell organization. The HEPM cells utilized in these investigations could be differentiated into osteoblasts over time. While ultrasound represents a mechanical stimulus capable of assisting this process, it is not sufficient to create the distributed cell organization of natural bone. Bioreactor based perfusion was postulated to help maintain the nutrient flow natural to trabecular and cortical bone. From the perfusion based analysis of the scaffolds, HA was selected from previously mentioned studies due to its lack of resorbtion and stability. The addition of a nano based surface feature by sol-gel was postulated to increase the cellular attachment locations on the material. Additionally, the nano coating provided greater calcium release assisting osteoblast precursor differentiation [Maeno 05].

The use of sol-gel based nano coating was able to significantly increase early cell attachment supporting the first claim of hypothesis 6 , but did not change the early viability of these materials disproving the second part of this hypothesis. The application of perfusion fluid flow had previously demonstrated activation of bone cell gene markers in vitro [Ogata 00, Owan 97, Reich 91]. The postulated mechanisms of action responsible for these effects included; mass transport and membrane based shear 
components or streaming potentials [Bakker 01, McAllister 99]. Observations of these mechanisms have already been performed in scaffold tissue engineering techniques [Cartmell 03, Holtorf 05]. The selection of media perfusion rate in these studies reflected a mid-level range compared to other research [Cartmell 03, Glowacki 98, Goldstein 01]. From the results of these studies the statement in hypothesis 7 that nano HA scaffolds could induce earlier differentiation in both static and perfusion was specifically disproved. While perfusion significantly improved expression of bone differentiation markers, nano coatings did not significantly alter this response.

\subsection{HA scaffolds for in vivo bone repair}

The final aim of this research was to provide clinical relevance of the mechanisms explored previously and to confirm the regenerative capability of the scaffold design for segmental defect repair. The final study investigated the bone and angio-conductive capability of the micro and nano surface scaffolds after 3 and 12 weeks post implantation into the canine mandible. This study also served to link the data available in the literature regarding natural bone organization [Feldkamp 89, Navarro 04] with bone formation in scaffolds.

HA scaffolds of both surface compositions demonstrated remarkable ability to span the defect location and conduct bone formation throughout the design.

Differentiation of bone cells could be observed visually by the presence of osteoid and mineralized tissue as early as 3 weeks post-implantation, matching the observed increase in differentiation seen with in vitro flow perfusion, supporting hypothesis 7 and linking the in vitro and in vivo studies. Nano HA scaffolds were able to increase the amount of 
early tissue formed within the construct but did not significantly affect the formation of mineralized tissue disproving part of hypothesis 8 stating that nano HA would outperform micro HA. The second part of hypothesis 8 stated that the newly formed bone tissue would be similar to natural organization and was confirmed by the morphometric presence of collagen arrangement forming in circular lamellae throughout the scaffold interior. Additionally, small nutrient channels were found tunneling throughout the tissue and while they were found to be less numerous than natural tissue they were slightly larger than cortical blood vessels permitting good nutrient supply. This vessel arrangement could be related to the scaffold architecture where open spaces permit less numerous but larger, interconnected, bone-blocks to form.

\subsection{Conclusion}

The development and characterization of calcium phosphate scaffold designs has been performed with respect to cell adhesion, stress signaling and differentiation mechanisms in laboratory and animal model studies. In summary, a significant disparity has been identified in the literature between testing performed in vitro and clinical results. It was postulated that environmental conditions significantly affect the results of traditional biomaterial testing. In these studies, scaffolds were constructed with particular emphasis on matching the architectural properties of natural bone with physical stress behavior characteristic of the true bone environment.

From the in vitro experiments it was observed that bone cells activate members of stress pathways in 3-D not normally activated in 2-D. Despite these elevated levels of stress, cells are capable of managing these signals without entering apoptosis. Further 
application of stress by ultrasound and perfusion flow demonstrate that these signals may in fact be necessary for the correct signaling mechanisms to match that observed during bone repair and healing To support the role of scaffold architecture for true bone formation an animal model study was performed and demonstrated exceptional bone formation and organization within the scaffold design, with osteoid formation matching the time period of cell differentiation observed from perfusion studies. In conclusion, highly porous ceramic scaffolds represent an excellent platform for bone cell studies corresponding to a natural environment and represent a promising biomaterial for bone defect repair and clinical tissue engineering. 


\section{Chapter 8. Future directions}

Deciphering the complexity of cell communication and signaling behavior represents an important subject of cell biology that will undoubtedly occupy scientists for

many generations. These pathways are currently being decoded from many perspectives and the specific role of environment on cell response is critical for bone study. This is especially relevant for the emerging field of tissue engineering. A greater link between cell communication and tissue engineering strategies would benefit both disciplines.

From this research, future directions involving cell signaling during long term culture would further strengthen the conclusions. Cell stress response demonstrated high activation during the early attachment to the biomaterials studied, however, the environmental stress signals such as fluid shear and membrane perturbations continue over the lifetime of natural tissue. It would be beneficial to identify if these pathways are continually stimulated in long term cell culture and if they truly mediate the differentiation activity of bone cells.

Scaffold designs continue to undergo optimization from both laboratory and industrial perspectives. The open architecture characterized in this research has demonstrated the importance of interconnectivity, especially for in vivo bone repair and vascularization. It appears that the formation of quality bone tissue is coupled with angiogenesis. Selective design focusing towards angiogenesis rather than early bone formation may promote better clinical results. 


\section{LIST OF REFERENCES}

Agrawal CM, Anthanasiou KA, Heckman JD. Biodegradable PLA-PGA polymers for tissue engineering in orthopedics. Mater Sci Forum 1997;250:115-129.

Agarwal CM, Ray RB. Biodegradable polymeric scaffolds for musculoskeletal tissue engineering. J Biomed Mater Res 2001;55:141-150.

Appleford MR, Oh S, Cole JA, Carnes DL, Lee M, Bumgardner JD, Haggard WO, Ong JL. Effects of trabecular calcium phosphate scaffolds on stress signaling in osteoblast precursor cells. Biomaterials 2007;28:2747-2753.

Arinzeh TL, Tran T, Mcalary J, Daculsi G. A comparative study of biphasic calcium phosphate ceramics for human mesenchymal stem-cell-induced bone formation. Biomaterials 2005;26:3631-3638.

Arts JJ, Verdonschot N, Schreurs BW, Buma P. The use of a bioresorbable nanocrystalline hydroxyapatite paste in acetabular bone impaction grafting. Biomaterials 2006;27:1110-1118.

Ascenzi A, Bell G. Bone as a Mechanical Engineering Problem. In: Bourne G, ed. The Biochemistry and Physiology of Bone. New York, NY: Academic Press; 1972.

Azuma Y, Ito M, Harada Y, Takagi H, Ohta T, Jingushi S. Low-intensity pulsed ultrasound accelerates rat femoral fracture healing by acting on the various cellular reactions in the fracture callus. J Bone Miner Res 2001;16:671-680.

Bakker AD, Soejima K, Klein-Nulend J, Burger EH. The production of nitric oxide and prostaglandin (E2) by primary bone cells is shear stress dependent. J Biomech 2001;34:671-677.

Barou O, Mekraldi S, Vico L, Boivin G, Alexandre C, Lafage-Proust MH. Relationships between trabecular bone remodeling and bone vascularization: a quantitative study. Bone 2002;30(4):604-612.

Bonvin C, Guillon A, van Bemmelen MX, Gerwins P, Johnson GL, Widmann C. Role of the amino-terminal domains of MEKKs in the activation of NFkB and MAPK pathways and in the regulation of cell proliferation and apoptosis. Cell Signaling 2002;14:123-131.

Boyd JS, Paterson C, May AH. Color Atlas of Clinical anatomy of the Dog \& Cat, Second Edition. London: Harcourt Publishers Limited; 2001. 
Boyde A, Corsi A, Quarto R, Cancedda R, Bianco P. Osteoconduction in large macroporous hydroxyapatite ceramic implants: evidence for a complimentary integration and disintegration mechanism. Bone 1999;24:579-589.

Brunet A, Bonni A, Zigmond MJ, Lin MZ, Juo P, Hu LS, Anderson MJ, Arden KC, Blenis J, Greenberg ME. Akt promotes cell survival by phosphorylating and inhibiting a forkhead transcription factor. Cell 1999;96:857-868.

Buckwalter J, Glimcher M, Cooper, R., Recker, R. Bone biology part I: structure, blood supply, cells, matrix, and mineralization. Instr C Lect 1996;45:371-386.

Burg KJ, Porter S, Kellam JF. Biomaterial developments for bone tissue engineering. Biomaterials 2000;21:2347-2359.

Cardone MH, Roy N, Stennicke HR, Salvesen GS, Franke TF, Stanbridge E, Frisch S, Reed JC. Regulation of cell death protease caspase- 9 by phosphorylation. Science 1998;282:1318-1321.

Carter D, Hayes W. The compressive behavior of bone as a two-phase porous structure. J of Bone and Joint Surg 1977;59A:954-962.

Cartmell SH, Porter BD, Garcia AJ, Guldberg RE. Effects of medium perfusion rate on cell-seeded three-dimensional bone construct in vitro. T Engr 2003;9:1197-1203.

Chang BS, Lee CK, Hong KS, Youn HJ, Ryu HS, Chung SS, Park KW. Osteoconduction at porous hydroxyapatite with various pore configurations. Biomaterials. 2000; 21:1291-1298.

Chapekar MS. Tissue engineering: challenges and opportunities. J Biomed Mater Res 2000;53:617-620.

Chen CS, Mrksich M, Huang S, Whitesides GM, Ingber DE. Geometric control of cell life and death. Science 1997;276:1425-1428.

Chen P, Kinch MS, Lin TH, Burridge K, Juliano RL. Integrin-mediated cell adhesion activates mitogen-activated protein kinases. J Biol Chem 1994;6:26602-26605.

Chen YJ, Wang CJ, Yang KD, Chang PR, Huang HC, Huang YT, Sun YC, Wang FS. Pertussis toxin-sensitive Gai protein and ERK-dependent pathways mediate ultrasound promotion of osteogenic transcription in human osteoblasts. FEBS letters 2003;554:154-158.

De Oliveira JF, De Aguiar PF, Rossi AM, Soares GA. Effect of process parameters on the characteristics of porous calcium phosphate ceramics for bone tissue scaffolds. Artif Organs 2003;27(5):406-411. 
Diehl JA, Cheng M, Rooussel MF, Sherr CJ. Glycogen synthase kinase-3B regulates cyclin D1 proteolysis and subcellular localization. Genes Dev 1998;12:34993511.

Dong J, Kojima H, Uemura T, Kikuchi M, Tateishi T, Tanaka J. In vivo evaluation of a novel porous hydroxyapatite to sustain osteogenesis of transplanted bone marrowderived osteoblast cells. J Biomed Mater Res 2001;57:208-216.

Dong J, Uemura T, Shiraasaki Y, Tateishi T. Promotion of bone formation using highly pure porous beta-TCP combined with bone marrow-derived osteoprogenitor cells. Biomaterials 2002;23:4493-4502.

Duarte LR. The stimulation of bone growth by ultrasound. Arch Orthop Trauma Surg 1983;101(3):153-159.

Dunkelman NS, Zimber MP, LeBaron RG, Pavelec R, Kwan M, Purchio AF. Cartilage production by rabbit articular chondrocytes on polyglycolic acid scaffolds in a closed bioreactor system. Biotechnol Bioeng 1994;46:299-305.

Edlich M, Yellowley CE, Jacobs CR, Donahue HJ. Oscillating fluid flow regulates cytosolic calcium concentration in bovine articular chondrocytes. J Biomech 2001;34:59-65.

Feldkamp LA, Goldstein SA, Parfitt AM, Jesion G, Kleerekoper M. The direct examination of three-dimensional bone architecture in-vitro by computed tomography. J Bone Miner Res 1989;4:3-11.

Flautre B, Anselme K, Delecourt C, Lu J, Hardouin P, Descamps M. Histological aspects in bone regeneration of an association with porous hydroxyapatite and bone marrow cells. J Mater Sci Mater Med 1999;10:811-814.

Freed LE., Vunjak-Novakovic G, Biron RJ, Eagles DB, Lesnoy DC, Barlow SK, Langer R. Biodegradable polymer scaffolds for tissue engineering. Biotechnology 2000;12:689-693.

Gauthier O, Bouler JM, Aguado E, Pilet P, Daculsi G. Macroporous biphasic calcium phosphate ceramics: influence of macropore diameter and macroporosity percentage on bone ingrowth. Biomaterials 1998;19:133-139.

Gauthier O, Muller R, von Stechow D, Lamy B, Weiss P, Bouler JM, Aguado E, Daculsi G. In vivo bone regeneration with injectible calcium phosphate biomaterial: a three-dimensional mico-computed tomographic, biomechanical and SEM study. Biomaterials 2005;26:5444-5453. 
Gebauer GP, Lin SS, Beam HA, Vieira P, Parsons JR. Low-intensity pulsed ultrasound increases the fracture callus strength in diabetic BB Wistar rats but does not affect cellular proliferation. J Orthop Res 2002;20(3):587-592.

Glowacki J, Mizuno S, Greenberger JS. Perfusion enhances functions of bone marrow stromal cell in three-dimensional culture. Cell Transplant 1998;7:319-326.

Goldstein AS, Juarez TM, Helmke CD, Gustin MC, Mikos AG. Effect of convection on osteoblast cell growth and function in biodegradable polymer foam scaffolds. Biomaterials 2001;22:1279-1288.

Groeneveld EH, van den Bergh JP, Holzmann P, ten Bruggenkate CM, Tuinzing DB, Burger EH. Mineralization processes in demineralized bone matrix grafts in human maxillary sinus floor elevations. J Biomed Mater Res 1999;48:393-402.

Gross KA, Berndt CC, Goldschlag DD, Iacono VJ. In vitro changes of hydroxyapatite coatings. Inter J Oral Maxillofac Implants 1997;12:589-597.

Habibovic P, Yuan H, van der Valk C, Meijer G, van Blitterswijk C, de Groot K. 3D microenvironment as essential element for osteoinduction by biomaterials. Biomaterials 2005;26:3565-3575.

Hajduch E, Litherland GJ, Hundal HS. Protein kinase B (PKB/Akt) - a key regulator of glucose transport? FEBS Letters 2001;492:199-203.

Heckman JD, Ryaby JP, McCabe J, Frey JJ, Kilcoyne RF. Acceleration of tibial fracturehealing by non-invasive, low intensity pulsed ultrasound. J Bone Joint Surg 1994;76:26-34.

Hildebrand T, Laib A, Muller R, Dequekker J, Ruegsegger P. Direct three-dimensional morphometric analysis of human cancellous bone: microstructural data from spine, femur, iliac crest, and calcaneus. J Bone Miner Res 1999;14:1167-1174.

Holtorf HL, Datta N, Jansen JA, Mikos AG. Scaffold mesh size affects the osteoblastic differentiation of seeded marrow stromal cells cultured in a flow perfusion bioreactor. J Biomed Mater Res A. 2005 Aug 1;74(2):171-180.

Holy CE, Shoichet MS, Davies JE. Engineering three-dimensional bone tissue in vitro using biodegradable scaffolds: investigating initial cell-seeding density and culture period. J Biomed Mater Res 2000;51:376-382.

Ingber DE. Mechanosensation through integrins: cells act locally but think globally. PNAS 2003;100(4):1472-1474.

Inoki $\mathrm{K}$, Li Y, Zhu T, Wu J, Guan KL. TSC2 is phosphorylated and inhibited by Akt and suppresses mTOR signaling. Nature Cell Biol 2002;4:648-657. 
Ishaug SL, Crane GM, Miller MJ, Yasko AW, Yaszemski MJ, Mikos AG. Bone formation by three-dimensional stromal osteoblast culture in biodegradable polymer scaffolds. J Biomed Mater Res 1997;36:17-28.

Jacobs CR, Yellowley CE, Davis BR, Zhou Z, Cimbala JM, Donahue HJ. Differential effect of steady versus oscillating flow on bone cells. J. Biomech 1998;31:969976.

Jaiswal RK, Jaiswal N, Bruder SP, Mbalaviele G, Marshak DR, Pittenger MF. Adult human mesenchymal stem cell differentiation to the osteogenic or adipogenic lineage is regulated by mitogen-activated protein kinase. J Biol Chem 2000;275:9645-9652.

Karageorgiou V, Kaplan D. Porosity of 3D biomaterial scaffolds and osteogenesis. 2005;27:5474-5491.

Katz S, Boland R, Santillan G. Modulation of ERK 1/2 and p38 MAPK signaling pathways by ATP in osteoblasts: involvement of mechanical stress-activated calcium influx, PKC and Src activation. Int J Biochem Cell Biol 2006;38(12):2082-2091.

Klemke RL, Cai S, Giannini SL. Regulation of cell motility by mitogen-activated protein kinase. J C Biol 1997;137:481-93.

Kon E, Muraglia A, Corsi A, Bianco P, Marcacci M, Martin I, Boyde A, Ruspantini I, Chistolini P, Rocca M, Giardino R, Cancedda R, Quarto R. Autologous bone marrow stromal cells loaded onto porous hydroxyapatite ceramic accelerate bone repair in critical-size defects of sheep long bones. J Biomed Mater Res 1999;49:328-337.

Koshino T, Murase T, Takagi T, Saito T. New bone formation around porous hydroxyapatite wedge implanted in opening wedge high tibial osteotomy in patients with osteoarthritis. Biomaterials. 2001;22:1579-1582.

Kristiansen TK, Ryaby JP, McCabe J, et al. Accelerated healing of distal radius fractures with the use of specific, low-intensity ultrasound: a multicenter, prospective, randomized, double - blind, placebo - controlled study. J Bone Joint Surg 1997;79:961-73.

Lee HS, Millward-Sadler SJ, Wright MO, Nuki G, Salter DM. Integrin and mechanosensitive ion channel-dependent tyrosine phosphorylation of focal adhesion proteins and beta-catenin in human articular chondrocytes after mechanical stimulation. J Bone Miner Res 2000;15:1501-1509.

Livingston T, Ducheyne P, Garino J. In vivo evaluation of a bioactive scaffold for bone tissue engineering. J Biomed Mater Res 2002;62:1-13. 
Lu JX, Flautre B, Anselme K, Hardouin P, Gallur A, Descamps M, et al. Role of interconnections in porous bioceramics on bone recolonization in vitro and in vivo. J Mater Sci Mater Med 1999;10(2):111-120.

Lu JX, Gallur A, Flautre B, Anselme K, Descamps M, Thierry B, Hadouin P. Comparative study of tissue reactions to calcium phosphate ceramics among cancellous, cortical, and medullar bone sites in rabbits. J Biomed Mater Res 1998;42:357-367.

Maeno S, Niki Y, Matsumoto H, Morioka H, Yatabe T, Funayama A, Toyama Y, Taguchi T, Tanaka J. The effect of calcium ion concentration on osteoblast viability, proliferation and differentiation in monolayer and 3D culture. Biomaterials 2005;26:4847-55.

Mangano C, Bartolucci EG, Mazzocco C. A new porous hydroxyapatite for promotion of bone regeneration in maxillary sinus augmentation: clinical and histologic study in humans. Int J Oral Maxillofac Implants. 2003;18:23-30.

Mankani MH, Kuznetsov SA, Fowler B, Kingman A, Robey PG. In vivo bone formation by human bone marrow stromal cells: effect of carrier particle size and shape. Biotechnol Bioeng 2001;72(1):96-107.

Manning BD, Tee AR, Logsdon MN, Blenis J, Cantley LC. Identification of the tuberous sclerosis complex-2 tumor suppressor gene product tuberin as a target of the phosphoinositide 3-kinase/AKT pathway. Molec Cell 2002;10:151-162.

Marks SC, Odgren PR. Structure and development of theskeleton. In: Bilezikian JP, Raisz LG, Rodan GA, eds. Principles of bone biology. 2nd ed. San Diego: Academic Press;2002. p. 3-15.

Martin B, Burr D, Sharkey N. Skeletal Tissue Mechanics. Springer-Verlag New York, Inc., 1998.

Mastrogiacoma M, Scaglione S, Martinetti R, Dolcini L, Beltrame F, Cancedda R, Quarto R. Role of scaffold internal structure on in vivo bone formation in macroporous calcium phosphate bioceramics. Biomaterials 2006;27:3230-3237.

McAllister TN, Frangos JA. Steady and transient fluid shear stress stimulate NO release in osteoblasts through distinct biochemical pathways. J. Bone Miner Res 1999; 14:930-936.

Moalli MR, Caldwell NJ, Patil PV, Goldstein SA. An in vivo model for investigations of mechanical signal transduction in trabecular bone. J Bone Min Res 2000;15(7):1346-1353. 
Morino N, Mimura T, Hamasaki K, Tobe K, Ueki K, Kikuchi K, Takehara K, Kadowaki T, Yazaki Y, Nojima Y. Matrix/integrin interaction activates the mitogenactivated protein kinase, p44ERK-1 and p42ERK-2. J Biol Chem 1995;270:269273.

Navarro M, del Valle S, Martinez S, Zeppetelli S, Ambrosio L, Planell JA, et al. New macroporous calcium phosphate glass ceramic for guided bone regeneration. Biomaterials 2004;25(18):4233-4241.

Nave BT, Ouwens DM, Withers DJ, Alessi DR, Shepherd PR. Mammalian target of rapamycin is a direct target for protein kinase $\mathrm{B}$ : identification of a convergence point for opposing effects of insulin and amino-acid deficiency on protein translation. Biochem J 1999;344:427-431.

Ogata, T. Fluid flow-induced tyrosine phosphorylation and participation of growth factor signaling pathway in osteoblast-like cells. J Cell Biochem 2000;76:529-538.

Owan I, Burr DB, Turner CH, Qiu J, Tu Y, Onyia JE, Duncan RL. Mechanotransduction in bone: osteoblasts are more responsive to fluid forces than mechanical strain. Am J Physiol 1997;273:C810-815.

Parfitt AM, Drezner MK, Glorieux FH, Kanis JA, Malluche H, Meunier PJ, Ott SM, Recker RR. Bone Histomorphometry: standardization of nomenclature, symbols and units. Journal of Bone and Mineral Research 1987;2(6):595-610.

Perry CR. Bone repair techniques, bone graft, and bonegraft substitutes. Clin Orthop 1999;360:71-86.

Peter SJ, Miller MJ, Yasko AW, Yaszemski MJ, Mikos AG. Polymer concepts in tissue engineering. J Biomed Mater Res 1998;43:422-427.

Posner AS. Bone Mineral on the molecular level. Fed Proc 1973;32:1933-1937.

Reich KM, Frangos JA. Effect of flow on prostaglandin E2 and inositol trisphosphate levels in osteoblasts. Am J Physiol 1991;26:C428-432.

Reilly D, Burstein A. The elastic and ultimate properties of compact bone tissue. J Biomech 1975;8:393-405.

Richard M, Aguada E, Cottrel M, Daculsi G. Ultrastructural and electron diffraction of the bone-ceramic interfacial zone in coral and biphasic $\mathrm{CaP}$ implants. Calcif Tissue Int 1998;62:437-442.

Robinson MJ, Cobb MH. Mitogen-activated protein kinase pathways. Curr Opin in Cell Biol 1997;9:180-186. 
Rose FR, Oreffo RO. Breakthroughs and views, bone tissue engineering: hope vs hype. Biochem Biophy Res Comm 2002;292:1-7.

Sandberg MM, Aro HT, Vuorio EI. Gene expression during bone repair. Clin. Orthop 1993;289:292-312.

Schlaepfer DD, Hanks SK, Hunter T, van der Greer P. Integrin mediated signal transduction linked to Ras pathway by GRB2 binding to focal adhesion kinase. Nature 1994;372:786-791.

Schlaepfer DD, Hunter T. Integrin signaling and tyrosine phosphorylation: just the FAKs? Trends Cell Biol 1998;8:151-157.

Schugens C, Maquet V, Grandfils C, Jerome R, Teyssie P. Biodegradable and macroporous polylactide implants for cell transplantation: preparation of polylactide foams by solid-liquid phase separation. Polymer 1996;30:449-461.

Sepulveda P, Binner JG, Rogero SO, Higa OZ, Bressiani JC. Production of porous hydroxyapatite by the gel-casting of foams and cytotoxic evaluation. J Biomed Mater Res 2000;50:27-34.

Simmons CA, Matlis S, Thornton AJ, Chen S, Wang CY, Mooney D. Cyclic strain enhances matrix mineralization by adult human mesenchymal stem cells via the extracellular signal-regulated kinase (ERK1/2) signaling pathway. J Biomech 2003;36:1087-1096.

Spector M. Biomaterial failure. Orthop. Clin. North Am.1992;23:211-217.

Staal SP, Hartley JW, Rowe WP. Isolation of transforming murine leukemia viruses from mice with a high incidence of spontaneous lymphoma. Proc Natl Acad Sci 1977;74(7):3065-3067.

Uemura T, Dong J, Wang Y, Kojima H, Saito T, Iejima D, Kikuchi M, Tanaka J, Tateishi T. Transplantation of cultured bone cells using combinations of scaffolds and culture techniques. Biomaterials 2003;24:2277-2286.

Versteeg HH, Nijhuis E, van der Brink GR, Evertzen M, Pynaert GN, van Deventer SJ, Coffer PJ, Peppelenbosch MP. A new phosphospecific cell-based ELISA for p42/44 mitogen-activated protein kinase (MAPK), p38 MAPK, protein kinase B and cAMP-response-element-binding protein. J Biochem 2000;350:717-722.

Wang X, Shen X, Li X, Agrawal M. Age-related changes in the collagen network and toughness of bone. Bone 2002;31:1-7. 
Widmann C, Gibson S, Jarpe MB, Johnson GL. Mitogen-activated protein kinase: conservation of a three-kinase module from yeast to human. Physiol. Rev. 1999;79:143-180.

Williams AR. Ultrasound: biological effects and potential hazards. New York, NY: Academic Press, 1983.

You, C, Oh S, Kim S. Influences of heating condition and substrate-surface roughness on the characteristics of sol-gel-derived hydroxyapatite coatings. J Sol-Gel Science Tech 2001;21:49-54.

Zhou S, Schmelz A, Seufferlein T, Li Y, Zhao J, Bachem MG. Molecular mechanisms of low intensity pulsed ultrasound in human skin fibroblasts. J Biol Chem 2004;279:54463-54469.

Zhu X, Assoian RK. Integrin-dependant activation of MAP kinase: a link to shapedependant cell proliferation. Mol Biol Cell 1995;6:273-282.

Zimmerman S, Moelling K. Phosphorylation and regulation of raf by akt (protein kinase B). Science 1999;286:1741-1744.

Zyman Z, Ivanov I, Glushko V, Dedukh N, Malyshkina S. Inorganic phase composition of remineralisation in porous CaP ceramics. Biomaterials. 1998; 19:1269-1273. 


\section{VITA}

Mark Ryan Appleford was born in 1979 in Thousand Oaks, California. He attended Newbury Park High School graduating in 1997. He entered college at the California Polytechnic State University at San Luis Obispo, graduating with his Bachelor of Science degree in Biological Science in 2001. He completed the requirements for his Master of Science degree in Bioengineering at Cal Poly in 2003. During his time at Cal Poly, Mr. Appleford also worked as a materials scientist with Rockwell Science Center. He entered the joint Biomedical Engineering Doctor of Philosophy program with University of Tennessee Health Science Center and University of Memphis in 2003. Mr. Appleford considers it a distinct privilege to work in this field and plans to continue research in regenerative tissue engineering. 